Review

\title{
Personalizing Colon Cancer Therapeutics: Targeting Old and New Mechanisms of Action
}

\author{
Christina Leah B. Kline and Wafik S. El-Deiry * \\ Hematology/Oncology Division, Penn State Hershey Medical Center, Hershey, PA 17033, USA; \\ E-Mail: ckline@hmc.psu.edu \\ * Author to whom correspondence should be addressed; E-Mail: Wafik.eldeiry@gmail.com or \\ wse2@psu.edu; Tel.: +1-717-531-5059; Fax: +1-717-531-5076.
}

Received: 4 June 2013; in revised form: 30 July 2013 / Accepted: 16 August 2013 /

Published: 21 August 2013

\begin{abstract}
The use of pharmaceuticals for colon cancer treatment has been increasingly personalized, in part due to the development of new molecular tools. In this review, we discuss the old and new colon cancer chemotherapeutics, and the parameters that have been shown to be predictive of efficacy and safety of these chemotherapeutics. In addition, we discuss how alternate pharmaceuticals have been developed in light of a potential lack of response or resistance to a particular chemotherapeutic.
\end{abstract}

Keywords: colorectal cancer; personalized medicine; genetic polymorphisms

\section{Introduction: Personalizing Colon Cancer Therapeutics}

Personalized medicine is at the heart of patient care as doctors adjust therapeutic strategies based on their personal observations of their patients. With the development of 21 st century scientific tools, however, personalized medicine has been taken to a different level. The benefits of these are now being increasingly seen in the treatment of patients with colon cancer.

It is imperative that we afford the advantages of personalized cancer therapy to colon cancer patients. Colon cancer is the 4th leading cause of cancer-related death worldwide [1]. The rate of survival for colon cancer depends largely on the pathologic state of the disease. Currently, the treatment strategy is also highly dependent on the stage of the disease at diagnosis. In disease stages where cancer cells have not spread to distant organs (Stages II and III), surgical removal of the tumor is warranted. In Stage III tumors, the stage where the cancer cells have spread to lymph nodes, chemotherapeutics are also given after surgery. This is what is referred to as adjuvant chemotherapy. It has been shown that giving 
adjuvant chemotherapy is superior to surgical intervention alone in terms of preventing disease recurrence [2] and improving disease-free and overall survival [3]. The 5-year survival rate for Stage III cancer patients is $69.2 \%$. Once the colon cancer cells have spread to other organs in the case of metastatic colon cancer, the 5-year survival rate of patients drops drastically to $11.7 \%$ [4]. Thus, much research is being done to develop therapeutic strategies for metastatic colon cancer. In addition to the need to increase the efficacy of current chemotherapeutic regimens, there is also a need to reduce toxicity. Eighty percent of patients undergoing chemotherapy experience side-effects [5]. These side effects are brought about at least in part by the effects of the chemotherapeutics on normal cells. These efficacy and toxicity data underscore the need for more effective and targeted therapeutic regimen.

In this review, we discuss how the use of old and new colon cancer chemotherapeutic drugs is increasingly being personalized to maximize the benefit to the patients. In addition, we discuss how alternate pharmaceuticals have been developed in light of a potential lack of response or resistance to a particular chemotherapeutic.

\section{Targeting Old Mechanisms of Action: Inhibitors that Target the DNA}

\subsection{Personalizing the Use of a 55-Year Old Drug: 5-Fluorouracil (5-FU)}

\subsubsection{How 5-FU Works}

5-FU has been the mainstay of colon cancer chemotherapy for more than 50 years. This is probably in part due to its impact on multiple pathways - DNA synthesis, DNA repair, and RNA metabolism (Figure 1). After promising results with tumors grown in rats and mice [6], 5-FU was tried in humans, first, by giving a single intravenous injection for 5 days. Unfortunately, tumor regression was only observed when toxic 5-FU concentrations were used. Thus, for decades, studies have been done to optimize the dose [7], schedule [8-10] and mode of administration [11,12] to maximize therapeutic effect and minimize toxicity. Currently, 5-FU is administered with leucovorin in regimens that consist of combinations of bolus injection and continuous intravenous infusions.

The development of 5-FU as a chemotherapeutic came, in part, from the seminal observation that there was enhanced utilization of uracil by rat liver tumor cells in comparison to their normal liver cell counterparts [13]. Both uracil and 5-fluorouracil can be metabolized in cells to form nucleoside monophosphates (Scheme 1). Their nucleoside monophosphate derivatives can complex with thymidylate synthase in the presence of the cofactor 5,10-methylenetetrahydrofolate (5,10-methyleneTHF) (Scheme 2). In the case of the 5-fluoro-2'-deoxyuridine monophosphate formed from 5-FU, however, the carbon-fluorine bond cannot be cleaved by thymidylate synthase. This locks the enzyme in the complex, making it less available for deoxythymidine monophosphate (dTMP) synthesis [14]. Consequently, DNA replication is inhibited. The conversion of 5-FU to its nucleotide monophosphate form is catalyzed by thymidine phosphorylase and thymidine kinase. Thymidine phosphorylase expression [15] and activity [16] have been found to be significantly higher in tumor tissue than in noncancerous tissue. This can explain in part why 5-FU hits tumor cells harder. On the other hand, because 5-FU targets DNA synthesis, actively dividing normal cells (e.g., cells lining the gut, the skin, blood cells) are also affected. Thus, gastrointestinal toxicity, bone marrow suppression and hand-foot syndrome are side-effects of 5-FU based chemotherapy [17]. 
The impact of 5-FU goes beyond the downregulation of dTMP synthesis. As a result of thymidylate synthase inhibition by 5-FU, deoxyuridine monophosphate (dUMP) and deoxyuridine triphosphate (dUTP) accumulate [18-21]. dUTP accumulation promotes the misincorporation of uracil into DNA by DNA polymerase. Although the DNA repair pathway can excise the misincorporated uracil [22,23], the excised dUMP can be rephosphorylated to dUTP and reincorporated and the process keeps on repeating in what is referred to as futile cycling. DNA strand breakage [24] and lethal damage occurs as the repair mechanism fails.

Fluorouridine triphosphate (FUTP) formed from 5-FU disrupts RNA metabolism. FUTP can be incorporated into the $45 \mathrm{~S}$ and $32 \mathrm{~S}$ pre-ribosomal RNA, inhibiting the processing of these molecules into the $28 \mathrm{~S}$ and $18 \mathrm{~S}$ RNA components of the ribosome [25]. Pre-mRNA splicing is inhibited as a result of insertion of FUTP into the U2 spliceosomal snRNA. 5-FU, therefore, disrupts key metabolic processes involving RNA; namely, pre-mRNA splicing, ribosome formation, and protein synthesis.

The response rate to 5-FU monotherapy among colorectal cancer patients is $11 \%$ [26]. Thus, much research has been done to increase the efficacy of 5-FU. Given that one of the targets of 5-FU is thymidylate synthase (TS), efforts to increase the duration of the thymidylate synthase inhibition have been made. A strategy to accomplish this is to increase the levels of the cofactor 5,10-methylene-THF. Increased 5,10-methylene-THF levels promote the maximal binding of FdUMP to TS [27] and decrease the dissociation of the FdUMP-TS complex [28].

Scheme 1. Anabolism and effects of 5-FU. 5-FU can be metabolized in cells via different pathways.

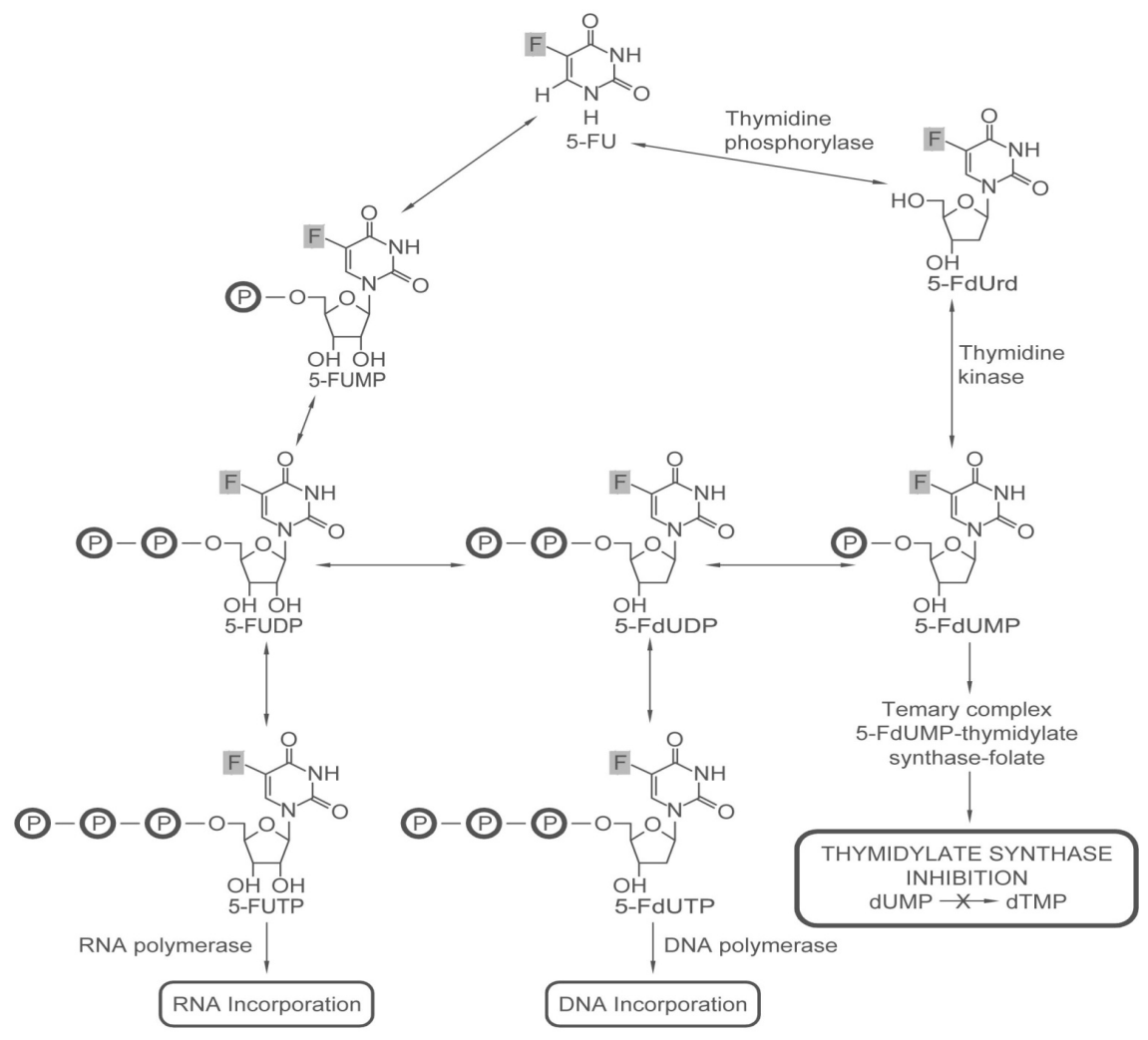


Scheme 2. Activities of thymidylate synthase and methylene tetrahydrofolate reductase. Thymidylate synthase converts dUTP to dTMP, in the presence of 5,10-methylene-THF. 5-FdUMP competes with dUMP, blocking dTMP synthesis. Methylene tetrahydrofolate reductase reduces 5, 10-methylene-THF levels by converting it to 5-methyltetrahydrofolate.

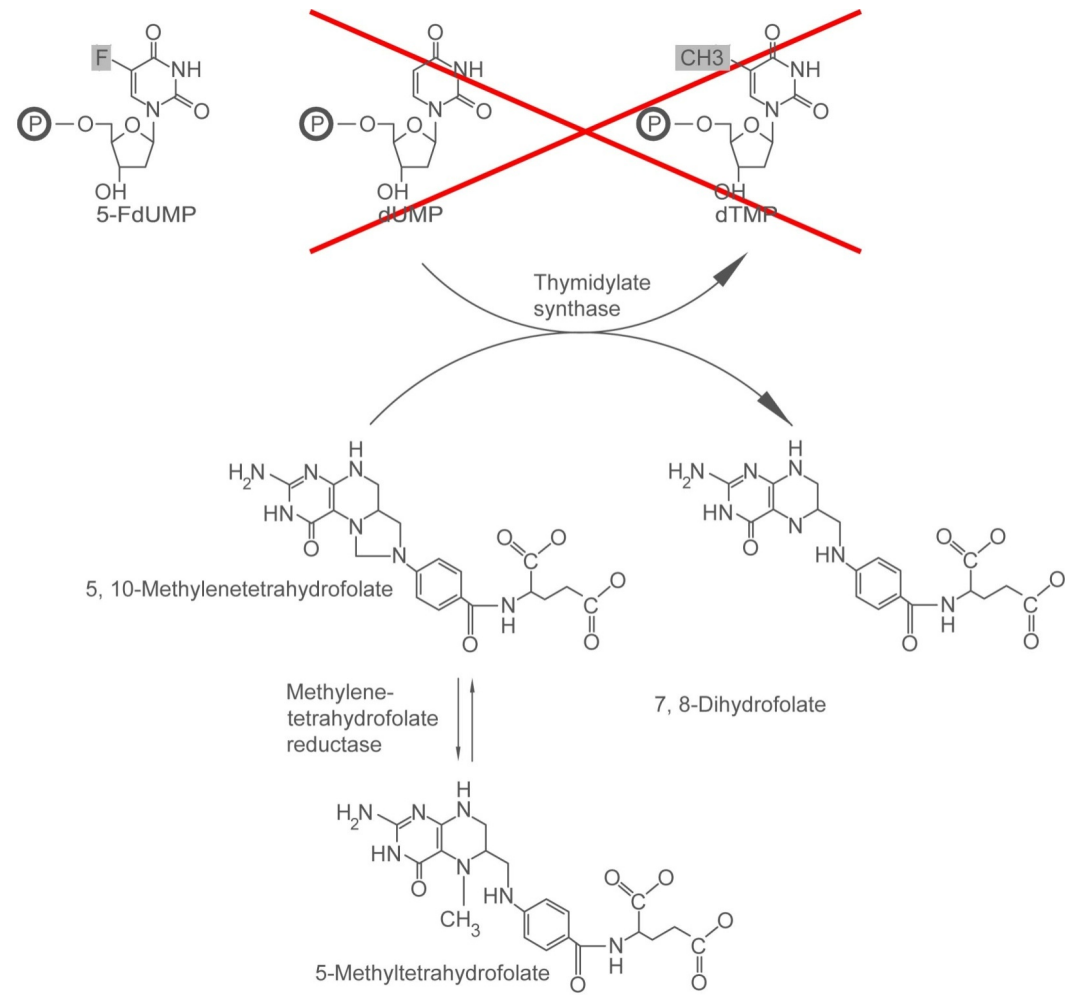

Folinic acid or leucovorin (LV), a formyl derivative of 5,10-CH2-THF, can be converted to 5,10-methylene-THF in cells, increasing the efficacy of 5-FU and FdUMP [27,29]. Given the favorable in vitro effects of leucovorin in combination with 5-FU, it has been administered with 5 -FU in the clinic. The 5-FU/LV combination increased response rate to $23 \%$ [26], and prolonged overall survival and time to disease progression [30,31].

\subsubsection{Who May and May not Benefit from 5-FU}

Currently, whatever stage of the disease a colorectal cancer patient has, the first option that will be offered to them for chemotherapy would involve 5-FU as a single agent or in combination with other drugs, depending on the stage of the tumor and the patient's performance status. It is therefore beneficial to be able to identify the factors that determine 5-FU response. Efforts are being made to identify mutations or genetic polymorphisms in patients who are sensitive or resistant to 5-FU. As has been mentioned above, one of the targets of 5-FU is the enzyme thymidylate synthase. The therapeutic response to 5-FU has been shown to be associated with the extent of inhibition of thymidylate synthase activity [32]. The extent of inhibition of TS activity depend in part on the levels of thymidylate synthase and 5,10-methylene-THF. The amount of 5,10-methyleneTHF in cells is regulated by methylenetetrahydrofolate reductase (MTHFR). MTHFR reduces the cofactor to 5-methyltetrahydrofolate [33] (Scheme 2). Given the importance of the level of TS and the activity of MTHFR to thymidylate synthase inhibition, candidate genes that would influence response to 5-FU 
would be the genes that encode these two enzymes, TYMS (for TS) and MTHFR (for MTHFR). A common variant of MTHFR is $677 \mathrm{C}>\mathrm{T}(\mathrm{A} 222 \mathrm{~V})$. This polymorphism has been associated with reduced MTHFR activity [34]. In a number of studies [35,36], the presence of the polymorphism, especially in a homozygous fashion [37,38], has been correlated with response to 5-FU-based treatment. In other studies, no relationship has been found between the polymorphism and response to different 5-FU based chemotherapeutic regimens [39,40]. The conflicting results on the impact of MTHFR polymorphism on response to 5-FU can explain at least in part why screening for MTHFR variant prior to 5-FU-based treatment has not been adopted. TYMS polymorphisms have also been shown to influence sensitivity to 5-FU-based chemotherapy. The promoter enhancer region of the TYMS gene contains a tandemly repeated sequence [41]. The number of repeats of this sequence influences the translational efficiency of the TYMS mRNA [42,43]. The most common alleles have a double repeat $(2 R)$ and triple repeat $(3 R)$ [44]. Cells [42] and gastrointestinal cancer tissues [45] that have 3 repeats $(3 R)$ of this sequence have higher TS expression [46]. Poorer response to 5-FU has been seen among patients with the $3 R$ allele [46-49]. Not all patients, however, that are $3 R / 3 R$ have high TS expression [46] or are unresponsive to 5FU treatment [50]. A $\mathrm{G}>\mathrm{C}$ variant has been identified in the 2nd repeat of the $3 R$ allele [51]. This transversion reduces the transcriptional activity of the TYMS promoter. Patients that homozygous $3 R$ but have the $\mathrm{G}>\mathrm{C}$ variant $(* 3 \mathrm{C})$ have lower TS expression and respond better to 5-FU than patients with the $3 R$ allele containing the $G(3 G)$ [52].

The use of thymidylate synthase expression in resected tumors to predict 5-FU response has been explored. Patients that have high TYMS expression levels in their resected tumors respond poorly to 5-FU and leucovorin [53-56] and to a combination of 5-FU/LV and oxaliplatin [57]. On the other hand, not all patients that have low TYMS expression respond to 5-FU-based therapy [54]. Thus, TS expression may actually be more of a predictor of 5-FU resistance, rather than response.

TYMS copy number gains may also be predictive of 5-FU resistance. Patients that have been previously treated with 5-FU based chemotherapy and had amplification of their TYMS gene had shorter survival times than patients that did not have TYMS gene amplification $[58,59]$.

The efficacy of 5-FU-based chemotherapy is dependent in part on the 5-FU plasma levels achieved in a patient [60-62]. Given that $80 \%$ of administered 5-FU is degraded [63] and only $1-3 \%$ of the drug is actually anabolized [64], the extent of 5-FU catabolism largely determines 5-FU levels. The rate-limiting step in 5-FU catabolism is catalyzed by the enzyme dihydropyrimidine dehydrogenase (DPD) [64]. Low DPD expression has been observed among patients who responded to 5 -FU treatment $[65,66]$. However, no genetic polymorphism has been found to be predictive of DPD deficiency [67]. Nonetheless, some DPYD SNPs have been proposed for clinical use to avoid severe side effects from 5-FU [68] (see below).

One of the mechanisms of action of 5-FU involves the DNA repair pathway. It is conceivable, therefore, that response to 5-FU can be affected by the status of the DNA repair machinery. It has been found that $12-28 \%$ of colorectal cancers have numerous mutations at microsatellite sequencesa phenotype that has been referred to as microsatellite instability (MSI) [69]. These mutations are brought about by defects in the DNA mismatch repair (MMR) system. Stage II and stage III patients that have MSI-high tumors [70] or mismatch repair deficiency [71] do not appear to benefit from adjuvant 5-FU based chemotherapy. One mechanism that has been proposed to explain this is the higher incorporation of 5-FU into DNA in the presence of a deficient mismatch repair system, and 
therefore, reduced formation of the FdUMP-TS complex [72]. In light of the lack of response to 5-FU among patients with MSI-high tumors, MSI testing is now recommended for Stage II patients prior to treating them with single-agent 5-fluorouracil [73]. In the case of Stage III patients, even if those with MSI-high tumors may not respond to 5-FU, these patients are more commonly treated with 5-FU in combination with oxaliplatin, in a regimen referred to as FOLFOX. Stage III patients with deficient mismatch repair have been shown to respond better to FOLFOX than to 5-FU alone [74].

The administration of chemotherapy does not only involve maximizing response but also minimizing toxicity. Close to half of patients who have received 5-FU/leucovorin have experienced toxicities that necessitated dose reduction [75]. 5-FU induced toxicity has been associated with 5-FU plasma levels [76]. As has been mentioned above, 5-FU levels are largely determined by the rate of 5-FU catabolism and the activity of DPD [77]. Patients with DPD deficiency have high 5-FU plasma levels [78,79], and thus experience severe side effects [80]. It is estimated that approximately $2-12 \%$ of colorectal cancer patients have at least partial deficiency in DPD [81]. The DPYD gene has been implicated the most in 5-FU-induced toxicity. The most common DPYD single nucleotide polymorphism (SNP) that has been associated with 5-FU-induced toxicity is the splice-site mutation c. $1905+1 \mathrm{G}>\mathrm{A}$ (IVS14+1G $>$ A) $[68,82,83]$. Two other SNP's that have been correlated with adverse side effects are 2846A $>\mathrm{T}[68,84]$ and $1679 \mathrm{~T}>\mathrm{G}$ [68]. Sixty percent of patients with either IVS14 $+1 \mathrm{G}>\mathrm{A}$ or $2846 \mathrm{~A}>\mathrm{T}$ have experienced severe side effects $[68,85]$. Aside from a subset of $D P Y D$ polymorphisms, the combination of an MTHFR polymorphism (MTHFR $1298 \mathrm{~A}>\mathrm{C}$ ) with TYMS 3'-UTR ins/del polymorphisms has been associated with 5-FU toxicity [44].

Given the preceding discussion, are we close to identifying patients who will benefit from and patients who will react adversely to 5-FU? Currently, screening for MSI is recommended for patients with Stage II disease prior to administering single-agent 5-FU. If they are found to have MSI-H tumors, treating them with 5-FU may bring more harm than benefit. There may be benefit in screening for TYMS polymorphisms, especially the $3 R$ allele containing the $G$, to identify patients that are less likely to respond to 5-FU. In addition, it is important to identify patients who are predicted to experience severe adverse side-effects from 5-FU, specifically those with the following DPYD polymorphisms: IVS14+1G $>$ A or $2846 \mathrm{~A}>\mathrm{T}$. Analyzing metastatic lesions of patients previously treated with 5-FU for TYMS gene amplification can guide decisions as to whether to re-treat these patients with 5-FU. Previous results suggest that re-treating patients with TYMS amplification may not provide additional benefit and also expose them unnecessarily to 5-FU's toxic effects. On the other hand, the use of TS and DPYD expression in tumors as a screening strategy must be done with caution. Exposure to 5-FU itself perturbs the expression of these two enzymes. DPD expression [86] and activity [87] can be downregulated in response to 5-FU treatment. On the other hand, TS expression is upregulated in response to 5-FU treatment in vitro [88] and in vivo [89]. Another caveat in the use of TS expression is that although low TS has been predictive of response in metastatic colorectal cancer patients, the opposite has been found in patients with Stage II and Stage III disease on adjuvant therapy [90-92]. 


\subsubsection{Options for Those Who May not Benefit from 5-FU}

All is not lost for patients who are expected to react adversely to 5-FU-based chemotherapy. Toxicities can be avoided in these patients by administering reduced doses of 5-FU [93] and by closely monitoring 5-FU levels during treatment. The latter is referred to as 5-FU pharmacokinetic (PK) monitoring. 5-FU doses have been determined conventionally by calculating body surface area (BSA) from the patient's weight and height. With 5-FU pharmacokinetic monitoring, however, actual 5-FU levels are measured during administration of continuous infusion 5-FU chemotherapy. 5-FU doses are adjusted in the succeeding cycles of chemotherapy to achieve 5-FU levels that are within what is referred to as the therapeutic range. The minimum value in this range is the minimum 5-FU plasma level that has been observed to be efficacious. The maximum value in this range is the highest 5-FU plasma level that has been observed that has not resulted in dose-limiting toxicities in patients. The therapeutic range is dependent on the mode of administration of 5-FU. The benefits of PK monitoring in metastatic colorectal cancer patients have been shown in a number of studies. In patients treated with 5-FU and leucovorin via a weekly 8 -H infusion, objective response rate was found to be increased and toxicity was decreased with the use of PK monitoring versus the use of the BSA method [94]. Similar results were observed when 5-FU/LV was combined with oxaliplatin in the FOLFOX regimen [95]. Through PK monitoring, a patient who is predicted to react adversely to 5-FU by virtue of an IVS $+\mathrm{G}>\mathrm{A} D P Y D$ polymorphism can be given 5-FU at a reduced dose [68].

The degree of TS inhibition achieved with 5-FU/LV in patients has been associated with therapeutic response [32]. Thus, the use of TS inhibitors for colorectal cancer therapy continues. In the case of 5-FU, the 5-FU metabolite FdUMP competes against the normal substrate of TS in cells, dUMP. On the other hand, TS inhibitors have been developed to compete against the cofactor of TS, 5,10-methylene-THF. These inhibitors are referred to as antifolate inhibitors (Figure 1). Tomudex (Raltitrexed $^{\circledR}$, Astra Zeneca) is an antifolate TS inhibitor that is now used in clinics outside the USA as an alternative to 5-FU for patients who are sensitive to 5-FU and the 5-FU oral prodrug form, capecitabine, including in a patient with DPD deficiency [96-98]. Tomudex has been shown to have similar efficacy as 5-FU in combination with other agents used with 5-FU (e.g., oxaliplatin) [99]. Unfortunately, tomudex can also cause toxic side effects, including death [100-102]. The mechanism behind the adverse effects of tomudex, however, is not well elucidated. Pemetrexed (Alimta ${ }^{\mathrm{TM}}$, Lilly, first referred to as LY231514), another antifolate TS inhibitor [103], targets two other enzymes involved in folate metabolism-dihydrofolate reductase and glycinamide ribonucleotide formyltransferase. The efficacy and safety of pemetrexed in colorectal cancer therapy, whether as a single-agent $[104,105]$ or in combination with irinotecan $[106,107]$ has been shown to be comparable but nonsuperior to 5-FU. The use of pemetrexed among patients predicted to react adversely to 5-FU remains to be explored [107]. 
Figure 1. Chemical structures of (a) 5,10-methylene-THF, (b) leucovorin and the antifolate inhibitors (c) tomudex and (d) pemetrexed.
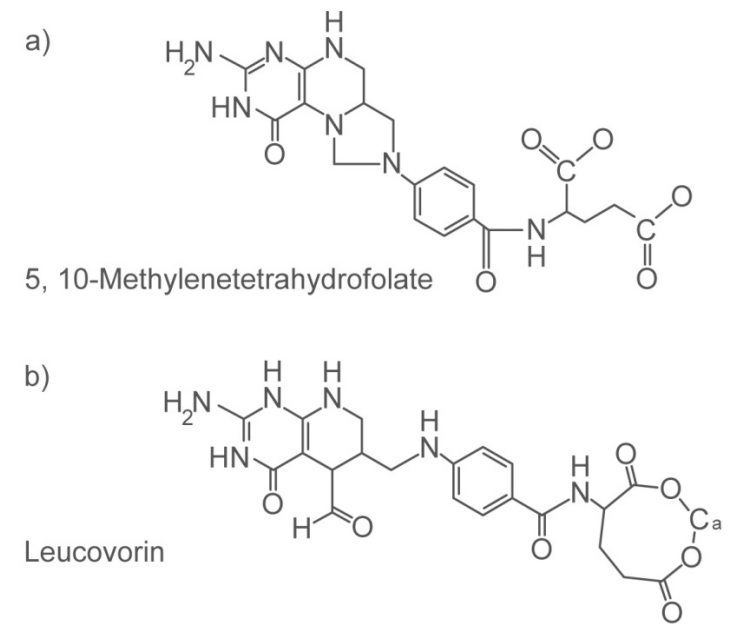

c)

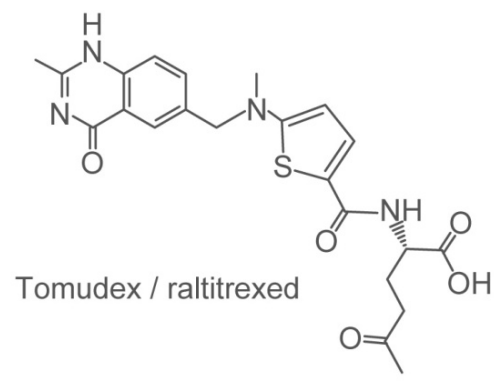

d)

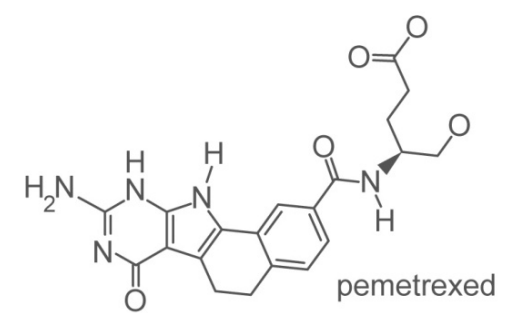

\subsection{Personalizing the Choice of DNA-Damaging Agent: Oxaliplatin or Irinotecan}

\subsubsection{How Oxaliplatin and Irinotecan Work}

Chemotherapeutics have been combined with 5-FU and leucovorin to increase treatment success. The use of platinum compounds for cancer chemotherapy started with the observation that bacterial cell division is inhibited by platinum compounds [108]. Among 34 compounds in this chemical class that have been tested, cisplatin (cis-dichlorodiamine platinum II) was shown to have the highest antitumor activity in mice [109]. However, partly due to the toxicity of cisplatin [110], a platinum (II) complex of trans-l-diaminocyclohexane, oxaliplatin was synthesized. Oxaliplatin has been shown to be as effective as and less toxic than cisplatin for therapy of colorectal cancer [111], although cisplatin continues to be used for non-colorectal cancer tumor types. Oxaliplatin and cisplatin bind to DNA and form adducts (Scheme 3) [112,113]. The structures of the DNA adducts that they form, however, differ by virtue of the diaminocyclohexane (DACH) ring of oxaliplatin. Mismatch repair proteins recognize the cisplatin-DNA adducts [114,115], resulting in the eventual engagement of apoptosis. However, cancer cells that have a defective mismatch repair system escape this killing mechanism and exhibit 
resistance to cisplatin [116]. On the other hand, the hydrophobicity and bulkiness of the DACH ring of oxaliplatin prevents the binding of the mismatch repair proteins [117], and therefore, the cytotoxic effect of oxaliplatin is not dependent on a functional mismatch repair system. This can partly explain the observation that cells that have lost a functional mismatch repair system lose their susceptibility to cisplatin but not to oxaliplatin [116]. The addition of oxaliplatin to 5-FU/LV in the clinic in a regimen referred to as FOLFOX [118] has resulted in a 50-60\% response rate [119,120] and prolonged progression-free survival [120].

Scheme 3. Structures of DNA adducts formed by a) cisplatin and b) oxaliplatin.

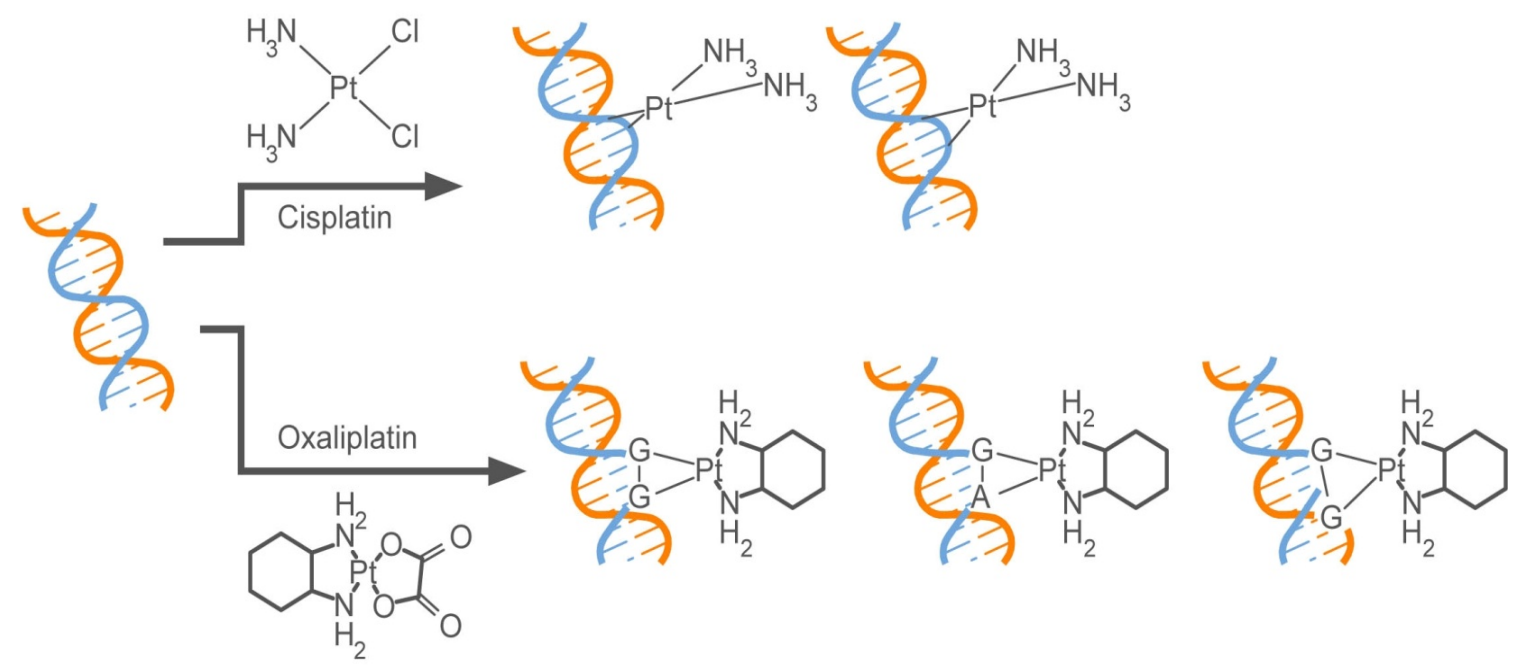

Another agent that is being used in combination with 5-FU/LV is irinotecan. Irinotecan (or CPT-11) is converted in vivo [121] to SN-38 (Figure 2a) [122] with the carboxylesterase-mediated removal of a bulky piperidino side chain [123]. Combining irinotecan with 5-FU/LV has increased response rate and prolonged time to progression and overall survival versus treatment with 5-FU/LV [124]. The target of irinotecan is DNA topoisomerase I (Top1), another enzyme involved in DNA metabolism. Top1 catalyzes DNA unwinding in an ATP-independent manner, a critical step in DNA replication [125] and transcription [126,127]. Top1 cleaves one of the DNA strands, facilitating the smooth rotation of the complementary strand around the first strand, and reseals the nick in the first strand $[128,129]$. The irinotecan metabolite SN-38 binds to the DNA-Top1 complex, inhibiting the religation of the nicked DNA strand (Figure 2b) [130]. The SN-38-DNA-Top1 complex can also impede the movement of DNA polymerase along the DNA strand and a double strand break ensues [131,132]. Irinotecan has been used in combination with 5-FU/LV (FOLFIRI), with a response rate among colorectal cancer patients of $49 \%$ [124].

2.2.2. Who May and May not Benefit from Oxaliplatin and Irinotecan

Using oxaliplatin (in the FOLFOX regimen) and irinotecan (in the FOLFIRI regimen) have similar benefits in terms of response rate [133,134]. These two agents, however, have different adverse effects. Oxaliplatin causes an acute and transient neurotoxicity and a chronic, cumulative sensory neuropathy [135]. On the other hand, irinotecan can cause diarrhea in 16-24\% of patients [136]. It is 
important to identify predictive parameters for response and toxicity that can be used to guide the choice between oxaliplatin and irinotecan.

Figure 2. (a) Chemical structure of irinotecan and its metabolite, and (b) the mechanism of action of irinotecan, DNA topoisomerase I (Top1) cleaves and unwinds the DNA, as part of DNA replication and transcription. SN-38 forms a complex with DNA and Top1, inhibiting the religation of the DNA strand and blocking the movement of the DNA polymerase along the DNA. Consequently, a DNA double strand break ensues.

a)
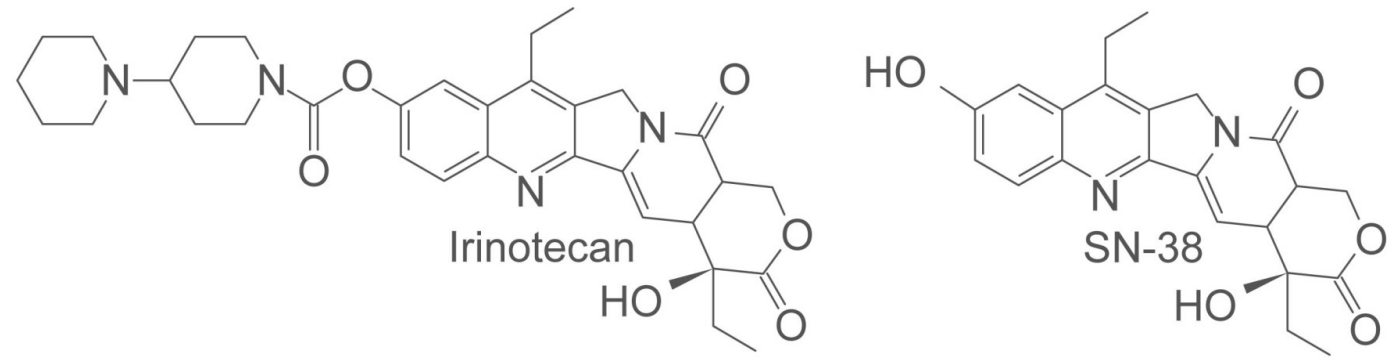

b)
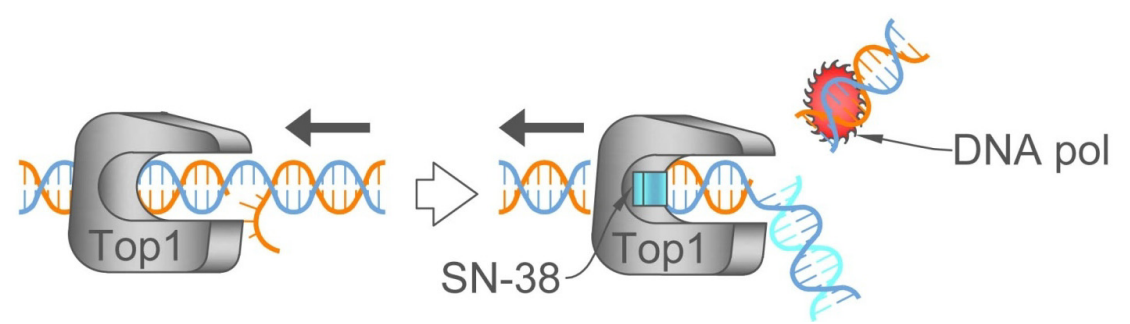

The response to oxaliplatin has been shown to be influenced by DNA repair capacity. The DNA adducts formed by oxaliplatin do not appear to be processed by the mismatch repair pathway [117] but may be removed by the nucleotide excision repair (NER) system (Scheme 4). At least 30 proteins [137] execute the different steps of NER that include recognition of DNA damage or structure distortion, separation of the DNA strands, DNA strand cleavage at the site of damage, and gap filling [138]. Polymorphisms have been identified in a subset of genes encoding for NER proteins [139], and a subset of these polymorphisms may be used to screen for oxaliplatin response or resistance.

ERCC2/XPD is part of a nine-subunit complex, TFIIH that is involved in the initial recognition of DNA damage [140]. ERCC2/XPD is one of two helicases in TFIIH that catalyzes the opening of the DNA duplex at the site of DNA damage [141]. It has been observed to be upregulated in response to oxaliplatin treatment in vitro and in the context of oxaliplatin resistance. A polymorphism, 13181T $>\mathrm{G}$ that results in a change from a lysine to a glutamine in codon 751(Lys751Gln) has been associated with decreased response (or increased resistance) to oxaliplatin [142-145]. However, the mechanism behind the effect of this ERCC2 polymorphism on oxaliplatin response has not been elucidated.

ERCC1, in complex with another protein XPF, and ERCC5/XPG cleave the DNA 5' and 3', respectively, to the site of the DNA damage [146,147]. Patients with low ERCC1 mRNA expression in their tumors survive longer in response to treatment with 5-FU/oxaliplatin [148] than patients with elevated ERCC1 expression. Among the different polymorphisms that have been identified in the ERCC1 gene, one has been associated with response to oxaliplatin-118C $>\mathrm{T}$. Although this polymorphism does not result in an amino acid change, the resultant variant codon (AAT) is less frequently used than the common codon (118C) [149], possibly resulting in decreased ERCC1 
expression [150], and presumably, less efficient NER. This can explain in part why patients that have the variant allele respond better to oxaliplatin-based treatment [150,151]. In the case of ERCC5, two polymorphisms, $-763 \mathrm{~A}>\mathrm{G}$ and $+25 \mathrm{~A}>\mathrm{G}$, have been found to be associated with response to 5-FU/LV and oxaliplatin. Patients that had the $-763 \mathrm{GG}$ had a significantly higher response rate than patients with either the AG or AA genotypes. On the other hand, the variant $G$ allele at site 25 was associated with poorer response. These results, however, need further verification, especially since they were obtained from one clinical study of 83 patients [152].

Scheme 4. Schematic of the nucleotide excision repair pathway showing a subset of the proteins involved, especially those that have been implicated in response or resistance to oxaliplatin.

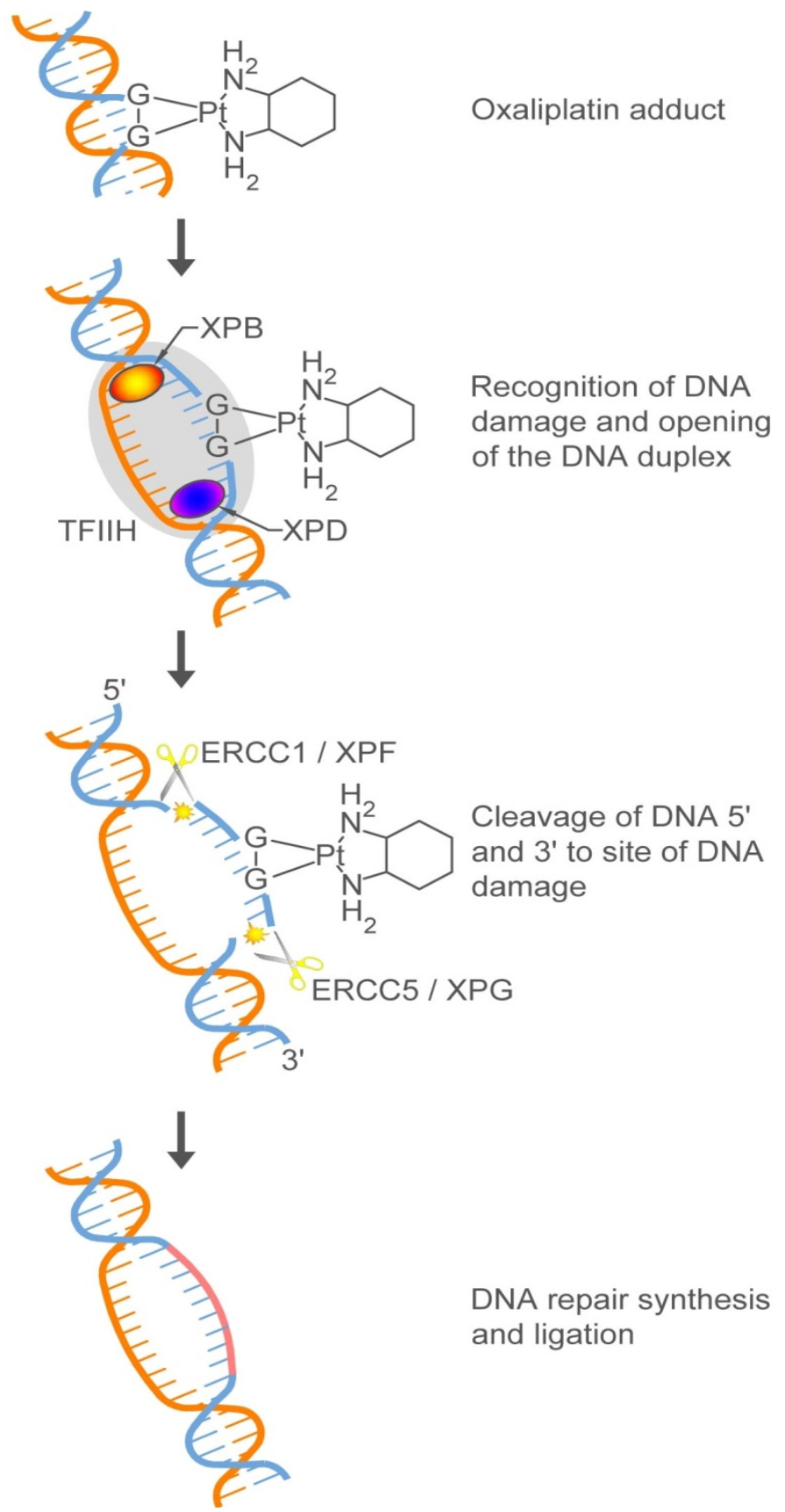


A subset of patients has been shown to experience oxaliplatin-induced neurotoxicity despite a lack of response to the drug. Thus, withholding oxaliplatin from these patients can potentially spare them from the toxic effects of the drug without sacrificing therapeutic goals [153]. Platinum compounds can be detoxified with the attachment of a glutathione residue by glutathione S-transferases (GSTs) [154]. There are at least eight distinct GST classes; namely, alpha, kappa, mu, omega, pi, sigma, theta and zeta [155], which differ in substrate specificities [156]. The pi class (GST P1-1) is overexpressed in a number of cancers [157], including colon cancer [158-160]. GSTP1 overexpression has been associated with resistance to cisplatin [161,162]. Polymorphisms in the gene coding for GSTP1, GSTP1, have been identified, specifically in exon 5 (Ile105Val) and exon 6 (Ala114Val) [163]. Normal lung tissues from individuals with the Ile105Val polymorphism have reduced GST activity [156]. There are indications that patients with this polymorphism experience oxaliplatin-induced neurotoxicity earlier [164] or are more susceptible to more severe side-effects [165]. In one study, this same polymorphism was also predictive of response to FOLFOX-4. It has been proposed that as a result of reduced GST activity in patients with this genetic variant, oxaliplatin is detoxified at a lesser extent and is therefore more effective. The flip side of that is that is causes more toxicity [165]. On the other hand, in another study, the polymorphism was associated with a decreased risk of oxaliplatininduced neurotoxicity [166]. In a meta-analysis, however, of 12 prospective trials and two retrospective clinical trials involving 2,191 participants, this polymorphism was not found to associate with oxaliplatin-induced neurotoxicity [167]. One limitation of this meta-analysis, however, is the analyses of trials that differ in specific chemotherapeutic regimens. In three trials where an association between the polymorphism and neurotoxicity has been observed [168], patients were treated with FOLFOX-4. Because of the conflicting results, however, on the association of the GSTP1 polymorphism with oxaliplatin toxicity, it is not currently recommended to screen patients for this genetic variant.

No genetic polymorphism has been identified that is associated with response to irinotecan. On the other hand, genetic variants have been identified that are associated with irinotecan toxicity. Irinotecan-induced diarrhea is attributed to the levels of the irinotecan metabolite SN-38 in the intestinal lumen [136]. SN-38 is glucuronidated by UDP-glucuronosyl transferase1A (UGT1A) to facilitate SN-38 elimination $[169,170]$. Low rates of glucuronidation have been associated with severity of irinotecan-induced diarrhea [171]. A UGT1A1 allele, UGT1A7*3, codes for a protein sequence with three nonsynonymous single nucleotide polymorphisms; namely, Asn129Lys, Arg131Lys, Trp208Arg [172]. The protein that it codes for has a significantly lower catalytic activity than that coded for by the wild-type allele [170,173]. Consequently, at least in part, patients who are homozygous $U G T 1 A 7 * 3$ have a 2.7 fold risk of experiencing diarrhea at the end of the treatment [174]. UGT1A1 gene expression is inversely correlated to the number of TA repeats in its promoter TATA box [175]. The UGTIAI*28 allele has seven repeats in contrast to the six repeats in the wild type [176,177], and therefore, patients with this allele would have lower UGT1A activity as manifested by lower glucuronidation rates [178]. The number of UGT1A1*28 alleles (i.e., whether a patient is homozygous or heterozygous) is inversely correlated with the glucuronidated $\mathrm{SN}-38 / \mathrm{SN}-38$ ratio [179]. Patients that are homozygous $U G T 1 A 1 * 28$ have a significantly higher risk of experiencing diarrhea, hematologic and non-hematologic toxicities in response to irinotecan-based chemotherapy $[174,179,180]$. 
The $U G T 1 A 1 * 28$ allele has been widely accepted as a predictor of irinotecan toxicity. Studies have been conducted on using information on the presence or absence of this allele to guide irinotecan dosing decisions [181]. The FOLFIRI regimen combines 5-FU/LV with $180 \mathrm{mg} / \mathrm{m}^{2}$ irinotecan [133]. However, results of a phase II trial indicate that there is advantage in terms of efficacy when a higher dose, $260 \mathrm{mg} / \mathrm{m}^{2}$, is administered [181,182]. Patients with the wild type UGT1A1 allele (UGT1A1*1) can be given as much as 390 and $340 \mathrm{mg} / \mathrm{m}^{2}$ irinotecan (depending on whether a patient is homozygous or heterozygous, respectively, for the allele), in combination with 5-FU/LV [181,183]. These results demonstrate how the knowledge of a patient's genotype can be used to guide drug dosing.

Currently, a patient's genotype is not largely considered when choosing to administer oxaliplatin or irinotecan. Studies covered in this section of the review suggest that there may be benefit to screening for specific genetic variants to maximize efficacy and decrease toxicity in patients. Prospective clinical trials are necessary to test the hypothesis that genotype-guided decision making can increase response and decrease toxicity in patients treated with oxaliplatin and irinotecan.

\section{Targeting New Mechanisms of Action: Targeting Cancer Cell-Specific Characteristics}

A modern approach to cancer therapy involves use of chemical or biologic agents that interfere with a specific molecular target that has been shown to be involved in tumor growth and progression (referred to as targeted agents) [184]. We discuss below how the choice of targeted agents that are used in combination with 5-FU/LV can be personalized.

\subsection{Personalizing Treatment with Antibodies against the Epidermal Growth Factor Receptor (EGFR)}

\subsubsection{How Antibodies against EGFR Work}

Higher expression of the epidermal growth factor receptor (EGFR) has been found in colorectal tumors of more advanced stage and poor differentiation, and those exhibiting vascular and lymphatic invasion [185]. Also, EGFR expression and tyrosine kinase activity are upregulated in metastatic colon cancer cells [186]. Consequent to binding to its ligand, which includes epidermal growth factor, EGFR phosphorylates itself and recruits a number of intracellular proteins containing Src homology 2 or phosphotyrosine binding domains [187]. A number of pathways are then engaged, including two that are involved in tumorigenesis; namely, the Ras/Raf/mitogen-activated protein kinase pathway (Ras/Raf/MAPK) and the phosphatidylinositol 3-kinase (PI3K)/Akt pathway [188] (Figure 3). The engagement of these two pathways promotes cell survival and proliferation. Mouse monoclonal antibodies raised against the EGFR (mAb 225IgG1 and mAb 528 IgG2a) block the binding of EGFR ligands and inhibit proliferation in vitro [189,190], tumor growth in vivo [191-193], and EGF-activated tyrosine kinase activity [194]. MAb 225IgG1 also induces receptor dimerization and downregulation [195]. This particular mouse monoclonal antibody has been chimerized to the human IgG1 constant region [196] and the chimera is now referred to as cetuximab (C225, Erbitux ${ }^{\circledR}$, ImClone). Cetuximab has been as effective as $\mathrm{mAb} 225 \mathrm{IgG} 1$ in vitro, and more effective than mAb225 IgG1 in inhibiting tumor growth in vivo [197]. Cetuximab is immunogenic in about $5 \%$ of patients, however [198,199]. Thus, a fully human antibody (and not a human-mouse chimera) against EGFR, panitumumab [200] has been developed and has also been shown to inhibit tumor growth in vivo. 
Given the upregulation of EGFR expression and activity in colorectal cancer, small molecule inhibitors of EGFR have also been developed and tested for colorectal cancer therapy. Unfortunately, no or minimal objective response (1\% response rate) was observed in patients treated with the small molecule inhibitor gefitinib as a single agent $[201,202]$ or in combination with capecitabine [203,204]. Furthermore, the addition of gefitinib to irinotecan did not seem to augment treatment efficacy [205]. Nevertheless, there is potential in combining an EGFR inhibitor with an EGFR antibody. In a clinical study of 50 patients, the combination of the EGFR inhibitor erlotinib with cetuximab was more effective than cetuximab alone [206].

Figure 3. Activation of the EGFR pathway and the consequent engagement of the Ras/Raf/MAPK and PI3K/Akt pathways.

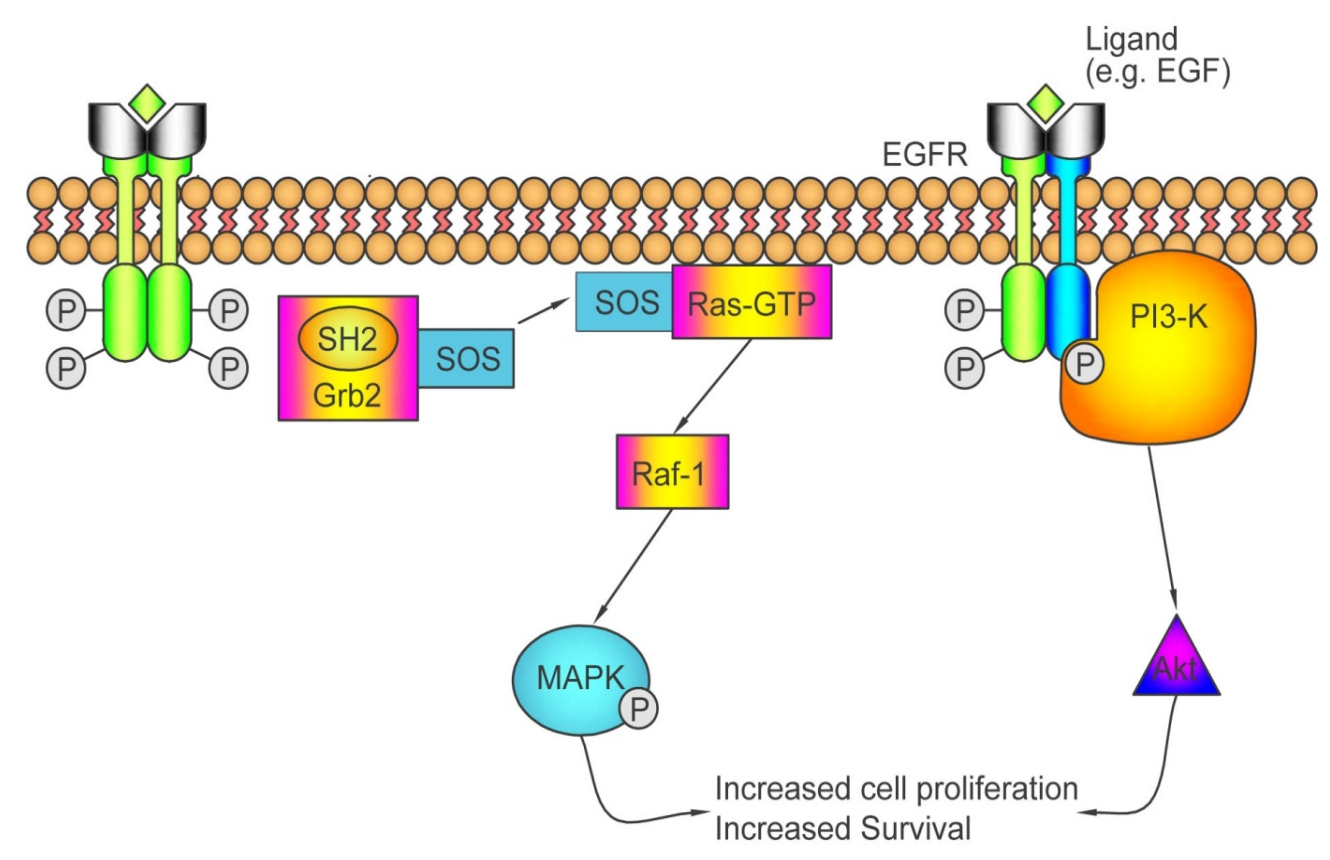

\subsubsection{Who May and May not Benefit from Antibodies against EGFR}

Lack of response to cetuximab or panitumumab-mediated blockade of the EGFR can be brought about by mutations that result in constitutive activation of the Ras/Raf/MAPK and/or PI3K/Akt pathways. The Ras proteins of the Ras/Raf/MAPK pathway bind the guanine nucleotides GTP and GDP, and have intrinsic GTPase activity [207]. They cycle between a GTP-bound active state and an inactive GDP-bound state [208]. GTPase activating proteins (GAPs) stimulate the GTPase activity of Ras proteins while guanine nucleotide exchange factors (GEFs) activate Ras by stimulating the release of GDP bound to Ras and exchange of GTP [209,210]. When EGFR binds to its ligand and the receptor dimerizes, a Ras GEF, Son of Sevenless (SOS), is recruited to the receptor, and Ras is subsequently activated [211]. The K-ras gene is one of three genes that code for one of four Ras proteins; namely, H-Ras, N-Ras, K-Ras4A, and K-Ras4B. Mutations in the K-Ras gene have been detected in 35-40\% of colorectal cancers while mutations in genes encoding for other Ras proteins, $N$-Ras and H-Ras are only found in 1-3\% of colorectal cancers [212,213]. Most of the mutations in the $K$-Ras gene have been detected in codon 12 [212], with the most frequent mutation being the 
substitution of glycine with aspartate (i.e., G12D). The second most prevalent mutation (22.5\% of samples tested) also changes codon 12-from glycine to valine (G12V). Twenty percent of K-Ras mutations are in codon 13, substituting an aspartate for the glycine (i.e., G13D) [213,214].

Clinical studies have shown that cetuximab and panitumumab are not effective in patients with a K-Ras mutation in codon 12 or 13 [215-219]. In light of this, it has now become standard to screen for mutations at these sites prior to prescribing cetuximab or panitumumab [216]. These mutations code for K-Ras proteins that have impaired GTPase activity. In addition, the GTPase activities of these mutant K-ras proteins are not stimulated by GAPs [209]. The mutant K-Ras proteins remain bound to GTP and are therefore, constitutively active [209,220]. Consequently, Ras downstream pathways are activated in a growth factor receptor-independent manner. In two large retrospective studies, however, it has been found that among patients with mutant $K$-Ras, patients with the K-Ras G13D mutation may benefit from cetuximab-containing chemotherapy (40-43\% response rate with cetuximab versus $22 \%$ response without cetuximab) [221,222], even if their response is still lower than patients with wild-type K-Ras [222]. Patients with G13D respond better to cetuximab than patients with $K$-Ras codon 12 mutations [222]. This can be explained in part by in vitro results that showed that levels of activated Ras are lower in cells transfected with K-Ras G13D than in cells transfected with K-Ras G12V [223,224]. On the other hand, there are a number of in vitro results that show that cells possessing the K-Ras G13D mutation are resistant to cetuximab [225,226]. It has even been observed that cells that have been induced to become cetuximab-resistant by continuously exposing them to cetuximab have acquired either K-Ras $G 12 \mathrm{~V}$ or $K$-Ras G13D mutations [227]. Moreover, in a large retrospective study of patients treated with panitumumab, the outcome in patients with the $G 13 D$ mutation was not better than other KRas mutations. This study confirmed that only patients with wild-type $K$-Ras benefit from panitumumab-containing chemotherapy [228]. It is possible that the benefit seen among patients with K-Ras G13D mutants in response to cetuximab but not panitumumab is brought about in part by the ability of cetuximab to induce antibody-dependent cellular cytotoxicity (ADCC) [229]. Cetuximab is an IgG1 antibody while panitumumab is an IgG2 antibody. IgG1 antibodies have a high affinity for the Fc gamma receptors (Fc $\gamma \mathrm{Rs}$ ) found on the surfaces of immune effector cells, e.g. natural killer (NK) lymphocytes and macrophages. IgG1but not IgG2 antibodies interact with FcyRIIIa that is expressed by NK cells. Thus, tumors coated by an IgG1 antibody, like cetuximab (and not panitumumab) can be recognized by NK cells and be susceptible to NK-mediated cytolysis, a mechanism that is referred to as antibody-dependent cellular cytotoxicity (ADCC) [230]. Given the retrospective nature of the studies that showed that patients with K-Ras G13D may potentially benefit from cetuximab, it is recommended that this finding be verified in prospective trials. In another study, it has been shown that patients with this mutation can also benefit from an antibody against vascular endothelial growth factor, bevacizumab (discussed below) [231]. N-Ras mutations, although not as prevalent as $K$-Ras mutations in colorectal cancer, may also be predictive of poor response among wild-type $K$-Ras patients [232].

Administering cetuximab or panitumumab only to patients that have wild-type $K$-Ras keeps potentially resistant patients from experiencing undue side effects. However, even among wild-type $K$-Ras patients, up to $65 \%$ of them do not respond to chemotherapy incorporating anti-EGFR antibodies [216,221]. Thus, the search for more markers predictive of response/resistance to EGFR antibodies, in addition to $K$-Ras, continues. 
Active GTP-bound Ras activates the Raf serine/threonine kinases (B-Raf, C-Raf, and A-Raf), resulting in the activation of MAPKs. Mutations in the $B$-Raf gene have been found in $5-17 \%$ of colorectal cancers. Approximately $90 \%$ of the $B$-Raf mutations codes for a substitution of glutamic acid for the wild-type valine in residue 600 (i.e., V600E), resulting in a constitutively active protein [233]. In two clinical studies, only 2 out of 26 patients with mutant B-Raf responded to cetuximab or panitumumab, even if these patients had wild type $K$-Ras [232,234]. It has been shown in vitro that resistance to cetuximab in colorectal cancer cell lines with mutant $B$-Raf can be reversed by combining cetuximab with a B-Raf kinase inhibitor sorafenib [234]. A recent case report describes the benefits of this strategy in treating a patient who has a $B$-Raf mutation [235]. Combining an EGFR inhibitor with a B-Raf kinase inhibitor is worth exploring in clinical studies [236]. The next most common $B$-Raf mutation in colorectal cancer is D594G $(<1 \%$ of colorectal cancers) [232,237]. In a study of 370 wild-type $K$-Ras colorectal tumor samples, this mutation was detected in one sample. This sample came from a patient that responded to cetuximab [232].

The EGFR does not only activate the Ras/Raf/MAPK pathway but also the PI3K/Akt pathway. Similar to the impact of activating mutations in the players in the Ras/Raf/MAPK signaling cascade, mutations resulting in the activation in the PI3K/Akt pathway are expected to impart resistance to EGFR antibodies. EGFR, among other growth factor receptors, activates Class $\mathrm{I}_{\mathrm{A}} \mathrm{PI} 3 \mathrm{Ks}$. The class $\mathrm{I}_{\mathrm{A}}$ PI3Ks are heterodimers of a regulatory subunit (of which the most studied is p85a or p85) and a $110 \mathrm{kDa}$ catalytic subunit [238]. There are three isoforms of the catalytic subunit; namely, 110 $\alpha, 110 \beta$, and $110 \delta$ [238]. Mutations in the gene coding for the p110 $\alpha$ subunit, PIK3CA, have been detected in up to $32 \%$ of colorectal cancers analyzed [239-241]. The most prevalent mutations lie on sequences that are in the helical and kinase domains of the protein, specifically in exons 9 and 20 [242]. The H1047R, E542K and E545K mutations, all detected in colorectal cancers, code for mutant proteins with higher lipid kinase activity than the wild-type protein [241,243]. These mutations result in Akt activation and cellular transformation [243]. In a clinical study involving 110 patients, none of the patients with the abovementioned PIK3CA gene mutations respond to panitumumab or cetuximab [244]. In another study that included 370 wild-type $K$-Ras patients, patients with mutant $P I K 3 C A$, particularly H1047R, had a significantly lower response rate than patients with wild-type PIK3CA [118]. The $\mathrm{PI} 3 \mathrm{~K} /$ Akt pathway is negatively regulated by phosphatase and tensin homolog (PTEN). Thus, PTEN downregulation can result in activation of the PI3K pathway. Majority of patients that have a dramatic reduction/loss of PTEN expression in their tumors do not respond to cetuximab [244,245].

Mutations in the K-Ras, B-Raf, and PIK3CA and loss of PTEN expression are predictive of resistance to EGFR antibodies. However, no parameter has been established to help predict which patients will gain the maximum benefit from these agents. EGFR gene copy number or EGFR amplification, as assessed by fluorescence or chromogenic in situ hybridization, is associated with response to cetuximab-involved chemotherapy [218,246-249]. One of the hurdles in the use of EGFR gene amplification as a positive predictor for response, however, is the conflicting results at least in part due to differences in methodology. Assessing EGFR gene copy number by RT-PCR in 34 patients did not demonstrate an association between EGFR copy number and response [250]. In the case of the use of FISH for EGFR amplification analysis, there has been difficulty in standardizing the protocol. Even established pathology labs that were given the same samples assessed EGFR gene amplification 
status differently. This issue needs to be addressed before EGFR gene copy number testing can be used to identify cetuximab- or panitumumab-responsive patients [251].

There are indications that sensitivity to EGFR antibodies among patients with wild-type $K$-Ras is positively associated with the mRNA expression of the EGFR ligands epiregulin and amphiregulin in tumor samples [219,252]. Downregulating amphiregulin or epiregulin in vitro decreases response to cetuximab [253]. The mechanism, however, behind the association between epiregulin/amphiregulin expression with cetuximab sensitivity remains to be elucidated.

The decision to incorporate EGFR antibodies in a colon cancer chemotherapeutic regimen also involves the choice between using cetuximab or panitumumab. Although both cetuximab and panitumumab are antibodies against EGFR, their binding sites are not identical. This can explain in part why patients can respond to panitumumab even after progressing under cetuximab [254,255]. Panitumumab can still bind to an EGFR mutant S492R to which cetuximab cannot bind to. This particular EGFR mutant was detected in tumors of patients that progressed under cetuximab [255]. It has been found that although the panitumumab epitope overlaps with the binding site of cetuximab, there are still distinctions between the binding sites of these two EGFR antibodies [256]. It remains to be seen how the differences in their binding specificities can be used to guide treatment decisions as to which EGFR antibody to use.

\subsection{Personalizing Treatment with Inhibitors of Vascular Endothelial Growth Factor}

Neovascularization, the formation of new blood vessels, is necessary for rapid tumor growth [257,258]. The extent of neovascularization, as manifested by the number of microvessels in the tumor, has been correlated with the disease stage [259,260], and recurrence rate in colorectal cancer [260,261]. Vascular endothelial factor (VEGF or VEGF-A) is the predominant regulator of angiogenesis in colon cancer. VEGF expression has been correlated with microvessel density in colon tumors [259,261], with expression being higher in tissue from patients with more advanced disease and metastases [259,262]. Other pro-angiogenic factors that have structural similarities to VEGF-A are VEGF-C, and VEGF-D [263] and placenta growth factor (P1GF) [264] Expression of PlGF has also been correlated with colorectal cancer progression [265,266]. VEGF-A is recognized by two receptor tyrosine kinases, VEGFR-1 (Flt-1) and VEGFR-2 (KDR or Flk-1) [267]. VEGF-C and -D bind to VEGFR-2 and VEGFR-3 [263], and PlGF binds only to VEGFR-1 [268].

Different strategies have been developed to inhibit VEGF-induced angiogenesis. One is through the use of antibodies specific against VEGF. Bevacizumab is the humanized form [269] of a mouse antibody against human VEGF that has been shown to inhibit tumor growth and reduce microvessel density in vivo [270]. In colorectal cancer patients, injecting bevacizumab has been shown to reduce tumor vascularity [271] and tumor perfusion [272]. The use of bevacizumab in combination with other chemotherapeutic agents (5-FU, LV, oxaliplatin, irinotecan) has improved survival [273-278].

Another strategy to inhibit angiogenesis is not only to inhibit VEGF but also to trap other pro-angiogenic factors. Aflibercept (VEGF Trap) has been developed by fusing sequences encoding for the binding domains of VEGFR-1 and VEGFR-2 with the Fe region of human IgG1 antibody. This fusion protein therefore can bind both VEGF-A and placental growth factor, and inhibit angiogenesis. 
Similar to bevacizumab, aflibercept can significantly improve survival, when administered in combination with FOLFIRI [279].

\subsubsection{Who May and May not Benefit from Inhibitors of VEGF}

The addition of bevacizumab or aflibercept to chemotherapeutic regimen, although potentially beneficial, significantly increases the occurrence of adverse events [278,279]. It is prudent, therefore, to identify patients who can gain the maximum benefit with the least toxicity.

A subset of VEGF genetic polymorphisms has been associated with variability in VEGF protein levels [280]. Polymorphisms that have been associated with lower VEGF production may predict for sensitivity to bevacizumab-containing chemotherapy. Patients with the $-634 \mathrm{G}>\mathrm{C}$ (also reported as $+405 \mathrm{G}>\mathrm{C}$ ) whether in heterozygous or homozygous form have a significantly higher response rate to FOLFIRI+bevacizumab than patients who are homozygous 634G [281]. The variant has been independently associated with decreased VEGF production by peripheral blood mononuclear cells that have been treated with lipopolysaccharide [282]. The value of screening for this polymorphism remains to be established given that in a different study, the variant has been associated with higher serum VEGF levels in healthy Japanese individuals [283]. Patients with the $-152 \mathrm{G}>\mathrm{A}$ and $1154 \mathrm{G}>\mathrm{A}$ $V E G F$ polymorphisms survived longer than patients with the respective homozygous wild-type alleles [281]. The $1154 \mathrm{G} / \mathrm{G}$ genotype is more common in patients who do not respond to chemotherapy combining bevacizumab with 5-FU (oral or infusional) and irinotecan than in patients who respond [284]. Peripheral blood mononuclear cells from healthy individuals who are homozygous $-1154 A$ produce significantly less VEGF than those from individuals who are homozygous for the $-1154 \mathrm{G}$ allele [285,286]. It is conceivable then that patients with the $1154 \mathrm{G}>\mathrm{A}$ polymorphism also produce less VEGF and therefore, respond better and survive longer in response to bevacizumab-based therapy. It is important to note that the predictive value of a particular VEGF polymorphism on response to bevacizumab is influenced by what agents are co-administered with the VEGF antibody. Among patients treated with FOLFOXIRI + bevacizumab, no association has been found between a $V E G F$ polymorphism and response [287]. In patients treated with a regimen involving capecitabine (the oral prodrug of 5-FU), oxaliplatin, and bevacizumab, a single $V E G F$ polymorphism is not predictive of outcome. However, the combination of the $V E G F 405 C$ allele with a thymidylate synthase polymorphism (TYMS 3G) is predictive of progression-free survival [288]. Another parameter that needs to be controlled in predicting response from $V E G F$ sequence is the choice of sample. A study on colorectal cancer tissue did not show a correlation between the $1154 G>A$ allele and tumor VEGF mRNA expression [289]. On the other hand, when the presence of this polymorphism was assessed in blood samples, the polymorphism has been shown to be correlated with VEGF production by PBMC's and survival outcome in response to FOLFIRI+ bevacizumab.

The number of circulating endothelial cells (CECs) in patients is a potential predictor of response to chemotherapy containing bevacizumab. CECs are believed to be shed from blood vessel walls as a result of vascular damage, although their biology is still not well understood. Nevertheless, they have been found to be more numerous in metastatic CRC patients than healthy subjects before treatment. Patients that have lower baseline CECs have a better survival outcome in response to bevacizumabcontaining chemotherapy than those with higher CEC counts [290,291]. Among the different CEC 
phenotypes that express different markers, the percentage of CECs expressing the chemokine receptor CXCR4 (CXCR4-CECs) is more predictive of survival outcome [292] in response to bevacizumab than those of CECs expressing other markers; namely, VEGFR-1, VEGFR-2, and the angiopoietin receptor Tie2. Patients that have lower percentage of CXCR4-CECs (distinguishing cut-off: 20\% CXCR4-positive) survived significantly longer than those with higher values. The interaction between CXCR4 and its ligand, stromal cell-derived factor 1 alpha (SDF-1 alpha), may play a role in tumor neovascularization in a VEGF-independent manner [293]. This can explain in part why high number of CXCR4-expressing CECs is predictive of poor response to bevacizumab. The use of CECs to guide chemotherapeutic decisions regarding bevacizumab still needs to be optimized. Conflicting results as to its predictive power [291,294] may be in part due to differences in methodologies in isolating them. Given that more recent work has shown that a particular subtype of CECs, the CXCR4-CECs, is more predictive of benefit than other CEC subtypes [292], methods have to be optimized to accurately quantitate CXCR4-CECs.

Other biomarkers for predicting and monitoring response and resistance to bevacizumab are being developed given the technical difficulty in detecting and monitoring CECs [295,296]. The most logical biomarker that has been explored is VEGF itself. The appropriate methodology, however, to measure VEGF remains under study. Measurement of total VEGF can include VEGF molecules that are actually bound to the VEGF antibody, and are therefore biologically inactive. On the other hand, assessment of free, and presumably, biologically active VEGF may be more indicative of the efficacy of the therapy. Free VEGF can be measured by passing serum samples through a column that removes all IgGs, including antibody that is bound to VEGF [297]. Total VEGF levels increase in response to bevacizumab [297-299]. Nevertheless, levels of free VEGF (i.e., unbound to antibody) decrease in response to bevacizumab [287,297,300]. Thus, amount of free and not total VEGF may be a better biomarker of response. Tissue samples may not be the best choice in assessing response to bevacizumab. When VEGF expression is assessed from tissue samples, no association is found between VEGF levels and response or survival outcomes [301].

\subsection{Personalizing Treatment with Multi-Kinase Inhibitors}

Resistance to inhibitors of EGFR and VEGF can be brought about by activation of alternate pathways that increase proliferation and promote survival in an EGFR- and VEGF-independent manner. A strategy to address this resistance is to design inhibitors against the signaling kinases involved in these alternate pathways. A mutation in the $B$-Raf gene leads to activation of the MAPK pathway [302], independent of EGFR activation. Blocking Raf-induced activation of the pathway has been shown to inhibit transformation in vitro and tumor progression in vivo [303], prompting the search for Raf inhibitors. In a high-throughput screen, 3-thienyl urea was identified as a reversible Raf kinase inhibitor. This discovery was made amidst findings from other groups that show that ureas may inhibit kinases [304]. Chemical modifications on the lead compound, 3-thienyl urea, were done to increase its activity, eventually resulting in the synthesis of the derivative, BAY 43-9006 (sorafenib), a bis-aryl urea [305] [Figure 4(a)]. Sorafenib inhibits the MAPK pathway in colorectal cancer cell lines (among other cancer cell types) that have $K$-Ras or B-Raf mutations [306]. 
Raf may not only have a role in cell proliferation but also in angiogenesis. Raf can be activated by basic fibroblast growth factor (bFGF) and VEGF, and inhibit endothelial cell apoptosis [307]. Injecting mice with nanoparticles conjugated to the mutant $B$-Raf gene to block endogenous endothelial Raf activity, inhibits angiogenesis [308]. Sorafenib has not only been shown to inhibit transformation and tumor growth but also angiogenesis. It blocks the tyrosine kinase activity of the pro-angiogenic VEGFR-1, -2, and -3 and platelet-derived growth factor receptor- $\beta$ [309]. In Phase I studies, 42\% of colorectal cancer patients treated with sorafenib experience disease stabilization [310]. Given its Raf kinase inhibitory activity, combining sorafenib with EGFR inhibitors is being considered. It is synergistic with cetuximab in inhibition of transformation (as assessed by a soft agar assay) in vitro [311]. The benefit of the use of sorafenib with CRC remains under investigation, whether it is used as a single-agent or in combination with other chemotherapeutics [312,313]. The impact of sorafenib is more on disease stabilization, even in combination with irinotecan or oxaliplatin [314,315].

Figure 4. Chemical structures of (a) sorafenib and (b) regorafenib.

a)

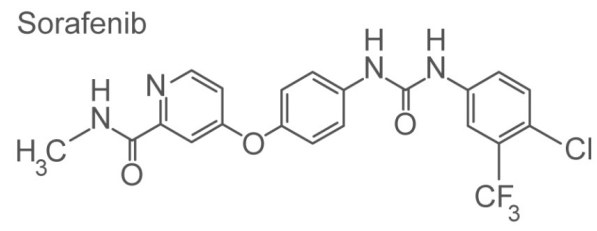

b)

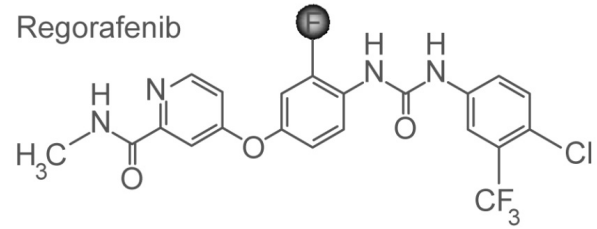

Regorafenib, like sorafenib, is also a bi-aryl urea compound. The only difference between the two is a fluorine atom in regorafenib (Figure 4b). Through mechanisms that remain undiscovered, this single change results in a distinct kinase inhibition profile. In addition to the kinases mentioned above that are inhibited by sorafenib, regorafenib inhibits Tie2 - the receptor of another proangiogenic factor angiopoietin. Regorafenib inhibits cell proliferation in vitro and inhibits angiogenesis in vivo of colorectal cancer cells. When regorafenib treatment of mice is terminated, a slow regrowth of Colo-205 (colorectal cancer) xenografts has been observed [316]. In a Phase I study of colorectal cancer patients, disease stabilization is seen in 19 out of 27 patients $(70 \%)$, and tumor perfusion is decreased in most patients [317]. In a Phase III study, regorafenib prolonged overall survival in comparison to giving best supportive care only, in patients with metastatic colorectal cancer whose disease progressed with currently approved standard chemotherapeutic regimen. Regorafenib treatment results mostly in disease stabilization, rather than tumor shrinkage [318].

The use of multi-kinase inhibitors in colorectal cancer is yet to be personalized. These inhibitors have been recently developed and their combination with other colon cancer chemotherapeutics is still the subject of exploration. It would be a challenge to identify patients who are susceptible or resistant by screening for polymorphism in one to three genes, given that these agents target multiple kinases. 
Strategies to personalize treatment with these inhibitors can involve monitoring drug levels and monitoring response more closely by assessing kinase inhibition and tumor angiogenesis.

\subsection{Personalizing Treatment with an Inhibitor Specific for Mutant B-Raf}

Patients who have a $B$-Raf mutation have been shown to have a poorer outcome than patients that have wild-type $B$-Raf [319-321]. Specifically, in colorectal cancer, more than $95 \%$ of the $B$-Raf mutations that have been found in colorectal cancer are V600E mutations [232,237]. A selective mutant B-Raf kinase inhibitor, vemurafenib (RG7204, PLX4032, RO5185426, Plexxicon/Genentech), has been developed [322]. It is currently being used for the treatment of metastatic or unresectable $\mathrm{BRaf}^{\mathrm{V} 600}$ melanoma. It has been shown that vemurafenib is also effective against a subset of colorectal cancer cell lines that had the B-Raf V600E mutation [323]. Unfortunately, when it was tested in the clinic with 19 evaluable patients, only one patient exhibited a response [324]. Similar to the results with $K$-Ras inhibitor, mutations in PIK3CA and reduction in PTEN promote resistance of $B$-Raf V600E colorectal cancer cells to vemurafenib [325]. Thus, patients that have mutant $B-R a f$, mutant $P I K 3 C A$, and PTEN downregulation may not benefit from vemurafenib alone. On the other hand, EGFR levels have been shown to affect response to vemurafenib, with low EGFR-expressing cells being susceptible to vemurafenib. EGFR activation [326,327] and consequent Akt phosphorylation [325,326] have been observed in cells treated with the B-Raf inhibitor, correlating with resistance. It is conceivable that EGFR upregulation does not contribute to a poor response if cells have low levels of EGFR. Combining an EGFR inhibitor with a B-Raf inhibitor has been shown to inhibit tumor growth in mice [326,327]. A related strategy that has promise is the combination of a B-Raf inhibitor with an Akt inhibitor [325]. More recently, it has also been shown that there is benefit in combining a B-Raf inhibitor with a PI3K/mTOR inhibitor given the observed activation of the PI3K/mTOR pathway in B-Raf inhibitor-treated cells [328]. In the clinic, the inhibition of B-Raf (by using the multi-kinase inhibitor sorafenib) and the inhibition of EGFR appeared to prolong survival [235]. A step that can be taken towards personalizing treatment with inhibitors specific for mutant $B$-Raf is to assess PIK3CA status and PTEN and EGFR expression. If the patient that has mutant $B$-Raf V600 also has wild-type PIK3CA mutation and PTEN is not downregulated, vemurafenib can be used. The assessment of EGFR expression can guide the decision on whether to combine vemurafenib with an EGFR inhibitor.

\subsection{Personalizing Treatment in View of Colorectal Cancer Stem Cells (Co-CSC) and Circulating} Tumor Cells (CTC)

One important task in our efforts to personalize treatment of CRC patients is to detect chemoresistance and/or disease recurrence and treat patients appropriately. When dissociated tumor cells from patient samples are treated with 5-FU, although the viability of the bulk population decreases, it has been found that the surviving population is enriched with a subset of cancer cells referred to as cancer stem cells (CSC) [329,330]. Cancer stem cells make up less than $10 \%$ of a tumor. Yet, they have been shown to be the cell subset that actually have the capability to form tumors, self-renew, and differentiate to recapitulate the characteristics of the primary tumor [331]. Because of how important it is to isolate, study, and eventually target CSC, efforts have been made to identify CSC-specific markers. In the case of colorectal cancer, putative markers include CD133 [332-334], 
EpCAM (epithelial adhesion molecule), CD44, CD166 [335], aldehyde dehydrogenase 1 (ALDH1) [336], CD26 [329], CD24, CD29, and Lgr5 [337].

It is proposed that one of the reasons behind treatment failure in patients is the resistance of cancer stem cells to chemotherapeutics. Although chemotherapeutics may affect the non-stem cell population, the surviving stem cell population can self-renew. Clinically, this can be observed as disease progression or recurrence. CD133+ cells that were purified from colon cancer samples have been found to be more resistant to 5-FU, oxaliplatin and the pro-apoptotic protein TRAIL than CD133cells [334]. CD26+ cells are resistant to 5-FU and oxaliplatin [329] and CD44+CD166+ cells are resistant to irinotecan [330]. CD133 positivity in patients' primary tumors has been found to be associated with a poorer response to chemotherapy [338,339]. Thus, one way to personalize CRC treatment is to assess the predominance of cancer stem cells in patients' primary tumors. This can help guide the choice of chemotherapeutic. The choice of sample, however, is critical. To predict chemotherapeutic response from CD133 expression, for instance, primary tumor samples need to be used. In metastatic tissue, both CD133+ and CD133- cells possess stem cell characteristics [340]. Thus, the extent of CD133 positivity in metastases may not be indicative of chemotherapeutic response/resistance.

Another cancer cell subset that may be used to predict response to chemotherapy is the circulating tumor cell (CTC). The presence of circulating tumor cells, i.e., tumor cells in the blood, was first described in 1869. Since then, researchers have devised methods to detect them more efficiently [341]. In 2004, the US Food and Drug Administration approved the use of an immunomagnetic CTC selection and enumeration system in the clinic. Based on the results of a clinical trial involving 430 metastatic colorectal cancer patients, the threshold count has been set to three CTC's in $7.5 \mathrm{~mL}$ blood [342]. A patient is predicted to have poor prognosis if three or more CTC's are detected in their blood sample. A number of clinical studies have shown that not only the baseline CTC count may be important but also the trend of the CTC count in response to treatment [343]. It has been shown that patients whose CTC counts decreased from an unfavorable number (i.e., above the threshold) to a favorable one had similar survival outcomes than those patients who maintained a favorable CTC count throughout chemotherapy [342,344]. the increase in CTCs in patients during chemotherapy may be an early predictor of resistance. Furthermore, patients with high baseline CTC who continue to have high CTC even after treatment have poor survival outcomes [345]. The trend in the patient's CTC counts may be as effective as radiographic imaging in showing a lack of response to the treatment [346]. The number of CTC's in a patient's blood after different durations of treatment is predictive of survival outcomes. Given this, it has been proposed that CTC counts can help guide decisions regarding whether and how long of a treatment break can be given to the patient [342].

\section{Conclusions}

In this review, we discussed how the use of old and new colon cancer chemotherapeutics is being personalized. Genotyping an individual to detect polymorphisms in the TYMS, MTHFR, DPYD, UGT1A, ERCC1, K-Ras, B-Raf, and PIK3CA, can help guide the choice of chemotherapeutic agent (Figure 5). As large scale genomic analyses are performed more often, the number of genes (e.g., N-Ras, Aurora kinase, $C D K 8$ ) and genetic changes (e.g., gene fusions) that can be used in the 
decision-making process is expected to increase [347]. Aside from genetic markers, however, there are other predictive parameters that can be used. PTEN and EGFR protein expression, EGFR and TYMS gene copy number, and number of circulating endothelial cells are additional markers that can be used to predict response. Personalizing treatment does not only involve choosing what chemotherapeutic to administer but also adjusting the dose of the drug to maximize benefit and minimize toxicity. Pharmacokinetic monitoring and dose adjustment of 5-FU has been shown to increase response and reduce toxicity. In addition, irinotecan doses can be optimized based on the knowledge of what UGT1A1 allele a patient has.

Figure 5. A decision-making flowchart that illustrates how the presence/absence of specific genetic mutations and polymorphisms discussed in this review article can be used to guide therapeutic decisions.

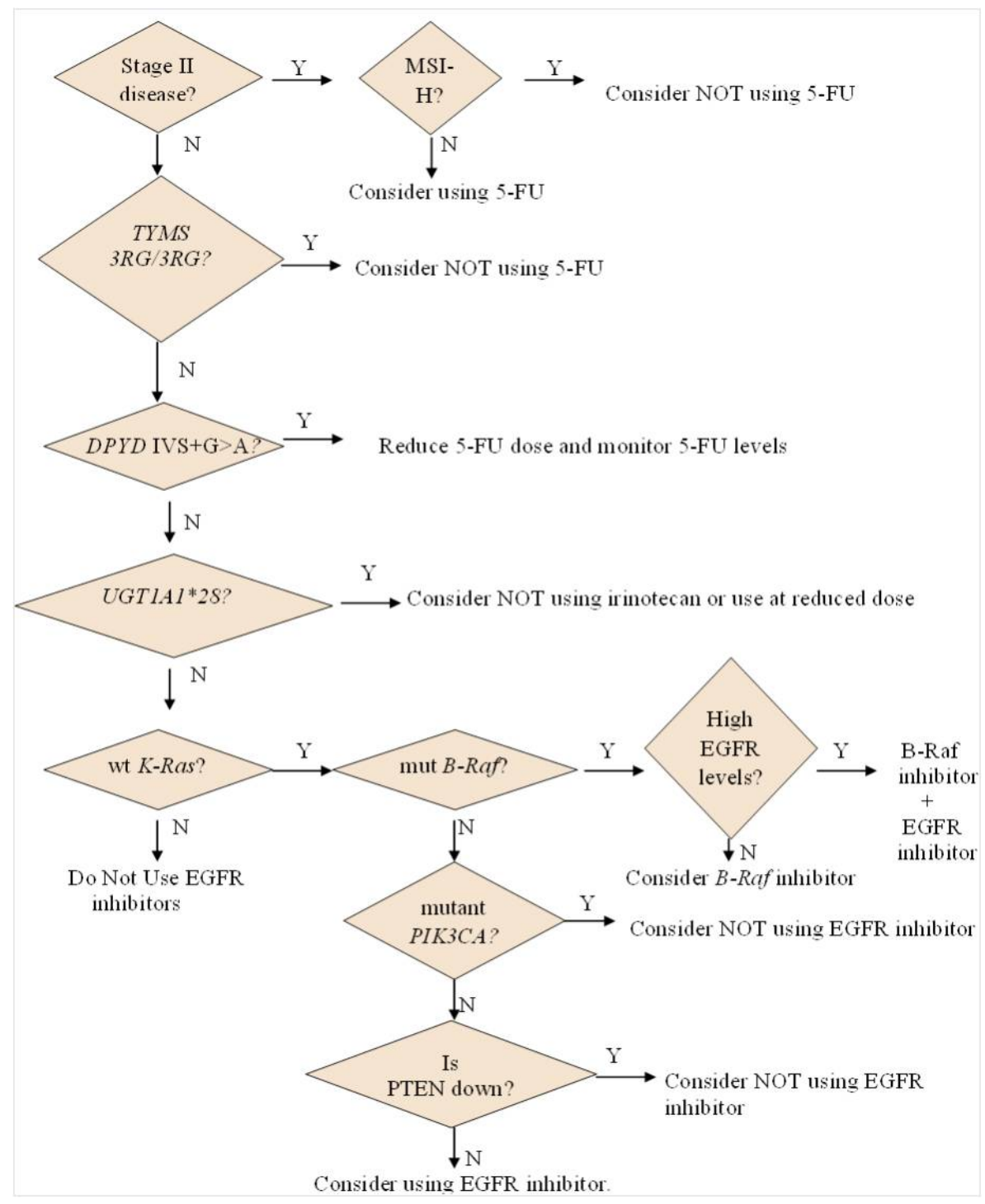

The real-life benefits of years of research to personalize colon cancer chemotherapeutics are increasingly being seen. In the clinic, a patient can have his tumor screened for specific polymorphisms and mutations that would predict what drugs they will respond to, and what drugs they may react adversely to. In particular, results of screening for the $K$-Ras mutation determine whether a 
patient will even be given an EGFR inhibitor. Once patients start 5-FU based chemotherapy, 5-FU pharmacokinetic monitoring can be performed and 5-FU doses adjusted based on actual drug levels. There is, however, more to be done. Because important clinical decisions are made based on laboratory tests, the reliability of these tests must be assured. An example of how different results from two genetic testing laboratories may have affected management of disease has been reported in a case report by Lamparella et al. [348]. In their experience, two reference laboratories obtained two different findings on the $K$-Ras mutation status of a patient. Given that EGFR antibodies are withheld from patients with mutant $K$-Ras, it is understandable how the conflicting results affected treatment decisions. It is imperative that standards for ensuring the reliability of results of genetic testing be laid out, to promote maximum clinical benefit to the patient.

A critical area of research is the understanding of the mechanisms behind chemotherapeutic failure. Possible reasons behind drug failure include tumor chemoresistance or suboptimal drug levels. There are no methodologies in place to ensure that the molecular targets of the chemotherapeutics are really being inhibited in the patient. Finally, as can be gleaned from the response rates with current chemotherapeutic regimens and the median overall survival of 2 years for metastatic colorectal cancer, one of the greatest challenges remains the development of more effective but safe pharmaceuticals. As more information is gained about an individual's normal and tumor genotype, especially with the optimization of whole genome sequencing, potentially, we can match the drug that will best fit the individual.

\section{Acknowledgments}

There has been much research done on personalizing colon cancer chemotherapeutics -- ranging from important laboratory experiments to clinical trials. Because of the immense body of work that has been done, we apologize if we have failed to reference some of the research that has facilitated progress in this field. We are grateful to Walter Kline II for assistance in preparing the figures used in this manuscript. W.S.E-D. is an American Cancer Society Research Professor.

\section{Conflicts of Interest}

The authors declare no conflict of interest.

\section{References}

1. Ferlay, J.; Shin, H.R.; Bray, F.; Forman, D.; Mathers, C.; Parkin, D.M. Estimates of worldwide burden of cancer in 2008: GLOBOCAN 2008. Int. J. Cancer 2010, 127, 2893-2917.

2. Laurie, J.A.; Moertel, C.G.; Fleming, T.R.; Wieand, H.S.; Leigh, J.E.; Rubin, J.; McCormack, G.W.; Gerstner, J.B.; Krook, J.E.; Malliard, J.; et al. Surgical adjuvant therapy of large-bowel carcinoma: An evaluation of levamisole and the combination of levamisole and fluorouracil. The North Central Cancer Treatment Group and the Mayo Clinic. J. Clin. Oncol. 1989, 7, 1447-1456.

3. Wolmark, N.; Fisher, B.; Rockette, H.; Redmond, C.; Wickerham, D.L.; Fisher, E.R.; Jones, J.; Glass, A.; Lerner, H.; Lawrence, W.; et al. Postoperative adjuvant chemotherapy or BCG for colon cancer: Results from NSABP protocol C-01. J. Natl. Cancer Inst. 1988, 80, 30-36. 
4. Howlader, N.; Noone, A.M.; Krapcho, M.; Neyman, N.; Aminou, R.; Waldron, W.; Altekruse, S.F.; Kosary, C.L.; Ruhl, J.; Tatalovich, Z.; et al. SEER Cancer Statistics Review, 1975-2008; National Cancer Institute: Bethesda, MD, USA, 2011

5. Schuell, B.; Gruenberger, T.; Kornek, G.V.; Dworan, N.; Depisch, D.; Lang, F.; Schneeweiss, B.; Scheithauer, W. Side effects during chemotherapy predict tumour response in advanced colorectal cancer. Br. J. Cancer 2005, 93, 744-748.

6. Heidelberger, C.; Chaudhuri, N.K.; Danneberg, P.; Mooren, D.; Griesbach, L.; Duschinsky, R.; Schnitzer, R.J.; Pleven, E.; Scheiner, J. Fluorinated pyrimidines, a new class of tumour-inhibitory compounds. Nature 1957, 179, 663-666.

7. Cudmore, J.T.; Groesbeck, H.P. Comparison of High-Dosage and Low-Dosage-Maintenance Therapy with 5-Fluorouracil in Solid Tumors. Cancer 1964, 17, 230-232

8. Jacobs, E.M.; Reeves, W.J., Jr.; Wood, D.A.; Pugh, R.; Braunwald, J.; Bateman, J.R. Treatment of cancer with weekly intravenous 5-fluorouracil. Study by the Western Cooperative Cancer Chemotherapy Group (WCCCG). Cancer 1971, 27, 1302-1305.

9. Seifert, P.; Baker, L.H.; Reed, M.L.; Vaitkevicius, V.K. Comparison of continuously infused 5-fluorouracil with bolus injection in treatment of patients with colorectal adenocarcinoma. Cancer 1975, 36, 123-128.

10. Lokich, J.J.; Ahlgren, J.D.; Gullo, J.J.; Philips, J.A.; Fryer, J.G. A prospective randomized comparison of continuous infusion fluorouracil with a conventional bolus schedule in metastatic colorectal carcinoma: A Mid-Atlantic Oncology Program Study. J. Clin. Oncol. 1989, 7, 425-432.

11. Brennan, M.J.; Talley, R.W.; Drake, E.H.; Vaitkevicius, V.K.; Poznanski, A.K.; Brush, B.E. 5-Fluorouracil Treatment of Liver Metastases by Continuous Hepatic Artery Infusion Via Cournand Catheter: Results and Suitability for Intensive Postsurgical Adjuvant Chemotherapy. Ann. Surg. 1963, 158, 405-419.

12. Cressy, N.L.; Schell, H.W., Jr. Effectiveness and Toxicity of Prolonged Infusions of 5-Fluorouracil in the Treatment of Cancer. Am. J. Med. Sci. 1965, 249, 52-55.

13. Rutman, R.J.; Cantarow, A.; Paschkis, K.E. Studies in 2-acetylaminofluorene carcinogenesis. III. The utilization of uracil-2-C14 by preneoplastic rat liver and rat hepatoma. Cancer Res. 1954, 14, $119-123$.

14. Longley, D.B.; Harkin, D.P.; Johnston, P.G. 5-fluorouracil: Mechanisms of action and clinical strategies. Nat. Rev. Cancer 2003, 3, 330-338.

15. Amatori, F.; Di Paolo, A.; Del Tacca, M.; Fontanini, G.; Vannozzi, F.; Boldrini, L.; Bocci, G.; Lastella, M.; Danesi, R. Thymidylate synthase, dihydropyrimidine dehydrogenase and thymidine phosphorylase expression in colorectal cancer and normal mucosa in patients. Pharmacogenet. Genomics 2006, 16, 809-816.

16. Ikeguchi, M.; Makino, M.; Kaibara, N. Thymidine phosphorylase and dihydropyrimidine dehydrogenase activity in colorectal carcinoma and patients prognosis. Langenbecks Arch. Surg. 2002, 387, 240-245.

17. Grem, J.L.; Chabner, B.A.; Ryan, D.P.; Wadlow, R.C. 5-Fluoropyrimidines. In Cancer Chemotherapy and Biotherapy: Principles and Practice; Chabner, B. A., Longo, D. L., Eds.; Lippincott Williams \& Wilkins: Philadelphia, PA, USA, 2010. 
18. Jackson, R.C. The regulation of thymidylate biosynthesis in Novikoff hepatoma cells and the effects of amethopterin, 5-fluorodeoxyuridine, and 3-deazauridine. J. Biol. Chem. 1978, 253, 7440-7446.

19. Grogan, B.C.; Parker, J.B.; Guminski, A.F.; Stivers, J.T. Effect of the thymidylate synthase inhibitors on dUTP and TTP pool levels and the activities of DNA repair glycosylases on uracil and 5-fluorouracil in DNA. Biochemistry 2011, 50, 618-627.

20. Goulian, M.; Bleile, B.; Tseng, B.Y. The effect of methotrexate on levels of dUTP in animal cells. J. Biol. Chem .1980, 255, 10630-10637.

21. Myers, C.E.; Young, R.C.; Chabner, B.A. Biochemical determinants of 5-fluorouracil response in vivo. The role of deoxyuridylate pool expansion. J. Clin. Invest. 1975, 56, 1231-1238.

22. Brynolf, K.; Eliasson, R.; Reichard, P. Formation of Okazaki fragments in polyoma DNA synthesis caused by misincorporation of uracil. Cell 1978, 13, 573-580.

23. Lonn, U.; Lonn, S. Interaction between 5-fluorouracil and DNA of human colon adenocarcinoma. Cancer Res. 1984, 44, 3414-3418.

24. Yoshioka, A.; Tanaka, S.; Hiraoka, O.; Koyama, Y.; Hirota, Y.; Ayusawa, D.; Seno, T.; Garrett, C.; Wataya, Y. Deoxyribonucleoside triphosphate imbalance. 5-Fluorodeoxyuridine-induced DNA double strand breaks in mouse FM3A cells and the mechanism of cell death. J. Biol. Chem. 1987, 262, 8235-8241.

25. Herrick, D.; Kufe, D.W. Lethality associated with incorporation of 5-fluorouracil into preribosomal RNA. Mol. Pharmacol. 1984, 26, 135-140.

26. Modulation of fluorouracil by leucovorin in patients with advanced colorectal cancer: Evidence in terms of response rate. Advanced Colorectal Cancer Meta-Analysis project. J. Clin. Oncol. 1992, 10, 896-903.

27. Ullman, B.; Lee, M.; Martin, D.W., Jr.; Santi, D.V. Cytotoxicity of 5-fluoro-2'-deoxyuridine: Requirement for reduced folate cofactors and antagonism by methotrexate. Proc. Natl. Acad. Sci. USA 1978, 75, 980-983.

28. Danenberg, P.V.; Danenberg, K.D. Effect of 5, 10-methylenetetrahydrofolate on the dissociation of 5-fluoro-2'-deoxyuridylate from thymidylate synthetase: Evidence for an ordered mechanism. Biochemistry 1978, 17, 4018-4024.

29. Evans, R.M.; Laskin, J.D.; Hakala, M.T. Effect of excess folates and deoxyinosine on the activity and site of action of 5-fluorouracil. Cancer Res. 1981, 41, 3288-3295.

30. Erlichman, C.; Fine, S.; Wong, A.; Elhakim, T. A randomized trial of fluorouracil and folinic acid in patients with metastatic colorectal carcinoma. J. Clin. Oncol. 1988, 6, 469-475.

31. Bobbio-Pallavicini, E.; Porta, C.; Moroni, M.; Spaghi, A.; Casagranda, I.; Nastasi, G. Folinic acid does improve 5-fluorouracil activity in vivo. Results of a phase III study comparing 5-fluorouracil to 5-fluorouracil and folinic acid in advanced colon cancer patients. J. Chemother. 1993, 5, 52-55.

32. Peters, G.J.; van der Wilt, C.L.; van Groeningen, C.J.; Smid, K.; Meijer, S.; Pinedo, H.M. Thymidylate synthase inhibition after administration of fluorouracil with or without leucovorin in colon cancer patients: Implications for treatment with fluorouracil. J. Clin. Oncol. 1994, 12, 2035-2042. 
33. Donaldson, K.O.; Keresztesy, J.C. Naturally occurring forms of folic acid. I. "Prefolic A": Preparation of concentrate and enzymatic conversion to citrovorum factor. J. Biol. Chem. 1959, 234, 3235-3240.

34. Frosst, P.; Blom, H.J.; Milos, R.; Goyette, P.; Sheppard, C.A.; Matthews, R.G.; Boers, G.J.; den Heijer, M.; Kluijtmans, L.A.; van den Heuvel, L.P.; et al. A candidate genetic risk factor for vascular disease: A common mutation in methylenetetrahydrofolate reductase. Nat. Genet. 1995, 10, 111-113.

35. Cohen, V.; Panet-Raymond, V.; Sabbaghian, N.; Morin, I.; Batist, G.; Rozen, R. Methylenetetrahydrofolate reductase polymorphism in advanced colorectal cancer: A novel genomic predictor of clinical response to fluoropyrimidine-based chemotherapy. Clin. Cancer Res. 2003, 9, 1611-1615.

36. Etienne-Grimaldi, M.C.; Milano, G.; Maindrault-Goebel, F.; Chibaudel, B.; Formento, J.L.; Francoual, M.; Lledo, G.; Andre, T.; Mabro, M.; Mineur, L.; et al. Methylenetetrahydrofolate reductase (MTHFR) gene polymorphisms and FOLFOX response in colorectal cancer patients. Br. J. Clin. Pharmacol. 2010, 69, 58-66.

37. Etienne, M.C.; Formento, J.L.; Chazal, M.; Francoual, M.; Magne, N.; Formento, P.; Bourgeon, A.; Seitz, J.F.; Delpero, J.R.; Letoublon, C.; et al. Methylenetetrahydrofolate reductase gene polymorphisms and response to fluorouracil-based treatment in advanced colorectal cancer patients. Pharmacogenetics 2004, 14, 785-792.

38. Jakobsen, A.; Nielsen, J.N.; Gyldenkerne, N.; Lindeberg, J. Thymidylate synthase and methylenetetrahydrofolate reductase gene polymorphism in normal tissue as predictors of fluorouracil sensitivity. J. Clin. Oncol. 2005, 23, 1365-1369.

39. Marcuello, E.; Altes, A.; Menoyo, A.; Rio, E.D.; Baiget, M. Methylenetetrahydrofolate reductase gene polymorphisms: Genomic predictors of clinical response to fluoropyrimidine-based chemotherapy? Cancer Chemother. Pharmacol. 2006, 57, 835-840.

40. Suh, K.W.; Kim, J.H.; Kim do, Y.; Kim, Y.B.; Lee, C.; Choi, S. Which gene is a dominant predictor of response during FOLFOX chemotherapy for the treatment of metastatic colorectal cancer, the MTHFR or XRCC1 gene? Ann. Surg. Oncol. 2006, 13, 1379-1385.

41. Takeishi, K.; Kaneda, S.; Ayusawa, D.; Shimizu, K.; Gotoh, O.; Seno, T. Human thymidylate synthase gene: Isolation of phage clones which cover a functionally active gene and structural analysis of the region upstream from the translation initiation codon. J. Biochem. 1989, 106, $575-583$.

42. Horie, N.; Aiba, H.; Oguro, K.; Hojo, H.; Takeishi, K. Functional analysis and DNA polymorphism of the tandemly repeated sequences in the 5'-terminal regulatory region of the human gene for thymidylate synthase. Cell. Struct. Funct. 1995, 20, 191-197.

43. Kawakami, K.; Salonga, D.; Park, J.M.; Danenberg, K.D.; Uetake, H.; Brabender, J.; Omura, K.; Watanabe, G.; Danenberg, P.V. Different lengths of a polymorphic repeat sequence in the thymidylate synthase gene affect translational efficiency but not its gene expression. Clin. Cancer Res. 2001, 7, 4096-4101.

44. Afzal, S.; Gusella, M.; Vainer, B.; Vogel, U.B.; Andersen, J.T.; Broedbaek, K.; Petersen, M.; Jimenez-Solem, E.; Bertolaso, L.; Barile, C.; et al. Combinations of polymorphisms in genes involved in the 5-Fluorouracil metabolism pathway are associated with gastrointestinal toxicity in chemotherapy-treated colorectal cancer patients. Clin. Cancer Res. 2011, 17, 3822-3829. 
45. Kawakami, K.; Omura, K.; Kanehira, E.; Watanabe, Y. Polymorphic tandem repeats in the thymidylate synthase gene is associated with its protein expression in human gastrointestinal cancers. Anticancer Res. 1999, 19, 3249-3252.

46. Pullarkat, S.T.; Stoehlmacher, J.; Ghaderi, V.; Xiong, Y.P.; Ingles, S.A.; Sherrod, A.; Warren, R.; Tsao-Wei, D.; Groshen, S.; Lenz, H.J. Thymidylate synthase gene polymorphism determines response and toxicity of 5-FU chemotherapy. Pharmacogenomics $J .2001,1,65-70$.

47. Lecomte, T.; Ferraz, J.M.; Zinzindohoue, F.; Loriot, M.A.; Tregouet, D.A.; Landi, B.; Berger, A.; Cugnenc, P.H.; Jian, R.; Beaune, P.; et al. Thymidylate synthase gene polymorphism predicts toxicity in colorectal cancer patients receiving 5-fluorouracil-based chemotherapy. Clin. Cancer Res. 2004, 10, 5880-5888.

48. Marsh, S.; McKay, J.A.; Cassidy, J.; McLeod, H.L. Polymorphism in the thymidylate synthase promoter enhancer region in colorectal cancer. Int. J. Oncol. 2001, 19, 383-386.

49. Uchida, K.; Hayashi, K.; Kawakami, K.; Schneider, S.; Yochim, J.M.; Kuramochi, H.; Takasaki, K.; Danenberg, K.D.; Danenberg, P.V. Loss of heterozygosity at the thymidylate synthase (TS) locus on chromosome 18 affects tumor response and survival in individuals heterozygous for a 28-bp polymorphism in the TS gene. Clin. Cancer Res. 2004, 10, 433-439.

50. Iacopetta, B.; Grieu, F.; Joseph, D.; Elsaleh, H. A polymorphism in the enhancer region of the thymidylate synthase promoter influences the survival of colorectal cancer patients treated with 5-fluorouracil. Br. J. Cancer 2001, 85, 827-830.

51. Mandola, M.V.; Stoehlmacher, J.; Muller-Weeks, S.; Cesarone, G.; Yu, M.C.; Lenz, H.J.; Ladner, R.D. A novel single nucleotide polymorphism within the $5^{\prime}$ tandem repeat polymorphism of the thymidylate synthase gene abolishes USF-1 binding and alters transcriptional activity. Cancer Res. 2003, 63, 2898-2904.

52. Marcuello, E.; Altes, A.; del Rio, E.; Cesar, A.; Menoyo, A.; Baiget, M. Single nucleotide polymorphism in the $5^{\prime}$ tandem repeat sequences of thymidylate synthase gene predicts for response to fluorouracil-based chemotherapy in advanced colorectal cancer patients. Int. J. Cancer 2004, 112, 733-737.

53. Johnston, P.G.; Lenz, H.J.; Leichman, C.G.; Danenberg, K.D.; Allegra, C.J.; Danenberg, P.V.; Leichman, L. Thymidylate synthase gene and protein expression correlate and are associated with response to 5-fluorouracil in human colorectal and gastric tumors. Cancer Res. 1995, 55, 1407-1412.

54. Leichman, C.G.; Lenz, H.J.; Leichman, L.; Danenberg, K.; Baranda, J.; Groshen, S.; Boswell, W.; Metzger, R.; Tan, M.; Danenberg, P.V. Quantitation of intratumoral thymidylate synthase expression predicts for disseminated colorectal cancer response and resistance to protracted-infusion fluorouracil and weekly leucovorin. J. Clin. Oncol. 1997, 15, 3223-3229.

55. Lenz, H.J.; Hayashi, K.; Salonga, D.; Danenberg, K.D.; Danenberg, P.V.; Metzger, R.; Banerjee, D.; Bertino, J.R.; Groshen, S.; Leichman, L.P.; et al. p53 point mutations and thymidylate synthase messenger RNA levels in disseminated colorectal cancer: An analysis of response and survival. Clin. Cancer Res. 1998, 4, 1243-1250. 
56. Aschele, C.; Debernardis, D.; Casazza, S.; Antonelli, G.; Tunesi, G.; Baldo, C.; Lionetto, R.; Maley, F.; Sobrero, A. Immunohistochemical quantitation of thymidylate synthase expression in colorectal cancer metastases predicts for clinical outcome to fluorouracil-based chemotherapy. J. Clin. Oncol. 1999, 17, 1760-1770.

57. Kumamoto, K.; Kuwabara, K.; Tajima, Y.; Amano, K.; Hatano, S.; Ohsawa, T.; Okada, N.; Ishibashi, K.; Haga, N.; Ishida, H. Thymidylate synthase and thymidine phosphorylase mRNA expression in primary lesions using laser capture microdissection is useful for prediction of the efficacy of FOLFOX treatment in colorectal cancer patients with liver metastasis. Oncol. Lett. 2012, 3, 983-989.

58. Wang, T.L.; Diaz, L.A., Jr.; Romans, K.; Bardelli, A.; Saha, S.; Galizia, G.; Choti, M.; Donehower, R.; Parmigiani, G.; Shih Ie, M.; et al. Digital karyotyping identifies thymidylate synthase amplification as a mechanism of resistance to 5-fluorouracil in metastatic colorectal cancer patients. Proc. Natl. Acad. Sci. USA 2004, 101, 3089-3094.

59. Watson, R.G.; Muhale, F.; Thorne, L.B.; Yu, J.; O’Neil, B.H.; Hoskins, J.M.; Meyers, M.O.; Deal, A.M.; Ibrahim, J.G.; Hudson, M.L.; et al. Amplification of thymidylate synthetase in metastatic colorectal cancer patients pretreated with 5-fluorouracil-based chemotherapy. Eur. J. Cancer 2010, 46, 3358-3364.

60. Hillcoat, B.L.; McCulloch, P.B.; Figueredo, A.T.; Ehsan, M.H.; Rosenfeld, J.M. Clinical response and plasma levels of 5-fluorouracil in patients with colonic cancer treated by drug infusion. Br. J. Cancer 1978, 38, 719-724.

61. Van Groeningen, C.J.; Pinedo, H.M.; Heddes, J.; Kok, R.M.; de Jong, A.P.; Wattel, E.; Peters, G.J.; Lankelma, J. Pharmacokinetics of 5-fluorouracil assessed with a sensitive mass spectrometric method in patients on a dose escalation schedule. Cancer Res. 1988, 48, 6956-6961.

62. Gamelin, E.C.; Danquechin-Dorval, E.M.; Dumesnil, Y.F.; Maillart, P.J.; Goudier, M.J.; Burtin, P.C.; Delva, R.G.; Lortholary, A.H.; Gesta, P.H.; Larra, F.G. Relationship between 5-fluorouracil (5-FU) dose intensity and therapeutic response in patients with advanced colorectal cancer receiving infusional therapy containing 5-FU. Cancer 1996, 77, 441-451.

63. Heggie, G.D.; Sommadossi, J.P.; Cross, D.S.; Huster, W.J.; Diasio, R.B. Clinical pharmacokinetics of 5-fluorouracil and its metabolites in plasma, urine, and bile. Cancer Res. 1987, 47, 2203-2206.

64. Zhang, X.; Diasio, R.B. Regulation of human dihydropyrimidine dehydrogenase: Implications in the pharmacogenetics of 5-FU-based chemotherapy. Pharmacogenomics 2007, 8, 257-265.

65. Salonga, D.; Danenberg, K.D.; Johnson, M.; Metzger, R.; Groshen, S.; Tsao-Wei, D.D.; Lenz, H.J.; Leichman, C.G.; Leichman, L.; Diasio, R.B.; et al. Colorectal tumors responding to 5-fluorouracil have low gene expression levels of dihydropyrimidine dehydrogenase, thymidylate synthase, and thymidine phosphorylase. Clin. Cancer Res. 2000, 6, 1322-1327.

66. Ichikawa, W.; Uetake, H.; Shirota, Y.; Yamada, H.; Nishi, N.; Nihei, Z.; Sugihara, K.; Hirayama, R. Combination of dihydropyrimidine dehydrogenase and thymidylate synthase gene expressions in primary tumors as predictive parameters for the efficacy of fluoropyrimidine-based chemotherapy for metastatic colorectal cancer. Clin. Cancer Res. 2003, 9, 786-791.

67. Collie-Duguid, E.S.; Etienne, M.C.; Milano, G.; McLeod, H.L. Known variant DPYD alleles do not explain DPD deficiency in cancer patients. Pharmacogenetics 2000, 10, 217-223. 
68. Morel, A.; Boisdron-Celle, M.; Fey, L.; Soulie, P.; Craipeau, M.C.; Traore, S.; Gamelin, E. Clinical relevance of different dihydropyrimidine dehydrogenase gene single nucleotide polymorphisms on 5-fluorouracil tolerance. Mol. Cancer Ther. 2006, 5, 2895-2904.

69. Boland, C.R.; Goel, A. Microsatellite instability in colorectal cancer. Gastroenterology 2010, 138, 2073-2087.e2073.

70. Ribic, C.M.; Sargent, D.J.; Moore, M.J.; Thibodeau, S.N.; French, A.J.; Goldberg, R.M.; Hamilton, S.R.; Laurent-Puig, P.; Gryfe, R.; Shepherd, L.E.; et al. Tumor microsatellite-instability status as a predictor of benefit from fluorouracil-based adjuvant chemotherapy for colon cancer. N. Engl. J. Med. 2003, 349, 247-257.

71. Sargent, D.J.; Marsoni, S.; Monges, G.; Thibodeau, S.N.; Labianca, R.; Hamilton, S.R.; French, A.J.; Kabat, B.; Foster, N.R.; Torri, V.; et al. Defective mismatch repair as a predictive marker for lack of efficacy of fluorouracil-based adjuvant therapy in colon cancer. J. Clin. Oncol. 2010, 28, 3219-3226.

72. Ng, K.; Schrag, D. Microsatellite instability and adjuvant fluorouracil chemotherapy: A mismatch? J. Clin. Oncol. 2010, 28, 3207-3210.

73. Febbo, P.G.; Ladanyi, M.; Aldape, K.D.; de Marzo, A.M.; Hammond, M.E.; Hayes, D.F.; Iafrate, A.J.; Kelley, R.K.; Marcucci, G.; Ogino, S.; et al. NCCN Task Force report: Evaluating the clinical utility of tumor markers in oncology. J. Natl. Compr. Canc. Netw. 2011, 9, S1-S32.

74. Zaanan, A.; Cuilliere-Dartigues, P.; Guilloux, A.; Parc, Y.; Louvet, C.; de Gramont, A.; Tiret, E.; Dumont, S.; Gayet, B.; Validire, P.; et al. Impact of p53 expression and microsatellite instability on stage III colon cancer disease-free survival in patients treated by 5 -fluorouracil and leucovorin with or without oxaliplatin. Ann. Oncol. 2010, 21, 772-780.

75. Hoff, P.M.; Ansari, R.; Batist, G.; Cox, J.; Kocha, W.; Kuperminc, M.; Maroun, J.; Walde, D.; Weaver, C.; Harrison, E.; et al. Comparison of oral capecitabine versus intravenous fluorouracil plus leucovorin as first-line treatment in 605 patients with metastatic colorectal cancer: Results of a randomized phase III study. J. Clin. Oncol. 2001, 19, 2282-2292.

76. Trump, D.L.; Egorin, M.J.; Forrest, A.; Willson, J.K.; Remick, S.; Tutsch, K.D. Pharmacokinetic and pharmacodynamic analysis of fluorouracil during 72-hour continuous infusion with and without dipyridamole. J. Clin. Oncol. 1991, 9, 2027-2035.

77. Naguib, F.N.; el Kouni, M.H.; Cha, S. Enzymes of uracil catabolism in normal and neoplastic human tissues. Cancer Res. 1985, 45, 5405-5412.

78. Diasio, R.B.; Beavers, T.L.; Carpenter, J.T. Familial deficiency of dihydropyrimidine dehydrogenase. Biochemical basis for familial pyrimidinemia and severe 5-fluorouracil-induced toxicity. J. Clin. Invest. 1988, 81, 47-51.

79. Di Paolo, A.; Danesi, R.; Falcone, A.; Cionini, L.; Vannozzi, F.; Masi, G.; Allegrini, G.; Mini, E.; Bocci, G.; Conte, P.F.; Del Tacca, M. Relationship between 5-fluorouracil disposition, toxicity and dihydropyrimidine dehydrogenase activity in cancer patients. Ann. Oncol. 2001, 12, 1301-1306.

80. Takimoto, C.H.; Lu, Z.H.; Zhang, R.; Liang, M.D.; Larson, L.V.; Cantilena, L.R., Jr.; Grem, J.L.; Allegra, C.J.; Diasio, R.B.; Chu, E. Severe neurotoxicity following 5-fluorouracil-based chemotherapy in a patient with dihydropyrimidine dehydrogenase deficiency. Clin. Cancer Res. 1996, 2, 477-481. 
81. Mattison, L.K.; Fourie, J.; Desmond, R.A.; Modak, A.; Saif, M.W.; Diasio, R.B. Increased prevalence of dihydropyrimidine dehydrogenase deficiency in African-Americans compared with Caucasians. Clin. Cancer Res. 2006, 12, 5491-5495.

82. Van Kuilenburg, A.B.; Haasjes, J.; Richel, D.J.; Zoetekouw, L.; Van Lenthe, H.; De Abreu, R.A.; Maring, J.G.; Vreken, P.; van Gennip, A.H. Clinical implications of dihydropyrimidine dehydrogenase (DPD) deficiency in patients with severe 5-fluorouracil-associated toxicity: Identification of new mutations in the DPD gene. Clin. Cancer Res. 2000, 6, 4705-4712.

83. Van Kuilenburg, A.B.; Vreken, P.; Abeling, N.G.; Bakker, H.D.; Meinsma, R.; van Lenthe, H.; de Abreu, R.A.; Smeitink, J.A.; Kayserili, H.; Apak, M.Y.; et al. Genotype and phenotype in patients with dihydropyrimidine dehydrogenase deficiency. Hum. Genet. 1999, 104, 1-9.

84. Loganayagam, A.; Arenas-Hernandez, M.; Fairbanks, L.; Ross, P.; Sanderson, J.D.; Marinaki, A.M. The contribution of deleterious DPYD gene sequence variants to fluoropyrimidine toxicity in British cancer patients. Cancer Chemother. Pharmacol. 2010, 65, 403-406.

85. Capitain, O.; Boisdron-Celle, M.; Poirier, A.L.; Abadie-Lacourtoisie, S.; Morel, A.; Gamelin, E. The influence of fluorouracil outcome parameters on tolerance and efficacy in patients with advanced colorectal cancer. Pharmacogenomics J. 2008, 8, 256-267.

86. Mauritz, R.; van Groeningen, C.J.; Smid, K.; Jansen, G.; Pinedo, H.M.; Peters, G.J. Thymidylate synthase and dihydropyrimidine dehydrogenase mRNA expression after administration of 5-fluorouracil to patients with colorectal cancer. Int. J. Cancer 2007, 120, 2609-2612.

87. McLeod, H.L.; Sludden, J.; Hardy, S.C.; Lock, R.E.; Hawksworth, G.M.; Cassidy, J. Autoregulation of 5-fluorouracil metabolism. Eur. J. Cancer 1998, 34, 1623-1627.

88. Chu, E.; Koeller, D.M.; Johnston, P.G.; Zinn, S.; Allegra, C.J. Regulation of thymidylate synthase in human colon cancer cells treated with 5-fluorouracil and interferon-gamma. Mol. Pharmacol. 1993, 43, 527-533.

89. Swain, S.M.; Lippman, M.E.; Egan, E.F.; Drake, J.C.; Steinberg, S.M.; Allegra, C.J. Fluorouracil and high-dose leucovorin in previously treated patients with metastatic breast cancer. J. Clin. Oncol. 1989, 7, 890-899.

90. Kornmann, M.; Schwabe, W.; Sander, S.; Kron, M.; Strater, J.; Polat, S.; Kettner, E.; Weiser, H.F.; Baumann, W.; Schramm, H.; et al. Thymidylate synthase and dihydropyrimidine dehydrogenase mRNA expression levels: Predictors for survival in colorectal cancer patients receiving adjuvant 5-fluorouracil. Clin. Cancer Res. 2003, 9, 4116-4124.

91. Takenoue, T.; Nagawa, H.; Matsuda, K.; Fujii, S.; Nita, M.E.; Hatano, K.; Kitayama, J.; Tsuruo, T.; Muto, T. Relation between thymidylate synthase expression and survival in colon carcinoma, and determination of appropriate application of 5-fluorouracil by immunohistochemical method. Ann. Surg. Oncol. 2000, 7, 193-198.

92. Edler, D.; Glimelius, B.; Hallstrom, M.; Jakobsen, A.; Johnston, P.G.; Magnusson, I.; Ragnhammar, P.; Blomgren, H. Thymidylate synthase expression in colorectal cancer: A prognostic and predictive marker of benefit from adjuvant fluorouracil-based chemotherapy. J. Clin. Oncol. 2002, 20, 1721-1728. 
93. Van Kuilenburg, A.B.; Hausler, P.; Schalhorn, A.; Tanck, M.W.; Proost, J.H.; Terborg, C.; Behnke, D.; Schwabe, W.; Jabschinsky, K.; Maring, J.G. Evaluation of 5-fluorouracil pharmacokinetics in cancer patients with a c.1905+1G $>$ A mutation in DPYD by means of a Bayesian limited sampling strategy. Clin. Pharmacokinet. 2012, 51, 163-174.

94. Gamelin, E.; Delva, R.; Jacob, J.; Merrouche, Y.; Raoul, J.L.; Pezet, D.; Dorval, E.; Piot, G.; Morel, A.; Boisdron-Celle, M. Individual fluorouracil dose adjustment based on pharmacokinetic follow-up compared with conventional dosage: Results of a multicenter randomized trial of patients with metastatic colorectal cancer. J. Clin. Oncol. 2008, 26, 2099-2105.

95. Capitain, O.; Asevoaia, A.; Boisdron-Celle, M.; Poirier, A.L.; Morel, A.; Gamelin, E. Individual Fluorouracil Dose Adjustment in FOLFOX Based on Pharmacokinetic Follow-Up Compared With Conventional Body-Area-Surface Dosing: A Phase II, Proof-of-Concept Study. Clin. Colorectal. Cancer 2012, 11, 263-267.

96. Volk, J.; Reinke, F.; van Kuilenburg, A.B.; van Gennip, A.H.; Schlichting, C.; Ganser, A.; Schoffski, P. Safe administration of irinotecan, oxaliplatin and raltitrexed in a DPD-deficient patient with metastatic colon cancer. Ann. Oncol. 2001, 12, 569-571.

97. Kohne, C.H.; Thuss-Patience, P.; Friedrich, M.; Daniel, P.T.; Kretzschmar, A.; Benter, T.; Bauer, B.; Dietz, R.; Dorken, B. Raltitrexed (Tomudex): An alternative drug for patients with colorectal cancer and 5-fluorouracil associated cardiotoxicity. Br. J. Cancer 1998, 77, 973-977.

98. Wilson, K.S.; Fitzgerald, C.A.; Barnett, J.B.; Gill, S.; Khoo, K.E. Adjuvant therapy with raltitrexed in patients with colorectal cancer intolerant of 5-fluorouracil: British Columbia Cancer Agency experience. Cancer Invest. 2007, 25, 711-714.

99. Gravalos, C.; Salut, A.; Garcia-Giron, C.; Garcia-Carbonero, R.; Leon, A.I.; Sevilla, I.; Maurel, J.; Esteban, B.; Garcia-Rico, E.; Murias, A.; et al. A randomized phase II study to compare oxaliplatin plus 5-fluorouracil and leucovorin (FOLFOX4) versus oxaliplatin plus raltitrexed (TOMOX) as first-line chemotherapy for advanced colorectal cancer. Clin. Transl. Oncol. 2012, 14, 606-612.

100. Popov, I.; Carrato, A.; Sobrero, A.; Vincent, M.; Kerr, D.; Labianca, R.; Raffaele Bianco, A.; El-Serafi, M.; Bedenne, L.; Paillot, B.; et al. Raltitrexed (Tomudex) versus standard leucovorinmodulated bolus 5-fluorouracil: Results from the randomised phase III Pan-European Trial in Adjuvant Colon Cancer 01 (PETACC-1). Eur. J. Cancer 2008, 44, 2204-2211.

101. Wenzel, C.; Urbauer, E.; Schwarz, C.; Funk, G.; Oehler, L.; Kornek, G.V.; Scheithauer, W. Severe enteropathy associated with raltitrexed and oxaliplatin chemotherapy: Report of two patients experiencing this rare, potentially lethal gastrointestinal adverse event. Anticancer Drugs 2006, 17, 865-868.

102. Ducreux, M.; Bouche, O.; Pignon, J.P.; Mousseau, M.; Raoul, J.L.; Cassan, P.; Leduc, B.; Berger, C.; Dunant, A.; Fournet, J.; et al. Randomised trial comparing three different schedules of infusional 5FU and raltitrexed alone as first-line therapy in metastatic colorectal cancer. Final results of the Federation Francophone de Cancerologie Digestive (FFCD) 9601 trial. Oncology 2006, 70, 222-230. 
103. Rinaldi, D.A.; Burris, H.A.; Dorr, F.A.; Woodworth, J.R.; Kuhn, J.G.; Eckardt, J.R.; Rodriguez, G.; Corso, S.W.; Fields, S.M.; Langley, C.; et al. Initial phase I evaluation of the novel thymidylate synthase inhibitor, LY231514, using the modified continual reassessment method for dose escalation. J. Clin. Oncol. 1995, 13, 2842-2850.

104. Cripps, C.; Burnell, M.; Jolivet, J.; Batist, G.; Lofters, W.; Dancey, J.; Iglesias, J.; Fisher, B.; Eisenhauer, E.A. Phase II study of first-line LY231514 (multi-targeted antifolate) in patients with locally advanced or metastatic colorectal cancer: An NCIC Clinical Trials Group study. Ann. Oncol. 1999, 10, 1175-1179.

105. John, W.; Picus, J.; Blanke, C.D.; Clark, J.W.; Schulman, L.N.; Rowinsky, E.K.; Thornton, D.E.; Loehrer, P.J. Activity of multitargeted antifolate (pemetrexed disodium, LY231514) in patients with advanced colorectal carcinoma: Results from a phase II study. Cancer 2000, 88, 1807-1813.

106. Hochster, H.; Kettner, E.; Kroning, H.; Becker, K.; Lordick, F.; Ramanathan, R.K.; Macdonald, J.; Hong, S.; John, W.; Schmoll, H.J. Phase I/II dose-escalation study of pemetrexed plus irinotecan in patients with advanced colorectal cancer. Clin. Colorectal. Cancer 2005, 5, 257-262.

107. Louvet, C.; Andre, T.; Gamelin, E.; Hebbar, M.; Mabro, M.; Bennamoun, M.; Rassam, H.; de Gramont, A. Phase II Study of Biweekly Pemetrexed Plus Irinotecan as Second-Line Therapy for Metastatic Colorectal Cancer. J. Oncol. 2010, $2010,785934$.

108. Rosenberg, B.; VanCamp, L.; Trosko, J.E.; Mansour, V.H. Platinum compounds: A new class of potent antitumour agents. Nature 1969, 222, 385-386.

109. Rosenberg, B.; VanCamp, L. The successful regression of large solid sarcoma 180 tumors by platinum compounds. Cancer Res. 1970, 30, 1799-1802.

110. Dentino, M.; Luft, F.C.; Yum, M.N.; Williams, S.D.; Einhorn, L.H. Long term effect of cis-diamminedichloride platinum (CDDP) on renal function and structure in man. Cancer 1978, 41, 1274-1281.

111. Mathe, G.; Kidani, Y.; Noji, M.; Maral, R.; Bourut, C.; Chenu, E. Antitumor activity of 1-OHP in mice. Cancer Lett. 1985, 27, 135-143.

112. Saris, C.P.; van de Vaart, P.J.; Rietbroek, R.C.; Blommaert, F.A. In vitro formation of DNA adducts by cisplatin, lobaplatin and oxaliplatin in calf thymus DNA in solution and in cultured human cells. Carcinogenesis 1996, 17, 2763-2769.

113. Woynarowski, J.M.; Chapman, W.G.; Napier, C.; Herzig, M.C.; Juniewicz, P. Sequence- and region-specificity of oxaliplatin adducts in naked and cellular DNA. Mol. Pharmacol. 1998, 54, 770-777.

114. Yamada, M.; O'Regan, E.; Brown, R.; Karran, P. Selective recognition of a cisplatin-DNA adduct by human mismatch repair proteins. Nucleic Acids Res. 1997, 25, 491-496.

115. Mello, J.A.; Acharya, S.; Fishel, R.; Essigmann, J.M. The mismatch-repair protein hMSH2 binds selectively to DNA adducts of the anticancer drug cisplatin. Chem. Biol. 1996, 3, 579-589.

116. Fink, D.; Nebel, S.; Aebi, S.; Zheng, H.; Cenni, B.; Nehme, A.; Christen, R.D.; Howell, S.B. The role of DNA mismatch repair in platinum drug resistance. Cancer Res. 1996, 56, 4881-4886.

117. Scheeff, E.D.; Briggs, J.M.; Howell, S.B. Molecular modeling of the intrastrand guanine-guanine DNA adducts produced by cisplatin and oxaliplatin. Mol. Pharmacol. 1999, 56, 633-643. 
118. De Gramont, A.; Vignoud, J.; Tournigand, C.; Louvet, C.; Andre, T.; Varette, C.; Raymond, E.; Moreau, S.; Le Bail, N.; Krulik, M. Oxaliplatin with high-dose leucovorin and 5-fluorouracil 48-hour continuous infusion in pretreated metastatic colorectal cancer. Eur. J. Cancer 1997, 33, 214-219.

119. Levi, F.; Misset, J.L.; Brienza, S.; Adam, R.; Metzger, G.; Itzakhi, M.; Caussanel, J.P.; Kunstlinger, F.; Lecouturier, S.; Descorps-Declere, A.; et al. A chronopharmacologic phase II clinical trial with 5-fluorouracil, folinic acid, and oxaliplatin using an ambulatory multichannel programmable pump. High antitumor effectiveness against metastatic colorectal cancer. Cancer 1992, 69, 893-900.

120. de Gramont, A.; Figer, A.; Seymour, M.; Homerin, M.; Hmissi, A.; Cassidy, J.; Boni, C.; Cortes-Funes, H.; Cervantes, A.; Freyer, G.; et al. Leucovorin and fluorouracil with or without oxaliplatin as first-line treatment in advanced colorectal cancer. J. Clin. Oncol. 2000, 18, 2938-2947.

121. Creemers, G.J.; Lund, B.; Verweij, J. Topoisomerase I inhibitors: Topotecan and irenotecan. Cancer Treat. Rev. 1994, 20, 73-96.

122. Kaneda, N.; Nagata, H.; Furuta, T.; Yokokura, T. Metabolism and pharmacokinetics of the camptothecin analogue CPT-11 in the mouse. Cancer Res. 1990, 50, 1715-1720.

123. Kunimoto, T.; Nitta, K.; Tanaka, T.; Uehara, N.; Baba, H.; Takeuchi, M.; Yokokura, T.; Sawada, S.; Miyasaka, T.; Mutai, M. Antitumor activity of 7-ethyl-10-[4-(1-piperidino)-1piperidino]carbonyloxy-camptothec in, a novel water-soluble derivative of camptothecin, against murine tumors. Cancer Res. 1987, 47, 5944-5947.

124. Douillard, J.Y.; Cunningham, D.; Roth, A.D.; Navarro, M.; James, R.D.; Karasek, P.; Jandik, P.; Iveson, T.; Carmichael, J.; Alakl, M.; et al. Irinotecan combined with fluorouracil compared with fluorouracil alone as first-line treatment for metastatic colorectal cancer: A multicentre randomised trial. Lancet 2000, 355, 1041-1047.

125. Dean, F.B.; Bullock, P.; Murakami, Y.; Wobbe, C.R.; Weissbach, L.; Hurwitz, J. Simian virus 40 (SV40) DNA replication: SV40 large T antigen unwinds DNA containing the SV40 origin of replication. Proc. Natl. Acad. Sci. USA 1987, 84, 16-20.

126. Garg, L.C.; DiAngelo, S.; Jacob, S.T. Role of DNA topoisomerase I in the transcription of supercoiled rRNA gene. Proc. Natl. Acad. Sci. USA 1987, 84, 3185-3188.

127. Zhang, H.; Wang, J.C.; Liu, L.F. Involvement of DNA topoisomerase I in transcription of human ribosomal RNA genes. Proc. Natl. Acad. Sci. USA 1988, 85, 1060-1064.

128. Halligan, B.D.; Davis, J.L.; Edwards, K.A.; Liu, L.F. Intra- and intermolecular strand transfer by HeLa DNA topoisomerase I. J. Biol. Chem. 1982, 257, 3995-4000.

129. Stewart, L.; Redinbo, M.R.; Qiu, X.; Hol, W.G.; Champoux, J.J. A model for the mechanism of human topoisomerase I. Science 1998, 279, 1534-1541.

130. Hsiang, Y.H.; Hertzberg, R.; Hecht, S.; Liu, L.F. Camptothecin induces protein-linked DNA breaks via mammalian DNA topoisomerase I. J. Biol. Chem. 1985, 260, 14873-14878.

131. Hsiang, Y.H.; Lihou, M.G.; Liu, L.F. Arrest of replication forks by drug-stabilized topoisomerase I-DNA cleavable complexes as a mechanism of cell killing by camptothecin. Cancer Res. 1989, 49, 5077-5082. 
132. Tsao, Y.P.; Russo, A.; Nyamuswa, G.; Silber, R.; Liu, L.F. Interaction between replication forks and topoisomerase I-DNA cleavable complexes: Studies in a cell-free SV40 DNA replication system. Cancer Res. 1993, 53, 5908-5914.

133. Tournigand, C.; Andre, T.; Achille, E.; Lledo, G.; Flesh, M.; Mery-Mignard, D.; Quinaux, E.; Couteau, C.; Buyse, M.; Ganem, G.; et al. FOLFIRI followed by FOLFOX6 or the reverse sequence in advanced colorectal cancer: A randomized GERCOR study. J. Clin. Oncol. 2004, 22, 229-237.

134. Colucci, G.; Gebbia, V.; Paoletti, G.; Giuliani, F.; Caruso, M.; Gebbia, N.; Carteni, G.; Agostara, B.; Pezzella, G.; Manzione, L.; et al. Phase III randomized trial of FOLFIRI versus FOLFOX4 in the treatment of advanced colorectal cancer: A multicenter study of the Gruppo Oncologico Dell'Italia Meridionale. J. Clin. Oncol. 2005, 23, 4866-4875.

135. Saif, M.W.; Reardon, J. Management of oxaliplatin-induced peripheral neuropathy. Ther. Clin. Risk Manag. 2005, 1, 249-258.

136. Stein, A.; Voigt, W.; Jordan, K. Chemotherapy-induced diarrhea: Pathophysiology, frequency and guideline-based management. Ther Adv. Med. Oncol 2010, 2, 51-63.

137. Kamileri, I.; Karakasilioti, I.; Garinis, G.A. Nucleotide excision repair: New tricks with old bricks. Trends Genet. 2012, 28, 566-573.

138. You, J.S.; Wang, M.; Lee, S.H. Biochemical analysis of the damage recognition process in nucleotide excision repair. J. Biol. Chem. 2003, 278, 7476-7485.

139. Shen, M.R.; Jones, I.M.; Mohrenweiser, H. Nonconservative amino acid substitution variants exist at polymorphic frequency in DNA repair genes in healthy humans. Cancer Res. 1998, 58, 604-608.

140. Shuck, S.C.; Short, E.A.; Turchi, J.J. Eukaryotic nucleotide excision repair: From understanding mechanisms to influencing biology. Cell. Res. 2008, 18, 64-72.

141. Evans, E.; Moggs, J.G.; Hwang, J.R.; Egly, J.M.; Wood, R.D. Mechanism of open complex and dual incision formation by human nucleotide excision repair factors. EMBO J. 1997, 16, 6559-6573.

142. Park, D.J.; Stoehlmacher, J.; Zhang, W.; Tsao-Wei, D.D.; Groshen, S.; Lenz, H.J. A Xeroderma pigmentosum group D gene polymorphism predicts clinical outcome to platinum-based chemotherapy in patients with advanced colorectal cancer. Cancer Res. 2001, 61, 8654-8658.

143. Stoehlmacher, J.; Park, D.J.; Zhang, W.; Yang, D.; Groshen, S.; Zahedy, S.; Lenz, H.J. A multivariate analysis of genomic polymorphisms: Prediction of clinical outcome to 5-FU/oxaliplatin combination chemotherapy in refractory colorectal cancer. Br. J. Cancer 2004, 91, 344-354.

144. Yin, M.; Yan, J.; Martinez-Balibrea, E.; Graziano, F.; Lenz, H.J.; Kim, H.J.; Robert, J.; Im, S.A.; Wang, W.S.; Etienne-Grimaldi, M.C.; et al. ERCC1 and ERCC2 polymorphisms predict clinical outcomes of oxaliplatin-based chemotherapies in gastric and colorectal cancer: A systemic review and meta-analysis. Clin. Cancer Res. 2011, 17, 1632-1640.

145. Lai, J.I.; Tzeng, C.H.; Chen, P.M.; Lin, J.K.; Lin, T.C.; Chen, W.S.; Jiang, J.K.; Wang, H.S.; Wang, W.S. Very low prevalence of XPD K751Q polymorphism and its association with XPD expression and outcomes of FOLFOX-4 treatment in Asian patients with colorectal carcinoma. Cancer Sci. 2009, 100, 1261-1266. 
146. Sijbers, A.M.; de Laat, W.L.; Ariza, R.R.; Biggerstaff, M.; Wei, Y.F.; Moggs, J.G.; Carter, K.C.; Shell, B.K.; Evans, E.; de Jong, M.C.; et al. Xeroderma pigmentosum group F caused by a defect in a structure-specific DNA repair endonuclease. Cell 1996, 86, 811-822.

147. O'Donovan, A.; Davies, A.A.; Moggs, J.G.; West, S.C.; Wood, R.D. XPG endonuclease makes the 3' incision in human DNA nucleotide excision repair. Nature 1994, 371, 432-435.

148. Shirota, Y.; Stoehlmacher, J.; Brabender, J.; Xiong, Y.P.; Uetake, H.; Danenberg, K.D.; Groshen, S.; Tsao-Wei, D.D.; Danenberg, P.V.; Lenz, H.J. ERCC1 and thymidylate synthase mRNA levels predict survival for colorectal cancer patients receiving combination oxaliplatin and fluorouracil chemotherapy. J. Clin. Oncol. 2001, 19, 4298-4304.

149. Yu, J.J.; Mu, C.; Lee, K.B.; Okamoto, A.; Reed, E.L.; Bostick-Bruton, F.; Mitchell, K.C.; Reed, E. A nucleotide polymorphism in ERCC1 in human ovarian cancer cell lines and tumor tissues. Mutat Res. 1997, 382, 13-20.

150. Viguier, J.; Boige, V.; Miquel, C.; Pocard, M.; Giraudeau, B.; Sabourin, J.C.; Ducreux, M.; Sarasin, A.; Praz, F. ERCC1 codon 118 polymorphism is a predictive factor for the tumor response to oxaliplatin/5-fluorouracil combination chemotherapy in patients with advanced colorectal cancer. Clin. Cancer Res. 2005, 11, 6212-6217.

151. Pare, L.; Marcuello, E.; Altes, A.; del Rio, E.; Sedano, L.; Salazar, J.; Cortes, A.; Barnadas, A.; Baiget, M. Pharmacogenetic prediction of clinical outcome in advanced colorectal cancer patients receiving oxaliplatin/5-fluorouracil as first-line chemotherapy. Br. J. Cancer 2008, 99, 1050-1055.

152. Chen, J.; Xie, F.; Chen, K.; Wang, D.; Jiang, H.; Li, J.; Pan, F.; Chen, S.; Zhang, Y.; Ruan, Z.; Huang, H.; Zou, L.; Liang, H. ERCC5 promoter polymorphisms at -763 and +25 predict the response to oxaliplatin-based chemotherapy in patients with advanced colorectal cancer. Cancer Biol. Ther. 2009, 8, 1424-1430.

153. McWhinney, S.R.; Goldberg, R.M.; McLeod, H.L. Platinum neurotoxicity pharmacogenetics. Mol. Cancer Ther. 2009, 8, 10-16.

154. Goto, S.; Iida, T.; Cho, S.; Oka, M.; Kohno, S.; Kondo, T. Overexpression of glutathione S-transferase pi enhances the adduct formation of cisplatin with glutathione in human cancer cells. Free Radic Res. 1999, 31, 549-558.

155. Mannervik, B.; Awasthi, Y.C.; Board, P.G.; Hayes, J.D.; Di Ilio, C.; Ketterer, B.; Listowsky, I.; Morgenstern, R.; Muramatsu, M.; Pearson, W.R.; et al. Nomenclature for human glutathione transferases. Biochem. J. 1992, 282 (Pt. 1), 305-306.

156. Watson, M.A.; Stewart, R.K.; Smith, G.B.; Massey, T.E.; Bell, D.A. Human glutathione Stransferase P1 polymorphisms: Relationship to lung tissue enzyme activity and population frequency distribution. Carcinogenesis 1998, 19, 275-280.

157. Ralat, L.A.; Colman, R.F. Glutathione S-transferase Pi has at least three distinguishable xenobiotic substrate sites close to its glutathione-binding site. J. Biol. Chem. 2004, 279, 50204-50213.

158. Ranganathan, S.; Tew, K.D. Immunohistochemical localization of glutathione S-transferases alpha, mu, and pi in normal tissue and carcinomas from human colon. Carcinogenesis 1991, 12, 2383-2387. 
159. Moorghen, M.; Cairns, J.; Forrester, L.M.; Hayes, J.D.; Hall, A.; Cattan, A.R.; Wolf, C.R.; Harris, A.L. Enhanced expression of glutathione S-transferases in colorectal carcinoma compared to non-neoplastic mucosa. Carcinogenesis 1991, 12, 13-17.

160. Peters, W.H.; Boon, C.E.; Roelofs, H.M.; Wobbes, T.; Nagengast, F.M.; Kremers, P.G. Expression of drug-metabolizing enzymes and P-170 glycoprotein in colorectal carcinoma and normal mucosa. Gastroenterology 1992, 103, 448-455.

161. Miyazaki, M.; Kohno, K.; Saburi, Y.; Matsuo, K.; Ono, M.; Kuwano, M.; Tsuchida, S.; Sato, K.; Sakai, M.; Muramatsu, M. Drug resistance to cis-diamminedichloroplatinum (II) in Chinese hamster ovary cell lines transfected with glutathione S-transferase pi gene. Biochem. Biophys. Res. Commun. 1990, 166, 1358-1364.

162. Ban, N.; Takahashi, Y.; Takayama, T.; Kura, T.; Katahira, T.; Sakamaki, S.; Niitsu, Y. Transfection of glutathione S-transferase (GST)-pi antisense complementary DNA increases the sensitivity of a colon cancer cell line to adriamycin, cisplatin, melphalan, and etoposide. Cancer Res. 1996, 56, 3577-3582.

163. Board, P.G.; Webb, G.C.; Coggan, M. Isolation of a cDNA clone and localization of the human glutathione S-transferase 3 genes to chromosome bands 11q13 and 12q13-14. Ann. Hum. Genet. 1989, 53, 205-213.

164. Inada, M.; Sato, M.; Morita, S.; Kitagawa, K.; Kawada, K.; Mitsuma, A.; Sawaki, M.; Fujita, K.; Ando, Y. Associations between oxaliplatin-induced peripheral neuropathy and polymorphisms of the ERCC1 and GSTP1 genes. Int. J. Clin. Pharmacol. Ther. 2010, 48, 729.

165. Chen, Y.C.; Tzeng, C.H.; Chen, P.M.; Lin, J.K.; Lin, T.C.; Chen, W.S.; Jiang, J.K.; Wang, H.S.; Wang, W.S. Influence of GSTP1 I105V polymorphism on cumulative neuropathy and outcome of FOLFOX-4 treatment in Asian patients with colorectal carcinoma. Cancer Sci. 2010, 101, $530-535$.

166. Lecomte, T.; Landi, B.; Beaune, P.; Laurent-Puig, P.; Loriot, M.A. Glutathione S-transferase P1 polymorphism (Ile105Val) predicts cumulative neuropathy in patients receiving oxaliplatinbased chemotherapy. Clin. Cancer Res. 2006, 12, 3050-3056.

167. Peng, Z.; Wang, Q.; Gao, J.; Ji, Z.; Yuan, J.; Tian, Y.; Shen, L. Association between GSTP1 Ile105Val polymorphism and oxaliplatin-induced neuropathy: A systematic review and meta-analysis. Cancer Chemother. Pharmacol. 2013, 72, 305-314

168. Ruzzo, A.; Graziano, F.; Loupakis, F.; Rulli, E.; Canestrari, E.; Santini, D.; Catalano, V.; Ficarelli, R.; Maltese, P.; Bisonni, R.; et al. Pharmacogenetic profiling in patients with advanced colorectal cancer treated with first-line FOLFOX-4 chemotherapy. J. Clin. Oncol. 2007, 25, $1247-1254$.

169. Iyer, L.; King, C.D.; Whitington, P.F.; Green, M.D.; Roy, S.K.; Tephly, T.R.; Coffman, B.L.; Ratain, M.J. Genetic predisposition to the metabolism of irinotecan (CPT-11). Role of uridine diphosphate glucuronosyltransferase isoform 1A1 in the glucuronidation of its active metabolite (SN-38) in human liver microsomes. J. Clin Invest. 1998, 101, 847-854.

170. Gagne, J.F.; Montminy, V.; Belanger, P.; Journault, K.; Gaucher, G.; Guillemette, C. Common human UGT1A polymorphisms and the altered metabolism of irinotecan active metabolite 7-ethyl-10-hydroxycamptothecin (SN-38). Mol. Pharmacol. 2002, 62, 608-617. 
171. Gupta, E.; Lestingi, T.M.; Mick, R.; Ramirez, J.; Vokes, E.E.; Ratain, M.J. Metabolic fate of irinotecan in humans: Correlation of glucuronidation with diarrhea. Cancer Res. 1994, 54, 3723-3725.

172. Guillemette, C. Pharmacogenomics of human UDP-glucuronosyltransferase enzymes. Pharmacogenomics J. 2003, 3, 136-158.

173. Guillemette, C.; Ritter, J.K.; Auyeung, D.J.; Kessler, F.K.; Housman, D.E. Structural heterogeneity at the UDP-glucuronosyltransferase 1 locus: Functional consequences of three novel missense mutations in the human UGT1A7 gene. Pharmacogenetics 2000, 10, 629-644.

174. Cecchin, E.; Innocenti, F.; D’Andrea, M.; Corona, G.; De Mattia, E.; Biason, P.; Buonadonna, A.; Toffoli, G. Predictive role of the UGT1A1, UGT1A7, and UGT1A9 genetic variants and their haplotypes on the outcome of metastatic colorectal cancer patients treated with fluorouracil, leucovorin, and irinotecan. J. Clin. Oncol. 2009, 27, 2457-2465.

175. Beutler, E.; Gelbart, T.; Demina, A. Racial variability in the UDP-glucuronosyltransferase 1 (UGT1A1) promoter: A balanced polymorphism for regulation of bilirubin metabolism? Proc. Natl. Acad. Sci. USA 1998, 95, 8170-8174.

176. Bosma, P.J.; Chowdhury, J.R.; Bakker, C.; Gantla, S.; de Boer, A.; Oostra, B.A.; Lindhout, D.; Tytgat, G.N.; Jansen, P.L.; Oude Elferink, R.P.; et al. The genetic basis of the reduced expression of bilirubin UDP-glucuronosyltransferase 1 in Gilbert's syndrome. N. Engl. J. Med. 1995, 333, 1171-1175.

177. Monaghan, G.; Ryan, M.; Seddon, R.; Hume, R.; Burchell, B. Genetic variation in bilirubin UPD-glucuronosyltransferase gene promoter and Gilbert's syndrome. Lancet 1996, 347, 578-581.

178. Iyer, L.; Das, S.; Janisch, L.; Wen, M.; Ramirez, J.; Karrison, T.; Fleming, G.F.; Vokes, E.E.; Schilsky, R.L.; Ratain, M.J. UGT1A1*28 polymorphism as a determinant of irinotecan disposition and toxicity. Pharmacogenomics J. 2002, 2, $43-47$.

179. Innocenti, F.; Undevia, S.D.; Iyer, L.; Chen, P.X.; Das, S.; Kocherginsky, M.; Karrison, T.; Janisch, L.; Ramirez, J.; Rudin, C.M.; et al. Genetic variants in the UDP-glucuronosyltransferase 1A1 gene predict the risk of severe neutropenia of irinotecan. J. Clin. Oncol. 2004, 22, 1382-1388.

180. Shulman, K.; Cohen, I.; Barnett-Griness, O.; Kuten, A.; Gruber, S.B.; Lejbkowicz, F.; Rennert, G. Clinical implications of UGT1A1*28 genotype testing in colorectal cancer patients. Cancer 2011, 117, 3156-3162.

181. Marcuello, E.; Paez, D.; Pare, L.; Salazar, J.; Sebio, A.; del Rio, E.; Baiget, M. A genotype-directed phase I-IV dose-finding study of irinotecan in combination with fluorouracil/leucovorin as first-line treatment in advanced colorectal cancer. Br. J. Cancer 2011, 105, 53-57.

182. Ychou, M.; Raoul, J.L.; Desseigne, F.; Borel, C.; Caroli-Bosc, F.X.; Jacob, J.H.; Seitz, J.F.; Kramar, A.; Hua, A.; Lefebvre, P.; et al. High-dose, single-agent irinotecan as first-line therapy in the treatment of metastatic colorectal cancer. Cancer Chemother. Pharmacol. 2002, 50, 383-391.

183. Toffoli, G.; Cecchin, E.; Gasparini, G.; D’Andrea, M.; Azzarello, G.; Basso, U.; Mini, E.; Pessa, S.; de Mattia, E.; Lo Re, G.; et al. Genotype-driven phase I study of irinotecan administered in combination with fluorouracil/leucovorin in patients with metastatic colorectal cancer. J. Clin. Oncol. 2010, 28, 866-871.

184. Sawyers, C. Targeted cancer therapy. Nature 2004, 432, 294-297. 
185. Kluftinger, A.M.; Robinson, B.W.; Quenville, N.F.; Finley, R.J.; Davis, N.L. Correlation of epidermal growth factor receptor and c-erbB2 oncogene product to known prognostic indicators of colorectal cancer. Surg. Oncol. 1992, 1, 97-105.

186. Radinsky, R.; Risin, S.; Fan, D.; Dong, Z.; Bielenberg, D.; Bucana, C.D.; Fidler, I.J. Level and function of epidermal growth factor receptor predict the metastatic potential of human colon carcinoma cells. Clin. Cancer Res. 1995, 1, 19-31.

187. Lemmon, M.A.; Schlessinger, J. Cell signaling by receptor tyrosine kinases. Cell. 2010, 141, 1117-1134.

188. Marmor, M.D.; Skaria, K.B.; Yarden, Y. Signal transduction and oncogenesis by ErbB/HER receptors. Int. J. Radiat. Oncol. Biol. Phys. 2004, 58, 903-913.

189. Sato, J.D.; Kawamoto, T.; Le, A.D.; Mendelsohn, J.; Polikoff, J.; Sato, G.H. Biological effects in vitro of monoclonal antibodies to human epidermal growth factor receptors. Mol. Biol. Med. 1983, 1, 511-529.

190. Kawamoto, T.; Sato, J.D.; Le, A.; Polikoff, J.; Sato, G.H.; Mendelsohn, J. Growth stimulation of A431 cells by epidermal growth factor: Identification of high-affinity receptors for epidermal growth factor by an anti-receptor monoclonal antibody. Proc. Natl. Acad. Sci. USA 1983, 80, 1337-1341.

191. Masui, H.; Kawamoto, T.; Sato, J.D.; Wolf, B.; Sato, G.; Mendelsohn, J. Growth inhibition of human tumor cells in athymic mice by anti-epidermal growth factor receptor monoclonal antibodies. Cancer Res. 1984, 44, 1002-1007.

192. Fan, Z.; Masui, H.; Altas, I.; Mendelsohn, J. Blockade of epidermal growth factor receptor function by bivalent and monovalent fragments of 225 anti-epidermal growth factor receptor monoclonal antibodies. Cancer Res. 1993, 53, 4322-4328.

193. Masui, H.; Moroyama, T.; Mendelsohn, J. Mechanism of antitumor activity in mice for anti-epidermal growth factor receptor monoclonal antibodies with different isotypes. Cancer Res. 1986, 46, 5592-5598.

194. Gill, G.N.; Kawamoto, T.; Cochet, C.; Le, A.; Sato, J.D.; Masui, H.; McLeod, C.; Mendelsohn, J. Monoclonal anti-epidermal growth factor receptor antibodies which are inhibitors of epidermal growth factor binding and antagonists of epidermal growth factor binding and antagonists of epidermal growth factor-stimulated tyrosine protein kinase activity. J. Biol. Chem. 1984, 259, 7755-7760.

195. Fan, Z.; Lu, Y.; Wu, X.; Mendelsohn, J. Antibody-induced epidermal growth factor receptor dimerization mediates inhibition of autocrine proliferation of A431 squamous carcinoma cells. J. Biol. Chem. 1994, 269, 27595-27602.

196. Naramura, M.; Gillies, S.D.; Mendelsohn, J.; Reisfeld, R.A.; Mueller, B.M. Therapeutic potential of chimeric and murine anti-(epidermal growth factor receptor) antibodies in a metastasis model for human melanoma. Cancer Immunol. Immunother. 1993, 37, 343-349.

197. Goldstein, N.I.; Prewett, M.; Zuklys, K.; Rockwell, P.; Mendelsohn, J. Biological efficacy of a chimeric antibody to the epidermal growth factor receptor in a human tumor xenograft model. Clin. Cancer Res. 1995, 1, 1311-1318. 
198. Baselga, J.; Pfister, D.; Cooper, M.R.; Cohen, R.; Burtness, B.; Bos, M.; D’Andrea, G.; Seidman, A.; Norton, L.; Gunnett, K.; et al. Phase I studies of anti-epidermal growth factor receptor chimeric antibody $\mathrm{C} 225$ alone and in combination with cisplatin. J. Clin. Oncol. 2000, 18, 904-914.

199. Robert, F.; Ezekiel, M.P.; Spencer, S.A.; Meredith, R.F.; Bonner, J.A.; Khazaeli, M.B.; Saleh, M.N.; Carey, D.; LoBuglio, A.F.; Wheeler, R.H.; et al. Phase I study of anti-epidermal growth factor receptor antibody cetuximab in combination with radiation therapy in patients with advanced head and neck cancer. J. Clin. Oncol. 2001, 19, 3234-3243.

200. Foon, K.A.; Yang, X.D.; Weiner, L.M.; Belldegrun, A.S.; Figlin, R.A.; Crawford, J.; Rowinsky, E.K.; Dutcher, J.P.; Vogelzang, N.J.; Gollub, J.; et al. Preclinical and clinical evaluations of ABX-EGF, a fully human anti-epidermal growth factor receptor antibody. Int. J. Radiat. Oncol. Biol. Phys. 2004, 58, 984-990.

201. Baselga, J.; Rischin, D.; Ranson, M.; Calvert, H.; Raymond, E.; Kieback, D.G.; Kaye, S.B.; Gianni, L.; Harris, A.; Bjork, T.; et al. Phase I safety, pharmacokinetic, and pharmacodynamic trial of ZD1839, a selective oral epidermal growth factor receptor tyrosine kinase inhibitor, in patients with five selected solid tumor types. J. Clin. Oncol. 2002, 20, 4292-4302.

202. Rothenberg, M.L.; LaFleur, B.; Levy, D.E.; Washington, M.K.; Morgan-Meadows, S.L.; Ramanathan, R.K.; Berlin, J.D.; Benson, A.B., 3rd; Coffey, R.J. Randomized phase II trial of the clinical and biological effects of two dose levels of gefitinib in patients with recurrent colorectal adenocarcinoma. J. Clin. Oncol. 2005, 23, 9265-9274.

203. Jimeno, A.; Gravalos, C.; Escudero, P.; Sevilla, I.; Vega-Villegas, M.E.; Alonso, V.; Juez, I.; Garcia-Carbonero, R.; Bovio, H.; Colomer, R.; et al. Phase I/II study of gefitinib and capecitabine in patients with colorectal cancer. Clin .Transl. Oncol. 2008, 10, 52-57.

204. Trarbach, T.; Reinacher-Schick, A.; Hegewisch-Becker, S.; Vanhoefer, U.; Frieling, T.; Lehnert, L.; Schmiegel, W.; Graeven, U. Gefitinib in combination with capecitabine as second-line therapy in patients with advanced colorectal cancer (aCRC): A phase I/II study of the Arbeitsgemeinschaft Internistische Onkologie (AIO). Onkologie 2010, 33, 89-93.

205. Chau, I.; Cunningham, D.; Hickish, T.; Massey, A.; Higgins, L.; Osborne, R.; Botwood, N.; Swaisland, A. Gefitinib and irinotecan in patients with fluoropyrimidine-refractory, irinotecan-naive advanced colorectal cancer: A phase I-II study. Ann. Oncol. 2007, 18, 730-737.

206. Weickhardt, A.J.; Price, T.J.; Chong, G.; Gebski, V.; Pavlakis, N.; Johns, T.G.; Azad, A.; Skrinos, E.; Fluck, K.; Dobrovic, A.; et al. Dual targeting of the epidermal growth factor receptor using the combination of cetuximab and erlotinib: Preclinical evaluation and results of the phase II DUX study in chemotherapy-refractory, advanced colorectal cancer. J. Clin. Oncol. 2012, 30, $1505-1512$.

207. Sweet, R.W.; Yokoyama, S.; Kamata, T.; Feramisco, J.R.; Rosenberg, M.; Gross, M. The product of ras is a GTPase and the T24 oncogenic mutant is deficient in this activity. Nature 1984, 311, 273-275.

208. Bourne, H.R.; Sanders, D.A.; McCormick, F. The GTPase superfamily: A conserved switch for diverse cell functions. Nature 1990, 348, 125-132.

209. Schubbert, S.; Shannon, K.; Bollag, G. Hyperactive Ras in developmental disorders and cancer. Nat. Rev. Cancer 2007, 7, 295-308. 
210. Buday, L.; Downward, J. Many faces of Ras activation. Biochim. Biophys. Acta 2008, 1786, 178-187.

211. Krasinskas, A.M. EGFR Signaling in Colorectal Carcinoma. Patholog. Res. Int. 2011, 2011, 932932.

212. Bos, J.L.; Fearon, E.R.; Hamilton, S.R.; Verlaan-de Vries, M.; van Boom, J.H.; van der Eb, A.J.; Vogelstein, B. Prevalence of ras gene mutations in human colorectal cancers. Nature 1987, 327, 293-297.

213. Normanno, N.; Tejpar, S.; Morgillo, F.; de Luca, A.; Van Cutsem, E.; Ciardiello, F. Implications for KRAS status and EGFR-targeted therapies in metastatic CRC. Nat. Rev. Clin. Oncol. 2009, 6, 519-527.

214. Forbes, S.; Clements, J.; Dawson, E.; Bamford, S.; Webb, T.; Dogan, A.; Flanagan, A.; Teague, J.; Wooster, R.; Futreal, P.A.; Stratton, M.R. Cosmic 2005. Br. J. Cancer 2006, 94, 318-322.

215. Kimura, T.; Okamoto, K.; Miyamoto, H.; Kimura, M.; Kitamura, S.; Takenaka, H.; Muguruma, N.; Okahisa, T.; Aoyagi, E.; Kajimoto, M.; et al. Clinical benefit of high-sensitivity KRAS mutation testing in metastatic colorectal cancer treated with anti-EGFR antibody therapy. Oncology 2012, 82, 298-304.

216. Allegra, C.J.; Jessup, J.M.; Somerfield, M.R.; Hamilton, S.R.; Hammond, E.H.; Hayes, D.F.; McAllister, P.K.; Morton, R.F.; Schilsky, R.L. American Society of Clinical Oncology provisional clinical opinion: Testing for KRAS gene mutations in patients with metastatic colorectal carcinoma to predict response to anti-epidermal growth factor receptor monoclonal antibody therapy. J. Clin. Oncol. 2009, 27, 2091-2096.

217. Lievre, A.; Bachet, J.B.; le Corre, D.; Boige, V.; Landi, B.; Emile, J.F.; Cote, J.F.; Tomasic, G.; Penna, C.; Ducreux, M.; et al. KRAS mutation status is predictive of response to cetuximab therapy in colorectal cancer. Cancer Res. 2006, 66, 3992-3995.

218. Laurent-Puig, P.; Cayre, A.; Manceau, G.; Buc, E.; Bachet, J.B.; Lecomte, T.; Rougier, P.; Lievre, A.; Landi, B.; Boige, V.; et al. Analysis of PTEN, BRAF, and EGFR status in determining benefit from cetuximab therapy in wild-type KRAS metastatic colon cancer. J. Clin. Oncol. 2009, 27, 5924-5930.

219. Khambata-Ford, S.; Garrett, C.R.; Meropol, N.J.; Basik, M.; Harbison, C.T.; Wu, S.; Wong, T.W.; Huang, X.; Takimoto, C.H.; Godwin, A.K.; et al. Expression of epiregulin and amphiregulin and K-ras mutation status predict disease control in metastatic colorectal cancer patients treated with cetuximab. J. Clin. Oncol. 2007, 25, 3230-3237.

220. Bollag, G.; McCormick, F. Regulators and effectors of ras proteins. Annu. Rev. Cell. Biol. 1991, 7, 601-632.

221. De Roock, W.; Jonker, D.J.; di Nicolantonio, F.; Sartore-Bianchi, A.; Tu, D.; Siena, S.; Lamba, S.; Arena, S.; Frattini, M.; Piessevaux, H.; et al. Association of KRAS p.G13D mutation with outcome in patients with chemotherapy-refractory metastatic colorectal cancer treated with cetuximab. JAMA 2010, 304, 1812-1820.

222. Tejpar, S.; Celik, I.; Schlichting, M.; Sartorius, U.; Bokemeyer, C.; Van Cutsem, E. Association of KRAS G13D tumor mutations with outcome in patients with metastatic colorectal cancer treated with first-line chemotherapy with or without cetuximab. J. Clin. Oncol. 2012, 30, 3570-3577. 
223. Horsch, M.; Recktenwald, C.V.; Schadler, S.; Hrabe de Angelis, M.; Seliger, B.; Beckers, J. Overexpressed vs mutated Kras in murine fibroblasts: A molecular phenotyping study. $\mathrm{Br}$. $J$. Cancer 2009, 100, 656-662.

224. Recktenwald, C.V.; Mendler, S.; Lichtenfels, R.; Kellner, R.; Seliger, B. Influence of Ki-ras-driven oncogenic transformation on the protein network of murine fibroblasts. Proteomics 2007, 7, 385-398.

225. Van Houdt, W.J.; Hoogwater, F.J.; de Bruijn, M.T.; Emmink, B.L.; Nijkamp, M.W.; Raats, D.A.; van der Groep, P.; van Diest, P.; Borel Rinkes, I.H.; Kranenburg, O. Oncogenic KRAS desensitizes colorectal tumor cells to epidermal growth factor receptor inhibition and activation. Neoplasia 2010, 12, 443-452.

226. Dunn, E.F.; Iida, M.; Myers, R.A.; Campbell, D.A.; Hintz, K.A.; Armstrong, E.A.; Li, C.; Wheeler, D.L. Dasatinib sensitizes KRAS mutant colorectal tumors to cetuximab. Oncogene 2011, 30, 561-574.

227. Misale, S.; Yaeger, R.; Hobor, S.; Scala, E.; Janakiraman, M.; Liska, D.; Valtorta, E.; Schiavo, R.; Buscarino, M.; Siravegna, G.; et al. Emergence of KRAS mutations and acquired resistance to anti-EGFR therapy in colorectal cancer. Nature 2012, 486, 532-536.

228. Peeters, M.; Douillard, J.Y.; Van Cutsem, E.; Siena, S.; Zhang, K.; Williams, R.; Wiezorek, J. Mutant KRAS codon 12 and 13 alleles in patients with metastatic colorectal cancer: Assessment as prognostic and predictive biomarkers of response to panitumumab. J. Clin Oncol 2013, 31, 759-765.

229. Patel, D.; Guo, X.; Ng, S.; Melchior, M.; Balderes, P.; Burtrum, D.; Persaud, K.; Luna, X.; Ludwig, D.L.; Kang, X. IgG isotype, glycosylation, and EGFR expression determine the induction of antibody-dependent cellular cytotoxicity in vitro by cetuximab. Hum. Antibodies 2010, 19, 89-99.

230. Desjarlais, J.R.; Lazar, G.A.; Zhukovsky, E.A.; Chu, S.Y. Optimizing engagement of the immune system by anti-tumor antibodies: An engineer's perspective. Drug Discov. Today 2007, 12, 898-910.

231. Modest, D.P.; Reinacher-Schick, A.; Stintzing, S.; Giessen, C.; Tannapfel, A.; Laubender, R.P.; Brodowicz, T.; Knittelfelder, R.; Vrbanec, D.; Schmiegel, W.; et al. Cetuximab-based or bevacizumab-based first-line treatment in patients with KRAS p.G13D-mutated metastatic colorectal cancer: A pooled analysis. Anticancer Drugs 2012, 23, 666-673.

232. De Roock, W.; Claes, B.; Bernasconi, D.; De Schutter, J.; Biesmans, B.; Fountzilas, G.; Kalogeras, K.T.; Kotoula, V.; Papamichael, D.; Laurent-Puig, P.; et al. Effects of KRAS, BRAF, NRAS, and PIK3CA mutations on the efficacy of cetuximab plus chemotherapy in chemotherapy-refractory metastatic colorectal cancer: A retrospective consortium analysis. Lancet Oncol. 2010, 11, 753-762.

233. Pratilas, C.A.; Xing, F.; Solit, D.B. Targeting oncogenic BRAF in human cancer. Curr. Top. Microbiol. Immunol. 2012, 355, 83-98.

234. Di Nicolantonio, F.; Martini, M.; Molinari, F.; Sartore-Bianchi, A.; Arena, S.; Saletti, P.; de Dosso, S.; Mazzucchelli, L.; Frattini, M.; Siena, S.; et al. Wild-type BRAF is required for response to panitumumab or cetuximab in metastatic colorectal cancer. J. Clin. Oncol. 2008, 26, 5705-5712. 
235. Al-Marrawi, M.; Saroya, B.; Brennan, M.; Yang, Z.; Dykes, T.; El-Deiry, W. Off-label use of cetuximab plus sorafenib and panitumumab plus regorafenib to personalize therapy for a patient with V600E BRAF-mutant metastatic colon cancer. Cancer Biol. Ther. 2013, in press.

236. Galal, K.M.; Khaled, Z.; Mourad, A.M. Role of cetuximab and sorafenib in treatment of metastatic colorectal cancer. Indian J. Cancer 2011, 48, 47-54.

237. W.T.S Institute. Catalogue of Somatic Mutations in Cancer. Available online: http://www.sanger.ac.uk/genetics/CGP/cosmic/ (accessed on 14 August 2013).

238. Yu, J.; Zhang, Y.; McIlroy, J.; Rordorf-Nikolic, T.; Orr, G.A.; Backer, J.M. Regulation of the p85/p110 phosphatidylinositol 3'-kinase: Stabilization and inhibition of the p110alpha catalytic subunit by the p85 regulatory subunit. Mol. Cell. Biol. 1998, 18, 1379-1387.

239. Miyaki, M.; Iijima, T.; Yamaguchi, T.; Takahashi, K.; Matsumoto, H.; Yasutome, M.; Funata, N.; Mori, T. Mutations of the PIK3CA gene in hereditary colorectal cancers. Int. J. Cancer 2007, 121, 1627-1630.

240. Velho, S.; Oliveira, C.; Ferreira, A.; Ferreira, A.C.; Suriano, G.; Schwartz, S., Jr.; Duval, A.; Carneiro, F.; Machado, J.C.; Hamelin, R.; et al. The prevalence of PIK3CA mutations in gastric and colon cancer. Eur. J. Cancer 2005, 41, 1649-1654.

241. Samuels, Y.; Wang, Z.; Bardelli, A.; Silliman, N.; Ptak, J.; Szabo, S.; Yan, H.; Gazdar, A.; Powell, S.M.; Riggins, G.J.; et al. High frequency of mutations of the PIK3CA gene in human cancers. Science 2004, 304, 554.

242. Kang, S.; Bader, A.G.; Vogt, P.K. Phosphatidylinositol 3-kinase mutations identified in human cancer are oncogenic. Proc. Natl .Acad. Sci.USA 2005, 102, 802-807.

243. Ikenoue, T.; Kanai, F.; Hikiba, Y.; Obata, T.; Tanaka, Y.; Imamura, J.; Ohta, M.; Jazag, A.; Guleng, B.; Tateishi, K.; et al. Functional analysis of PIK3CA gene mutations in human colorectal cancer. Cancer Res. 2005, 65, 4562-4567.

244. Sartore-Bianchi, A.; Martini, M.; Molinari, F.; Veronese, S.; Nichelatti, M.; Artale, S.; di Nicolantonio, F.; Saletti, P.; de Dosso, S.; Mazzucchelli, L.; et al. PIK3CA mutations in colorectal cancer are associated with clinical resistance to EGFR-targeted monoclonal antibodies. Cancer Res. 2009, 69, 1851-1857.

245. Frattini, M.; Saletti, P.; Romagnani, E.; Martin, V.; Molinari, F.; Ghisletta, M.; Camponovo, A.; Etienne, L.L.; Cavalli, F.; Mazzucchelli, L. PTEN loss of expression predicts cetuximab efficacy in metastatic colorectal cancer patients. Br. J. Cancer 2007, 97, 1139-1145.

246. Sartore-Bianchi, A.; Moroni, M.; Veronese, S.; Carnaghi, C.; Bajetta, E.; Luppi, G.; Sobrero, A.; Barone, C.; Cascinu, S.; Colucci, G.; et al. Epidermal growth factor receptor gene copy number and clinical outcome of metastatic colorectal cancer treated with panitumumab. J. Clin. Oncol. 2007, 25, 3238-3245.

247. Cappuzzo, F.; Finocchiaro, G.; Rossi, E.; Janne, P.A.; Carnaghi, C.; Calandri, C.; Bencardino, K.; Ligorio, C.; Ciardiello, F.; Pressiani, T.; et al. EGFR FISH assay predicts for response to cetuximab in chemotherapy refractory colorectal cancer patients. Ann. Oncol. 2008, 19, 717-723.

248. Li, Y.H.; Wang, F.; Shen, L.; Deng, Y.M.; Shao, Q.; Feng, F.; An, X.; Wang, F.H.; Wang, Z.Q.; $\mathrm{Xu}$, R.H.; Shao, J.Y. EGFR fluorescence in situ hybridization pattern of chromosome 7 disomy predicts resistance to cetuximab in KRAS wild-type metastatic colorectal cancer patients. Clin. Cancer Res. 2011, 17, 382-390. 
249. Scartozzi, M.; Bearzi, I.; Mandolesi, A.; Pierantoni, C.; Loupakis, F.; Zaniboni, A.; Negri, F.; Quadri, A.; Zorzi, F.; Galizia, E.; Berardi, R.; et al. Epidermal Growth Factor Receptor (EGFR) gene copy number $(\mathrm{GCN})$ correlates with clinical activity of irinotecan-cetuximab in K-RAS wild-type colorectal cancer: A fluorescence in situ (FISH) and chromogenic in situ hybridization (CISH) analysis. BMC Cancer 2009, 9, 303.

250. Lenz, H.J.; van Cutsem, E.; Khambata-Ford, S.; Mayer, R.J.; Gold, P.; Stella, P.; Mirtsching, B.; Cohn, A.L.; Pippas, A.W.; Azarnia, N.; et al. Multicenter phase II and translational study of cetuximab in metastatic colorectal carcinoma refractory to irinotecan, oxaliplatin, and fluoropyrimidines. J. Clin. Oncol. 2006, 24, 4914-4921.

251. Sartore-Bianchi, A.; Fieuws, S.; Veronese, S.; Moroni, M.; Personeni, N.; Frattini, M.; Torri, V.; Cappuzzo, F.; Vander Borght, S.; Martin, V.; et al. Standardisation of EGFR FISH in colorectal cancer: Results of an international interlaboratory reproducibility ring study. J. Clin. Pathol. 2012, 65, 218-223.

252. Jacobs, B.; de Roock, W.; Piessevaux, H.; van Oirbeek, R.; Biesmans, B.; de Schutter, J.; Fieuws, S.; Vandesompele, J.; Peeters, M.; van Laethem, J.L.; et al. Amphiregulin and epiregulin mRNA expression in primary tumors predicts outcome in metastatic colorectal cancer treated with cetuximab. J. Clin. Oncol. 2009, 27, 5068-5074.

253. Oliveras-Ferraros, C.; Cufi, S.; Queralt, B.; Vazquez-Martin, A.; Martin-Castillo, B.; de Llorens, R.; Bosch-Barrera, J.; Brunet, J.; Menendez, J.A. Cross-suppression of EGFR ligands amphiregulin and epiregulin and de-repression of FGFR3 signalling contribute to cetuximab resistance in wildtype KRAS tumour cells. Br. J. Cancer 2012, 106, 1406-1414.

254. Sonoda, H.; Mekata, E.; Shimizu, T.; Endo, Y.; Tani, T. Safety and efficacy of panitumumab therapy after metastatic colorectal cancer progression with cetuximab: Experience at a single Japanese institution. Oncol. Lett. 2013, 5, 1331-1334.

255. Montagut, C.; Dalmases, A.; Bellosillo, B.; Crespo, M.; Pairet, S.; Iglesias, M.; Salido, M.; Gallen, M.; Marsters, S.; Tsai, S.P.; et al. Identification of a mutation in the extracellular domain of the Epidermal Growth Factor Receptor conferring cetuximab resistance in colorectal cancer. Nat. Med. 2012, 18, 221-223.

256. Voigt, M.; Braig, F.; Gothel, M.; Schulte, A.; Lamszus, K.; Bokemeyer, C.; Binder, M. Functional dissection of the epidermal growth factor receptor epitopes targeted by panitumumab and cetuximab. Neoplasia 2012, 14, 1023-1031.

257. Folkman, J. Tumor angiogenesis: Therapeutic implications. N. Engl. J. Med. 1971, 285, 1182-1186.

258. Folkman, J. What is the evidence that tumors are angiogenesis dependent? J. Natl. Cancer Inst. 1990, 82, 4-6.

259. Takahashi, Y.; Kitadai, Y.; Bucana, C.D.; Cleary, K.R.; Ellis, L.M. Expression of vascular endothelial growth factor and its receptor, KDR, correlates with vascularity, metastasis, and proliferation of human colon cancer. Cancer Res. 1995, 55, 3964-3968.

260. Takebayashi, Y.; Aklyama, S.; Yamada, K.; Akiba, S.; Aikou, T. Angiogenesis as an unfavorable prognostic factor in human colorectal carcinoma. Cancer 1996, 78, 226-231.

261. Takahashi, Y.; Tucker, S.L.; Kitadai, Y.; Koura, A.N.; Bucana, C.D.; Cleary, K.R.; Ellis, L.M. Vessel counts and expression of vascular endothelial growth factor as prognostic factors in node-negative colon cancer. Arch. Surg. 1997, 132, 541-546. 
262. Ishigami, S.I.; Arii, S.; Furutani, M.; Niwano, M.; Harada, T.; Mizumoto, M.; Mori, A.; Onodera, H.; Imamura, M. Predictive value of vascular endothelial growth factor (VEGF) in metastasis and prognosis of human colorectal cancer. Br. J. Cancer 1998, 78, 1379-1384.

263. Li, X.; Eriksson, U. Novel VEGF family members: VEGF-B, VEGF-C and VEGF-D. Int $J$. Biochem. Cell. Biol. 2001, 33, 421-426.

264. Maglione, D.; Guerriero, V.; Viglietto, G.; Delli-Bovi, P.; Persico, M.G. Isolation of a human placenta cDNA coding for a protein related to the vascular permeability factor. Proc. Natl. Acad. Sci. USA 1991, 88, 9267-9271.

265. Escudero-Esparza, A.; Martin, T.A.; Davies, M.L.; Jiang, W.G. PGF isoforms, PLGF-1 and PGF-2, in colorectal cancer and the prognostic significance. Cancer Genomics Proteomics 2009, 6, 239-246.

266. Wei, S.C.; Tsao, P.N.; Yu, S.C.; Shun, C.T.; Tsai-Wu, J.J.; Wu, C.H.; Su, Y.N.; Hsieh, F.J.; Wong, J.M. Placenta growth factor expression is correlated with survival of patients with colorectal cancer. Gut 2005, 54, 666-672.

267. Ferrara, N.; Hillan, K.J.; Novotny, W. Bevacizumab (Avastin), a humanized anti-VEGF monoclonal antibody for cancer therapy. Biochem. Biophys. Res. Commun. 2005, 333, 328-335.

268. Cao, Y.; Chen, H.; Zhou, L.; Chiang, M.K.; Anand-Apte, B.; Weatherbee, J.A.; Wang, Y.; Fang, F.; Flanagan, J.G.; Tsang, M.L. Heterodimers of placenta growth factor/vascular endothelial growth factor. Endothelial activity, tumor cell expression, and high affinity binding to Flk-1/KDR. J. Biol. Chem. 1996, 271, 3154-3162.

269. Presta, L.G.; Chen, H.; O’Connor, S.J.; Chisholm, V.; Meng, Y.G.; Krummen, L.; Winkler, M.; Ferrara, N. Humanization of an anti-vascular endothelial growth factor monoclonal antibody for the therapy of solid tumors and other disorders. Cancer Res. 1997, 57, 4593-4599.

270. Kim, K.J.; Li, B.; Winer, J.; Armanini, M.; Gillett, N.; Phillips, H.S.; Ferrara, N. Inhibition of vascular endothelial growth factor-induced angiogenesis suppresses tumour growth in vivo. Nature 1993, 362, 841-844.

271. O'Connor, J.P.; Carano, R.A.; Clamp, A.R.; Ross, J.; Ho, C.C.; Jackson, A.; Parker, G.J.; Rose, C.J.; Peale, F.V.; Friesenhahn, M.; et al. Quantifying antivascular effects of monoclonal antibodies to vascular endothelial growth factor: Insights from imaging. Clin. Cancer Res. 2009, $15,6674-6682$.

272. Koukourakis, M.I.; Mavanis, I.; Kouklakis, G.; Pitiakoudis, M.; Minopoulos, G.; Manolas, C.; Simopoulos, C. Early antivascular effects of bevacizumab anti-VEGF monoclonal antibody on colorectal carcinomas assessed with functional CT imaging. Am. J. Clin. Oncol. 2007, 30, 315-318.

273. Saltz, L.B.; Clarke, S.; Diaz-Rubio, E.; Scheithauer, W.; Figer, A.; Wong, R.; Koski, S.; Lichinitser, M.; Yang, T.S.; Rivera, F.; et al. Bevacizumab in combination with oxaliplatin-based chemotherapy as first-line therapy in metastatic colorectal cancer: A randomized phase III study. J. Clin. Oncol. 2008, 26, 2013-2019.

274. Hurwitz, H.; Fehrenbacher, L.; Novotny, W.; Cartwright, T.; Hainsworth, J.; Heim, W.; Berlin, J.; Baron, A.; Griffing, S.; Holmgren, E.; Ferrara, N.; Fyfe, G.; Rogers, B.; Ross, R.; Kabbinavar, F. Bevacizumab plus irinotecan, fluorouracil, and leucovorin for metastatic colorectal cancer. N. Engl. J. Med. 2004, 350, 2335-2342. 
275. Fuchs, C.S.; Marshall, J.; Barrueco, J. Randomized, controlled trial of irinotecan plus infusional, bolus, or oral fluoropyrimidines in first-line treatment of metastatic colorectal cancer: Updated results from the BICC-C study. J. Clin. Oncol. 2008, 26, 689-690.

276. Giantonio, B.J.; Catalano, P.J.; Meropol, N.J.; O’Dwyer, P.J.; Mitchell, E.P.; Alberts, S.R.; Schwartz, M.A.; Benson, A.B., 3rd Bevacizumab in combination with oxaliplatin, fluorouracil, and leucovorin (FOLFOX4) for previously treated metastatic colorectal cancer: Results from the Eastern Cooperative Oncology Group Study E3200. J. Clin. Oncol. 2007, 25, 1539-1544.

277. Grothey, A.; Sugrue, M.M.; Purdie, D.M.; Dong, W.; Sargent, D.; Hedrick, E.; Kozloff, M. Bevacizumab beyond first progression is associated with prolonged overall survival in metastatic colorectal cancer: Results from a large observational cohort study (BRiTE). J. Clin. Oncol. 2008, $26,5326-5334$.

278. Grothey, A.; Allegra, C. Antiangiogenesis therapy in the treatment of metastatic colorectal cancer. Ther. Adv. Med. Oncol. 2012, 4, 301-319.

279. Van Cutsem, E.; Tabernero, J.; Lakomy, R.; Prenen, H.; Prausova, J.; Macarulla, T.; Ruff, P.; van Hazel, G.A.; Moiseyenko, V.; Ferry, D.; et al. Addition of aflibercept to fluorouracil, leucovorin, and irinotecan improves survival in a phase III randomized trial in patients with metastatic colorectal cancer previously treated with an oxaliplatin-based regimen. J. Clin. Oncol. 2012, 30, 3499-3506.

280. Kim, J.G.; Chae, Y.S.; Sohn, S.K.; Cho, Y.Y.; Moon, J.H.; Park, J.Y.; Jeon, S.W.; Lee, I.T.; Choi, G.S.; Jun, S.H. Vascular endothelial growth factor gene polymorphisms associated with prognosis for patients with colorectal cancer. Clin. Cancer Res. 2008, 14, 62-66.

281. Formica, V.; Palmirotta, R.; del Monte, G.; Savonarola, A.; Ludovici, G.; de Marchis, M.L.; Grenga, I.; Schirru, M.; Guadagni, F.; Roselli, M. Predictive value of VEGF gene polymorphisms for metastatic colorectal cancer patients receiving first-line treatment including fluorouracil, irinotecan, and bevacizumab. Int. J. Colorectal. Dis. 2011, 26, 143-151.

282. Watson, C.J.; Webb, N.J.; Bottomley, M.J.; Brenchley, P.E. Identification of polymorphisms within the vascular endothelial growth factor (VEGF) gene: Correlation with variation in VEGF protein production. Cytokine 2000, 12, 1232-1235.

283. Awata, T.; Inoue, K.; Kurihara, S.; Ohkubo, T.; Watanabe, M.; Inukai, K.; Inoue, I.; Katayama, S. A common polymorphism in the 5'-untranslated region of the VEGF gene is associated with diabetic retinopathy in type 2 diabetes. Diabetes 2002, 51, 1635-1639.

284. Koutras, A.K.; Antonacopoulou, A.G.; Eleftheraki, A.G.; Dimitrakopoulos, F.I.; Koumarianou, A.; Varthalitis, I.; Fostira, F.; Sgouros, J.; Briasoulis, E.; Bournakis, E.; et al. Vascular endothelial growth factor polymorphisms and clinical outcome in colorectal cancer patients treated with irinotecan-based chemotherapy and bevacizumab. Pharmacogenomics J. 2012, 12, 468-475.

285. Shahbazi, M.; Fryer, A.A.; Pravica, V.; Brogan, I.J.; Ramsay, H.M.; Hutchinson, I.V.; Harden, P.N. Vascular endothelial growth factor gene polymorphisms are associated with acute renal allograft rejection. J. Am. Soc. Nephrol. 2002, 13, 260-264.

286. Mohammadi, M.; Ollier, W.E.; Hutchinson, I.V. A functional association study of VEGF gene promoter polymorphisms with VEGF expression by stimulated PBM cells. Hum. Immunol. 2003, $64, \mathrm{~S} 125$. 
287. Loupakis, F.; Cremolini, C.; Fioravanti, A.; Orlandi, P.; Salvatore, L.; Masi, G.; di Desidero, T.; Canu, B.; Schirripa, M.; Frumento, P.; et al. Pharmacodynamic and pharmacogenetic angiogenesis-related markers of first-line FOLFOXIRI plus bevacizumab schedule in metastatic colorectal cancer. Br. J. Cancer 2011, 104, 1262-1269.

288. Pander, J.; Wessels, J.A.; Gelderblom, H.; van der Straaten, T.; Punt, C.J.; Guchelaar, H.J. Pharmacogenetic interaction analysis for the efficacy of systemic treatment in metastatic colorectal cancer. Ann. Oncol. 2011, 22, 1147-1153.

289. Cacev, T.; Loncar, B.; Seiwerth, S.; Spaventi, S.; Kapitanovic, S. Vascular endothelial growth factor polymorphisms $-1154 \mathrm{G} / \mathrm{A}$ and $-460 \mathrm{C} / \mathrm{T}$ are not associated with VEGF mRNA expression and susceptibility to sporadic colon cancer. DNA Cell Biol. 2008, 27, 569-574.

290. Manzoni, M.; Mariucci, S.; Delfanti, S.; Rovati, B.; Ronzoni, M.; Loupakis, F.; Brugnatelli, S.; Tinelli, C.; Villa, E.; Falcone, A.; et al. Circulating endothelial cells and their apoptotic fraction are mutually independent predictive biomarkers in Bevacizumab-based treatment for advanced colorectal cancer. J. Cancer Res. Clin. Oncol. 2012, 138, 1187-1196.

291. Ronzoni, M.; Manzoni, M.; Mariucci, S.; Loupakis, F.; Brugnatelli, S.; Bencardino, K.; Rovati, B.; Tinelli, C.; Falcone, A.; Villa, E.; et al. Circulating endothelial cells and endothelial progenitors as predictive markers of clinical response to bevacizumab-based first-line treatment in advanced colorectal cancer patients. Ann. Oncol. 2010, 21, 2382-2389.

292. Matsusaka, S.; Mishima, Y.; Suenaga, M.; Terui, Y.; Kuniyoshi, R.; Mizunuma, N.; Hatake, K. Circulating endothelial progenitors and CXCR4-positive circulating endothelial cells are predictive markers for bevacizumab. Cancer 2011, 117, 4026-4032.

293. Guleng, B.; Tateishi, K.; Ohta, M.; Kanai, F.; Jazag, A.; Ijichi, H.; Tanaka, Y.; Washida, M.; Morikane, K.; Fukushima, Y.; et al. Blockade of the stromal cell-derived factor-1/CXCR4 axis attenuates in vivo tumor growth by inhibiting angiogenesis in a vascular endothelial growth factor-independent manner. Cancer Res. 2005, 65, 5864-5871.

294. Simkens, L.H.; Tol, J.; Terstappen, L.W.; Teerenstra, S.; Punt, C.J.; Nagtegaal, I.D. The predictive and prognostic value of circulating endothelial cells in advanced colorectal cancer patients receiving first-line chemotherapy and bevacizumab. Ann. Oncol. 2010, 21, 2447-2448.

295. Bertolini, F.; Marighetti, P.; Shaked, Y. Cellular and soluble markers of tumor angiogenesis: From patient selection to the identification of the most appropriate postresistance therapy. Biochim. Biophys. Acta 2010, 1806, 131-137.

296. Bertolini, F.; Shaked, Y.; Mancuso, P.; Kerbel, R.S. The multifaceted circulating endothelial cell in cancer: Towards marker and target identification. Nat. Rev. Cancer 2006, 6, 835-845.

297. Gordon, M.S.; Margolin, K.; Talpaz, M.; Sledge, G.W., Jr.; Holmgren, E.; Benjamin, R.; Stalter, S.; Shak, S.; Adelman, D. Phase I safety and pharmacokinetic study of recombinant human anti-vascular endothelial growth factor in patients with advanced cancer. J. Clin. Oncol. 2001, $19,843-850$.

298. Willett, C.G.; Boucher, Y.; Duda, D.G.; di Tomaso, E.; Munn, L.L.; Tong, R.T.; Kozin, S.V.; Petit, L.; Jain, R.K.; Chung, D.C.; et al. Surrogate markers for antiangiogenic therapy and dose-limiting toxicities for bevacizumab with radiation and chemotherapy: Continued experience of a phase I trial in rectal cancer patients. J. Clin. Oncol. 2005, 23, 8136-8139. 
299. Yang, J.C.; Haworth, L.; Sherry, R.M.; Hwu, P.; Schwartzentruber, D.J.; Topalian, S.L.; Steinberg, S.M.; Chen, H.X.; Rosenberg, S.A. A randomized trial of bevacizumab, an anti-vascular endothelial growth factor antibody, for metastatic renal cancer. N. Engl. J. Med. 2003, 349, 427-434.

300. Loupakis, F.; Falcone, A.; Masi, G.; Fioravanti, A.; Kerbel, R.S.; del Tacca, M.; Bocci, G. Vascular endothelial growth factor levels in immunodepleted plasma of cancer patients as a possible pharmacodynamic marker for bevacizumab activity. J. Clin. Oncol. 2007, 25, 1816-1818.

301. Jubb, A.M.; Hurwitz, H.I.; Bai, W.; Holmgren, E.B.; Tobin, P.; Guerrero, A.S.; Kabbinavar, F.; Holden, S.N.; Novotny, W.F.; Frantz, G.D.; et al. Impact of vascular endothelial growth factor-A expression, thrombospondin-2 expression, and microvessel density on the treatment effect of bevacizumab in metastatic colorectal cancer. J. Clin. Oncol. 2006, 24, 217-227.

302. Wan, P.T.; Garnett, M.J.; Roe, S.M.; Lee, S.; Niculescu-Duvaz, D.; Good, V.M.; Jones, C.M.; Marshall, C.J.; Springer, C.J.; Barford, D.; et al. Mechanism of activation of the RAF-ERK signaling pathway by oncogenic mutations of B-RAF. Cell 2004, 116, 855-867.

303. Lyons, J.F.; Wilhelm, S.; Hibner, B.; Bollag, G. Discovery of a novel Raf kinase inhibitor. Endocr. Relat. Cancer 2001, 8, 219-225.

304. Smith, R.A.; Barbosa, J.; Blum, C.L.; Bobko, M.A.; Caringal, Y.V.; Dally, R.; Johnson, J.S.; Katz, M.E.; Kennure, N.; Kingery-Wood, J.; et al. Discovery of heterocyclic ureas as a new class of raf kinase inhibitors: Identification of a second generation lead by a combinatorial chemistry approach. Bioorg. Med. Chem. Lett. 2001, 11, 2775-2778.

305. Khire, U.R.; Bankston, D.; Barbosa, J.; Brittelli, D.R.; Caringal, Y.; Carlson, R.; Dumas, J.; Gane, T.; Heald, S.L.; Hibner, B.; et al. Omega-carboxypyridyl substituted ureas as Raf kinase inhibitors: SAR of the amide substituent. Bioorg. Med. Chem. Lett. 2004, 14, 783-786.

306. Wilhelm, S.M.; Carter, C.; Tang, L.; Wilkie, D.; McNabola, A.; Rong, H.; Chen, C.; Zhang, X.; Vincent, P.; McHugh, M.; et al. BAY 43-9006 exhibits broad spectrum oral antitumor activity and targets the RAF/MEK/ERK pathway and receptor tyrosine kinases involved in tumor progression and angiogenesis. Cancer Res. 2004, 64, 7099-7109.

307. Alavi, A.; Hood, J.D.; Frausto, R.; Stupack, D.G.; Cheresh, D.A. Role of Raf in vascular protection from distinct apoptotic stimuli. Science 2003, 301, 94-96.

308. Hood, J.D.; Bednarski, M.; Frausto, R.; Guccione, S.; Reisfeld, R.A.; Xiang, R.; Cheresh, D.A. Tumor regression by targeted gene delivery to the neovasculature. Science 2002, 296, 2404-2407.

309. Wilhelm, S.M.; Adnane, L.; Newell, P.; Villanueva, A.; Llovet, J.M.; Lynch, M. Preclinical overview of sorafenib, a multikinase inhibitor that targets both Raf and VEGF and PDGF receptor tyrosine kinase signaling. Mol. Cancer Ther. 2008, 7, 3129-3140.

310. Activity of the Raf kinase inhibitor BAY 43-9006 in patients with advanced solid tumors. Clin. Colorectal. Cancer 2003, 3, 16-18.

311. Martinelli, E.; Troiani, T.; Morgillo, F.; Rodolico, G.; Vitagliano, D.; Morelli, M.P.; Tuccillo, C.; Vecchione, L.; Capasso, A.; Orditura, M.; et al. Synergistic antitumor activity of sorafenib in combination with epidermal growth factor receptor inhibitors in colorectal and lung cancer cells. Clin. Cancer Res. 2010, 16, 4990-5001. 
312. Azad, N.; Dasari, A.; Arcaroli, J.; Taylor, G.E.; Laheru, D.A.; Carducci, M.A.; McManus, M.; Quackenbush, K.; Wright, J.J.; Hidalgo, M.; et al. Phase I pharmacokinetic and pharmacodynamic study of cetuximab, irinotecan and sorafenib in advanced colorectal cancer. Invest. New Drugs 2013, 31, 345-354.

313. Wehler, T.C.; Hamdi, S.; Maderer, A.; Graf, C.; Gockel, I.; Schmidtmann, I.; Hainz, M.; Berger, M.R.; Theobald, M.; Galle, P.R.; et al. Single-agent therapy with sorafenib or 5-FU is equally effective in human colorectal cancer xenograft-no benefit of combination therapy. Int. J. Colorectal Dis. 2013. 28, 385-398.

314. Mross, K.; Steinbild, S.; Baas, F.; Gmehling, D.; Radtke, M.; Voliotis, D.; Brendel, E.; Christensen, O.; Unger, C. Results from an in vitro and a clinical/pharmacological phase I study with the combination irinotecan and sorafenib. Eur. J. Cancer 2007, 43, 55-63.

315. Kupsch, P.; Henning, B.F.; Passarge, K.; Richly, H.; Wiesemann, K.; Hilger, R.A.; Scheulen, M.E.; Christensen, O.; Brendel, E.; Schwartz, B.; et al. Results of a phase I trial of sorafenib (BAY 43-9006) in combination with oxaliplatin in patients with refractory solid tumors, including colorectal cancer. Clin. Colorectal. Cancer 2005, 5, 188-196.

316. Wilhelm, S.M.; Dumas, J.; Adnane, L.; Lynch, M.; Carter, C.A.; Schutz, G.; Thierauch, K.H.; Zopf, D. Regorafenib (BAY 73-4506): A new oral multikinase inhibitor of angiogenic, stromal and oncogenic receptor tyrosine kinases with potent preclinical antitumor activity. Int. J. Cancer 2011, 129, 245-255.

317. Strumberg, D.; Scheulen, M.E.; Schultheis, B.; Richly, H.; Frost, A.; Buchert, M.; Christensen, O.; Jeffers, M.; Heinig, R.; Boix, O.; et al. Regorafenib (BAY 73-4506) in advanced colorectal cancer: A phase I study. Br. J. Cancer 2012, 106, 1722-1727.

318. Grothey, A. Regorafenib in metastatic colorectal cancer. Clin. Adv. Hematol. Oncol. 2012, 10, 324-325.

319. Yokota, T.; Ura, T.; Shibata, N.; Takahari, D.; Shitara, K.; Nomura, M.; Kondo, C.; Mizota, A.; Utsunomiya, S.; Muro, K.; et al. BRAF mutation is a powerful prognostic factor in advanced and recurrent colorectal cancer. Br. J. Cancer 2011, 104, 856-862.

320. Ogino, S.; Nosho, K.; Kirkner, G.J.; Kawasaki, T.; Meyerhardt, J.A.; Loda, M.; Giovannucci, E.L.; Fuchs, C.S. CpG island methylator phenotype, microsatellite instability, BRAF mutation and clinical outcome in colon cancer. Gut 2009, 58, 90-96.

321. Farina-Sarasqueta, A.; van Lijnschoten, G.; Moerland, E.; Creemers, G.J.; Lemmens, V.E.; Rutten, H.J.; van den Brule, A.J. The BRAF V600E mutation is an independent prognostic factor for survival in stage II and stage III colon cancer patients. Ann. Oncol. 2010, 21, 2396-2402.

322. Sala, E.; Mologni, L.; Truffa, S.; Gaetano, C.; Bollag, G.E.; Gambacorti-Passerini, C. BRAF silencing by short hairpin RNA or chemical blockade by PLX4032 leads to different responses in melanoma and thyroid carcinoma cells. Mol. Cancer Res. 2008, 6, 751-759.

323. Yang, H.; Higgins, B.; Kolinsky, K.; Packman, K.; Bradley, W.D.; Lee, R.J.; Schostack, K.; Simcox, M.E.; Kopetz, S.; Heimbrook, D.; Lestini, B.; Bollag, G.; Su, F. Antitumor activity of BRAF inhibitor vemurafenib in preclinical models of BRAF-mutant colorectal cancer. Cancer Res. 2012, 72, 779-789.

324. Kopetz, S.; Desai, J.; Chan, E.; Hecht, J.R.; O’Dwyer, P.; Lee, R.; Nolop, K.; Saltz, L. PLX4032 in metastatic colorectal cancer patients with mutant BRaf tumors. J. Clin. Oncol. 2010, 28, 15s. 
325. Mao, M.; Tian, F.; Mariadason, J.M.; Tsao, C.C.; Lemos, R., Jr.; Dayyani, F.; Gopal, Y.N.; Jiang, Z.Q.; Wistuba, II; Tang, X.M.; et al. Resistance to BRAF inhibition in BRAF-mutant colon cancer can be overcome with PI3K inhibition or demethylating agents. Clin. Cancer Res. 2013, 19, 657-667.

326. Prahallad, A.; Sun, C.; Huang, S.; Di Nicolantonio, F.; Salazar, R.; Zecchin, D.; Beijersbergen, R.L.; Bardelli, A.; Bernards, R. Unresponsiveness of colon cancer to BRAF(V600E) inhibition through feedback activation of EGFR. Nature 2012, 483, 100-103.

327. Corcoran, R.B.; Ebi, H.; Turke, A.B.; Coffee, E.M.; Nishino, M.; Cogdill, A.P.; Brown, R.D.; Della Pelle, P.; Dias-Santagata, D.; Hung, K.E.; et al. EGFR-mediated re-activation of MAPK signaling contributes to insensitivity of BRAF mutant colorectal cancers to RAF inhibition with vemurafenib. Cancer Discov. 2012, 2, 227-235.

328. Coffee, E.M.; Faber, A.C.; Roper, J.; Sinnamon, M.J.; Goel, G.; Keung, L.; Wang, W.V.; Vecchione, L.; de Vriendt, V.; Weinstein, B.J.; et al. Concomitant BRAF and PI3K/mTOR Blockade Is Required for Effective Treatment of BRAFV600E Colorectal Cancer. Clin. Cancer Res. 2013, 19, 2688-2698.

329. Pang, R.; Law, W.L.; Chu, A.C.; Poon, J.T.; Lam, C.S.; Chow, A.K.; Ng, L.; Cheung, L.W.; Lan, X.R.; Lan, H.Y.; et al. A subpopulation of CD26+ cancer stem cells with metastatic capacity in human colorectal cancer. Cell Stem Cell 2010, 6, 603-615.

330. Dylla, S.J.; Beviglia, L.; Park, I.K.; Chartier, C.; Raval, J.; Ngan, L.; Pickell, K.; Aguilar, J.; Lazetic, S.; Smith-Berdan, S.; et al. Colorectal cancer stem cells are enriched in xenogeneic tumors following chemotherapy. PLoS One 2008, 3, e2428.

331. Wilson, B.J.; Schatton, T.; Frank, M.H.; Frank, N.Y. Colorectal Cancer Stem Cells: Biology and Therapeutic Implications. Curr. Colorectal. Cancer Rep. 2011, 7, 128-135.

332. O’Brien, C.A.; Pollett, A.; Gallinger, S.; Dick, J.E. A human colon cancer cell capable of initiating tumour growth in immunodeficient mice. Nature 2007, 445, 106-110.

333. Ricci-Vitiani, L.; Lombardi, D.G.; Pilozzi, E.; Biffoni, M.; Todaro, M.; Peschle, C.; De Maria, R. Identification and expansion of human colon-cancer-initiating cells. Nature 2007, 445, 111-115.

334. Todaro, M.; Alea, M.P.; di Stefano, A.B.; Cammareri, P.; Vermeulen, L.; Iovino, F.; Tripodo, C.; Russo, A.; Gulotta, G.; Medema, J.P.; et al. Colon cancer stem cells dictate tumor growth and resist cell death by production of interleukin-4. Cell Stem Cell 2007, 1, 389-402.

335. Dalerba, P.; Dylla, S.J.; Park, I.K.; Liu, R.; Wang, X.; Cho, R.W.; Hoey, T.; Gurney, A.; Huang, E.H.; Simeone, D.M.; et al. Phenotypic characterization of human colorectal cancer stem cells. Proc. Natl. Acad. Sci. USA 2007, 104, 10158-10163.

336. Huang, E.H.; Hynes, M.J.; Zhang, T.; Ginestier, C.; Dontu, G.; Appelman, H.; Fields, J.Z.; Wicha, M.S.; Boman, B.M. Aldehyde dehydrogenase 1 is a marker for normal and malignant human colonic stem cells (SC) and tracks SC overpopulation during colon tumorigenesis. Cancer Res. 2009, 69, 3382-3389.

337. Langan, R.C.; Mullinax, J.E.; Raiji, M.T.; Upham, T.; Summers, T.; Stojadinovic, A.; Avital, I. Colorectal cancer biomarkers and the potential role of cancer stem cells. J. Cancer 2013, 4, 241-250.

338. Ong, C.W.; Kim, L.G.; Kong, H.H.; Low, L.Y.; Iacopetta, B.; Soong, R.; Salto-Tellez, M. CD133 expression predicts for non-response to chemotherapy in colorectal cancer. Mod. Pathol. 2010, 23, 450-457. 
339. Mia-Jan, K.; Jung, S.Y.; Kim, I.Y.; Oh, S.S.; Choi, E.; Chang, S.J.; Kang, T.Y.; Cho, M.Y. CD133 expression is not an independent prognostic factor in stage II and III colorectal cancer but may predict the better outcome in patients with adjuvant therapy. BMC Cancer 2013, 13, 166.

340. Shmelkov, S.V.; Butler, J.M.; Hooper, A.T.; Hormigo, A.; Kushner, J.; Milde, T.; St Clair, R.; Baljevic, M.; White, I.; Jin, D.K.; et al. CD133 expression is not restricted to stem cells, and both CD133+ and CD133- metastatic colon cancer cells initiate tumors. J. Clin. Invest. 2008, 118, 2111-2120.

341. Allard, W.J.; Matera, J.; Miller, M.C.; Repollet, M.; Connelly, M.C.; Rao, C.; Tibbe, A.G.; Uhr, J.W.; Terstappen, L.W. Tumor cells circulate in the peripheral blood of all major carcinomas but not in healthy subjects or patients with nonmalignant diseases. Clin. Cancer Res. 2004, 10, 6897-6904.

342. Cohen, S.J.; Punt, C.J.; Iannotti, N.; Saidman, B.H.; Sabbath, K.D.; Gabrail, N.Y.; Picus, J.; Morse, M.; Mitchell, E.; Miller, M.C.; et al. Relationship of circulating tumor cells to tumor response, progression-free survival, and overall survival in patients with metastatic colorectal cancer. J. Clin. Oncol. 2008, 26, 3213-3221.

343. Otsuka, K.; Imai, H.; Soeda, H.; Komine, K.; Ishioka, C.; Shibata, H. Practical utility of circulating tumour cells as biomarkers in cancer chemotherapy for advanced colorectal cancer. Anticancer Res. 2013, 33, 625-629.

344. Gazzaniga, P.; Raimondi, C.; Gradilone, A.; Biondi Zoccai, G.; Nicolazzo, C.; Gandini, O.; Longo, F.; Tomao, S.; Lo Russo, G.; Seminara, P.; et al. Circulating tumor cells in metastatic colorectal cancer: Do we need an alternative cutoff? J. Cancer Res. Clin. Oncol. 2013, 139, 1411-1416.

345. Sastre, J.; Maestro, M.L.; Gomez-Espana, A.; Rivera, F.; Valladares, M.; Massuti, B.; Benavides, M.; Gallen, M.; Marcuello, E.; Abad, A.; et al. Circulating tumor cell count is a prognostic factor in metastatic colorectal cancer patients receiving first-line chemotherapy plus bevacizumab: A Spanish Cooperative Group for the Treatment of Digestive Tumors study. Oncologist 2012, 17, 947-955.

346. De Albuquerque, A.; Kubisch, I.; Stolzel, U.; Ernst, D.; Boese-Landgraf, J.; Breier, G.; Stamminger, G.; Fersis, N.; Kaul, S. Prognostic and predictive value of circulating tumor cell analysis in colorectal cancer patients. J. Transl. Med. 2012, 10, 222.

347. Roychowdhury, S.; Iyer, M.K.; Robinson, D.R.; Lonigro, R.J.; Wu, Y.M.; Cao, X.; KalyanaSundaram, S.; Sam, L.; Balbin, O.A.; Quist, M.J.; et al. Personalized oncology through integrative high-throughput sequencing: A pilot study. Sci. Transl. Med. 2011, 3, 111 ra121.

348. Lamparella, N.; Saroya, B.; Yang, Z.; Sarwani, N.; El-Deiry, W. Contradictory KRAS mutation test results in a patient with metastatic colon cancer: A clinical dilemma in the era of personalized medicine. Cancer Biol. Ther. 2013, in press.

(C) 2013 by the authors; licensee MDPI, Basel, Switzerland. This article is an open access article distributed under the terms and conditions of the Creative Commons Attribution license (http://creativecommons.org/licenses/by/3.0/). 